University of Louisville

ThinkIR: The University of Louisville's Institutional Repository

$12-2011$

\title{
Examining teachers' perceptions of psychological gender and leadership behavior of principals in public elementary schools.
}

Brittany D. Carpenter

University of Louisville

Follow this and additional works at: https://ir.library.louisville.edu/etd

\section{Recommended Citation}

Carpenter, Brittany D., "Examining teachers' perceptions of psychological gender and leadership behavior of principals in public elementary schools." (2011). Electronic Theses and Dissertations. Paper 212. https://doi.org/10.18297/etd/212

This Doctoral Dissertation is brought to you for free and open access by ThinkIR: The University of Louisville's Institutional Repository. It has been accepted for inclusion in Electronic Theses and Dissertations by an authorized administrator of ThinkIR: The University of Louisville's Institutional Repository. This title appears here courtesy of the author, who has retained all other copyrights. For more information, please contact thinkir@louisville.edu. 
EXAMINING TEACHERS' PERCEPTIONS OF PSYCHOLOGICAL GENDER AND LEADERSHIP BEHAVIOR OF PRINCIPALS IN PUBLIC ELEMENTARY SCHOOLS

\title{
By
}

Brittany D. Carpenter

B.A., Bellarmine University, 2005

M.S., Spalding University, 2006

\author{
A Dissertation \\ Submitted to the Faculty of the \\ Graduate School of the University of Louisville \\ in Partial Fulfillment of the Requirements \\ for the Degree of \\ Doctor of Philosophy \\ College of Education and Human Development \\ University of Louisville \\ Louisville, Kentucky
}

December 2011 
Copyright 2011 by Brittany D. Carpenter

All rights reserved 


\title{
EXAMINING TEACHERS' PERCEPTIONS OF PSYCHOLOGICAL GENDER AND LEADERSHIP BEHAVIOR OF PRINCIPALS IN PUBLIC ELEMENTARY SCHOOLS
}

\author{
By \\ Brittany D. Carpenter \\ B.A., Bellarmine University, 2005 \\ M.S., Spalding University, 2006 \\ A Dissertation Approved on
}

November 22, 2011

By the following Dissertation Committee:

Dr. Namok Choi, Chair

Dr. Joseph Petrosko

Dr. Blake Haselton

Dr. Diane W. Kyle

Dr. Marco Munoz 


\section{DEDICATION}

This dissertation is dedicated to my mom

Rebecca Carpenter

for the constant strength and love long before this process began. 


\section{ACKNOWLEDGEMENTS}

I will instruct you and teach you in the way you should go, I will counsel you and watch over you.

Psalms 32:8

To God, thank you for your everlasting grace through this process.

I would like to express my deep appreciation to the chair of my dissertation committee, Dr. Namok Choi. Thank you for your patience, guidance, and encouragement throughout this process. I also would like to thank my committee members, Dr. Joseph Petrosko, Dr. Diane W. Kyle, Dr. Blake Haselton, and Dr. Marco Munoz, for lending your time, skills, and expertise and helping me to refine this research. I am extremely appreciative of those at the University of Louisville, Jefferson County Public Schools, Holmes Doctoral Scholars program, and Southern Region Education Board Doctoral Scholars program who have helped me to develop academically and professionally: Dr. Jill Adelson, Dr. Craig Hochbein, Dr. Fashaad Crawford Dr. Susan Lasky, Dr. Ann Larson, and Marita White. To Denise Dadisman, thank you for always making time, lending an ear, and providing unlimited prayers wherever and whenever needed.

My heart is also full of gratitude and affection for my classmates Peg Russell and Gerome Stephens. Thank you for sharing every step of this process with me, the journey would not have been the same without your laughs, love, tears and encouragement. A word of thanks goes to my fellow doctoral students and scholars who have offered support, advice, and friendship over the years. Thank you to Dr. Marion Hambrick, Tim 
Sauer, Dr. Jason Simmons, Kharod France, Christine Pilgrim, Armon Jackson, Matt Bergman, Dr. Judi Vanderhaar, and Dr. Florence Chang.

This dissertation could not have been completed without the unwavering dedication and love from my family. Words cannot express my sincerest gratitude for you all. Each of you could put a smile on face when the road I was traveling seemed too challenging. Thank you for always accepting and loving that "I had to study or write". Quante, you truly have been one of my biggest cheerleaders, your undoubting encouragement will forever remain in my heart. And to my grandpa, John Carpenter, for watching over me every step of the way.

Special thanks to my amazing mom for teaching me to always believe in myself against seemingly impossible odds. You were always a pillar for me to stand on when my own strength was not enough. For all that you have given up for me to succeed; this dissertation is as much mine as yours.

And, to my wonderful fiancé Chris. I am confident that I would not have reached this point in time if not for you. You have always showed me the light at the end of a seemingly endless dark tunnel. Words will never be enough to express my gratitude and love for you. 


\title{
ABSTRACT \\ EXAMINING TEACHERS' PERCEPTIONS OF PSYCHOLOGICAL GENDER AND LEADERSHIP BEHAVIOR OF PRINCIPALS IN PUBLIC ELEMENTARY SCHOOLS
}

\author{
Brittany D. Carpenter
}

November 22, 2011

Research has shown that various leadership styles have different impacts on leader outcomes such as satisfaction, extra effort, and effectiveness. Specifically, researchers have found that transformational leadership positively impacts follower perceptions of satisfaction, extra effort, and leader effectiveness (Avolio, Bass, \& Jung, 1995; Philbin, 1997; Yammarino, Spangler, \& Bass, 1993). However, research has shown that not all leaders display transformational leadership. In fact, Eagly, Karau, \& Johnson (1992) and their colleagues have shown transformational leadership in education to be linked to the extent to which male and female principals carry out their gender roles referring to role congruity. Currently, not much is known empirically about the relationship between the role of the elementary school principal leadership and gender roles and its combined effects on teachers' perceived satisfaction, perceived effectiveness of their principals, and their assessment of extra effort put forth towards their job.

The purpose of this study was to examine the relationship between leadership style (transformational, transactional, and laissez-faire) and psychological gender role group (masculine, feminine, undifferentiated, androgynous) of elementary school 
principals. Exploration of this topic filled a void in empirical investigations of the psychological gender perspective of school leadership. Multivariate Analysis of Variance techniques were used to examine the relationships between and among principal psychological gender role, biological gender, principal effectiveness, teacher satisfaction, and teacher extra effort. Additionally, canonical correlation was used to examine the relationship between leadership factor variable set and psychological gender role variable set.

Results detected one relationship exists between psychological gender role and leadership behavior variable sets. Specifically, findings suggest femininity, masculinity, idealized influence attribute, idealized influence behavior, inspiration-motivation, intellection stimulation, individual consideration, contingent reward, and laissez-faire provide the best linear combinations of Pearson correlations between the leadership behavior and psychological gender role variable sets. In addition, results indicated statistically significant differences in perceived principal effectiveness, teacher perceived satisfaction, and teacher extra effort based on teacher perceived level of principal psychological gender. Teachers who perceived their principals as androgynous and feminine reported higher levels of extra effort, satisfaction, and principal effectiveness. Leadership behavior did not appear to have a significant influence on extra effort, satisfaction, and principal effectiveness. Additionally, the interaction effect between perceived principal psychological gender role group and principal biological gender was not statistically significant. 


\section{TABLE OF CONTENTS}

PAGE

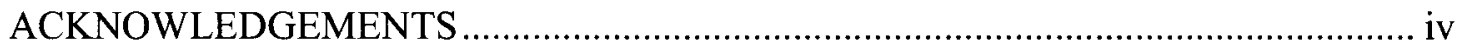

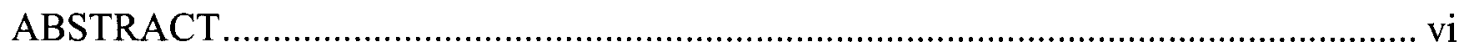

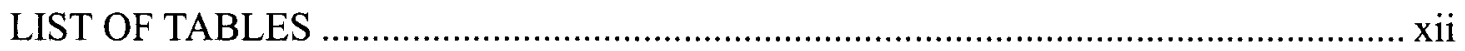

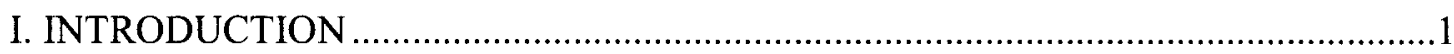

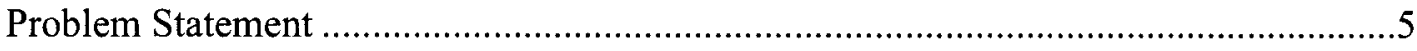

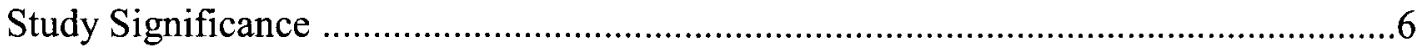

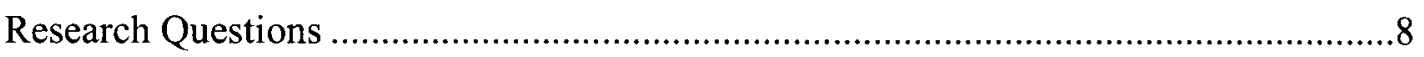

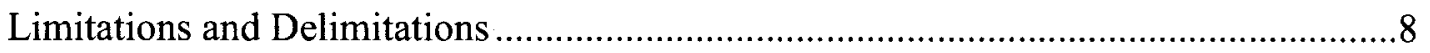

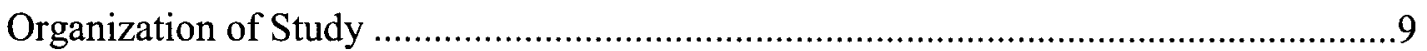

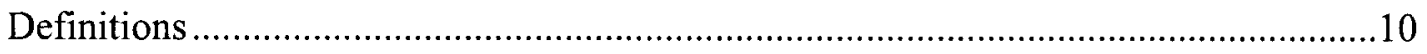

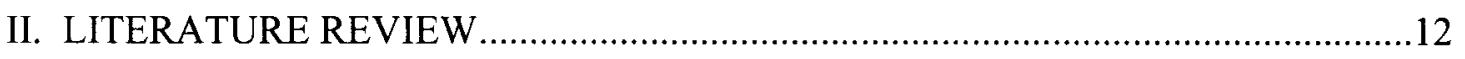

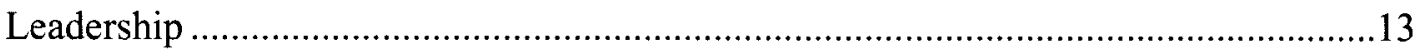

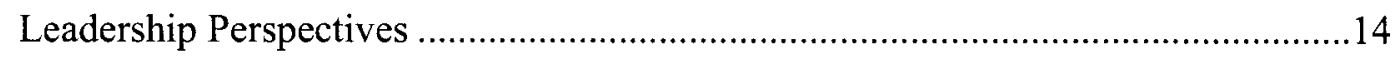

Leader-Centered Perspective .......................................................14

Situation-Centered Perspective ........................................................20

Follower-Centered Perspective ...................................................22

Process-Centered Perspective …......................................................25 
Multifactor Leadership Theory and Full Range Leadership Model .........................28

Transformational Components..........................................................30

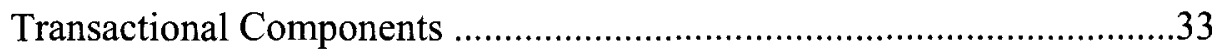

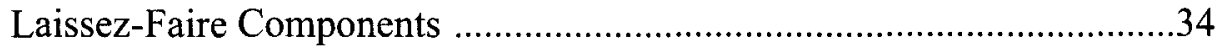

Research Supporting Multifactor Leadership Theory ..........................................34

Multifactor Leadership Theory and Public Education .....................................41

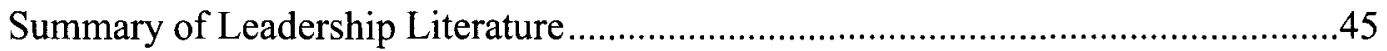

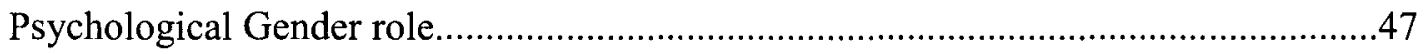

Traditional Perspective of Psychological Gender Role.......................................48

Modern Perspective of Psychological Gender Role ............................................50

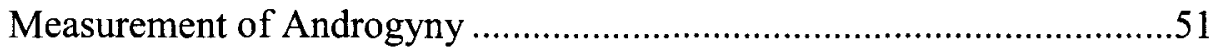

Development Perspective of Psychological Gender Role .......................................53

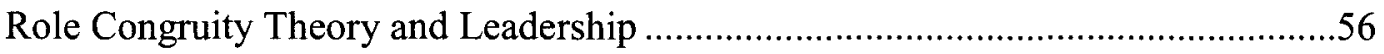

Gender Role Perspective of Public Elementary School Principals ..........................62

Summary of Psychological Gender Role Literature ........................................64

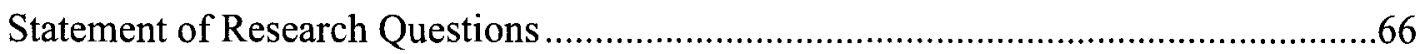

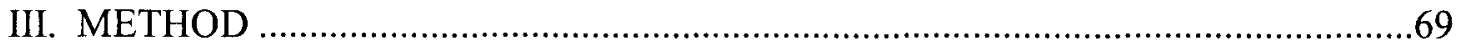

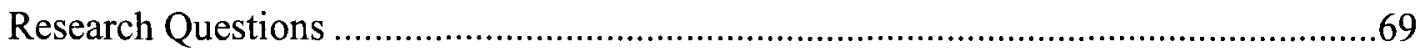

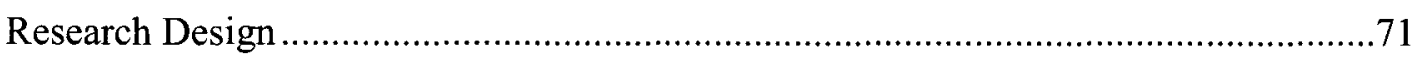

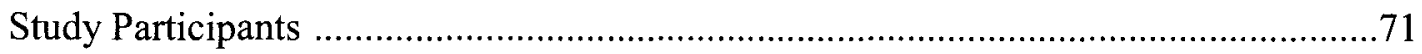

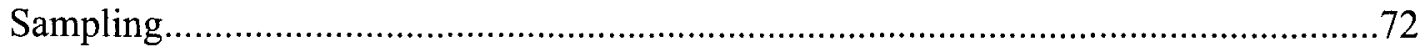

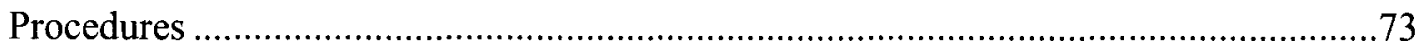

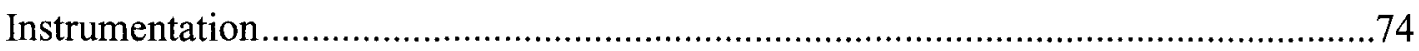


Multifactor Leadership Questionnaire Form 5X ...........................................74

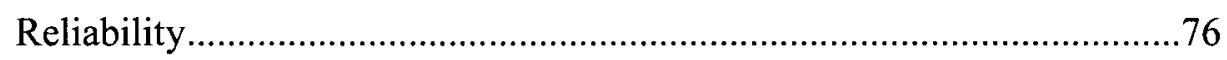

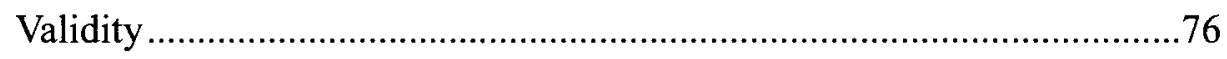

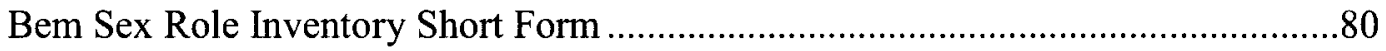

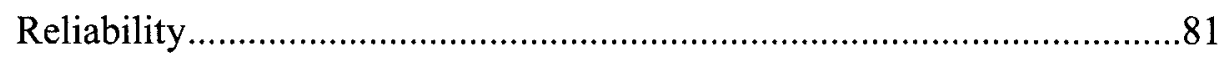

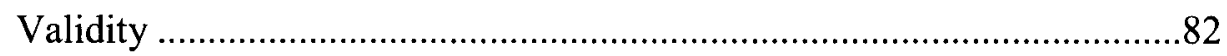

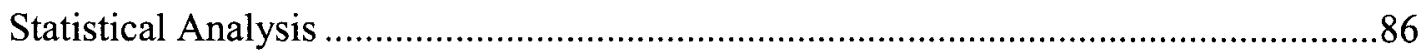

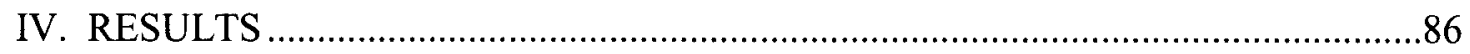

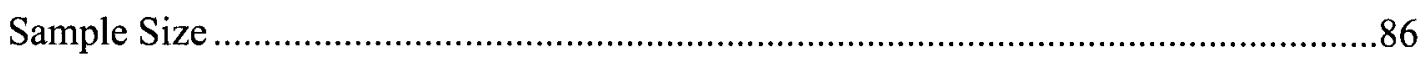

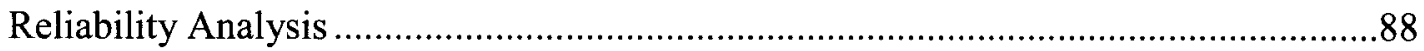

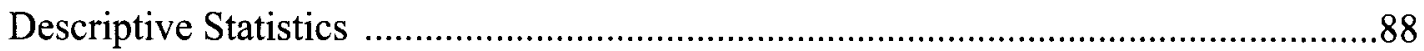

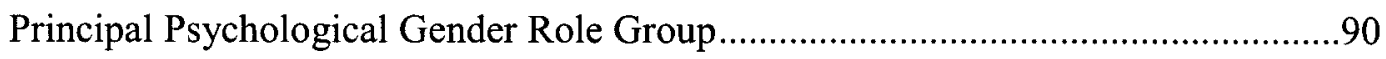

Perceived Principal Leadership by Variable .................................................... 92

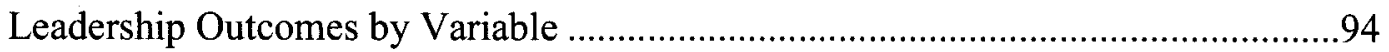

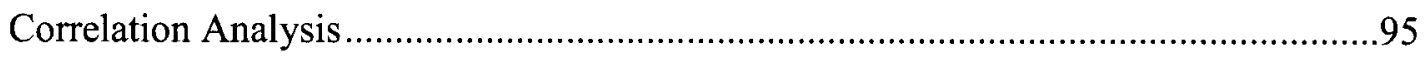

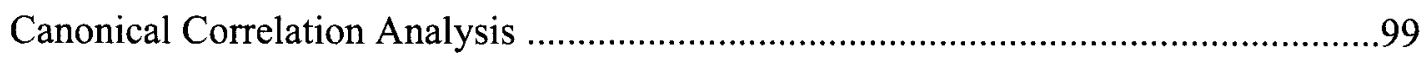

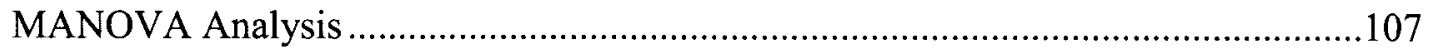

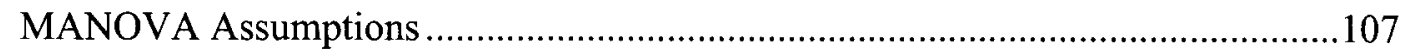

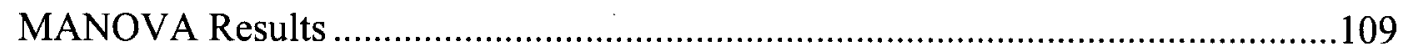

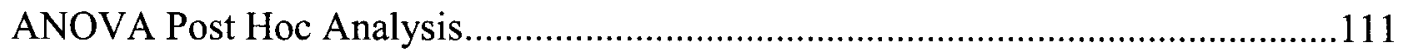

Psychological Gender and Leader Outcomes ...................................112

Principal Effectiveness.................................................... 112

Teacher Satisfaction......................................................... 112 
Summary of Results

V. DISCUSSION

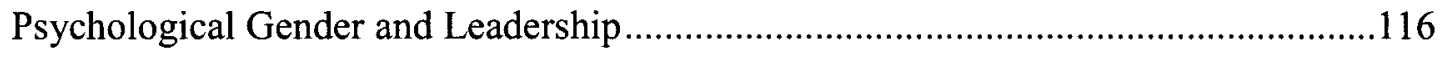

Biological Gender, Psychological Gender, and Leadership Outcomes .....................117

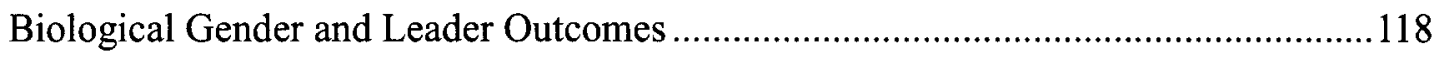

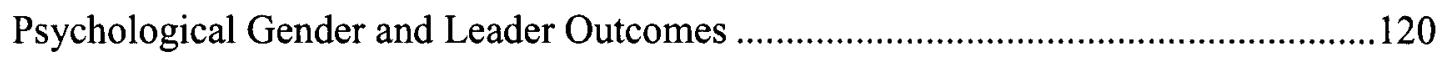

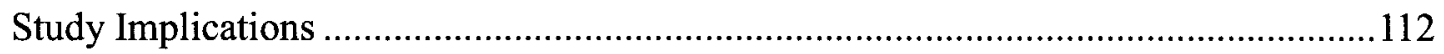

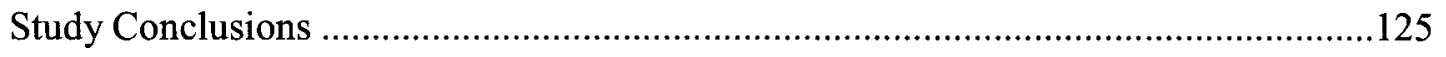

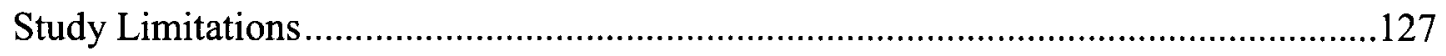

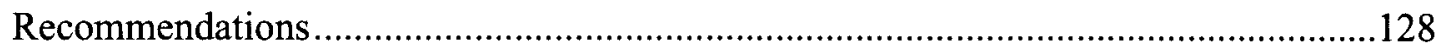

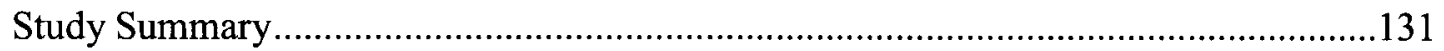

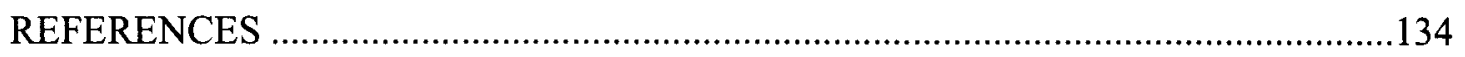

APPENDIX A: INITIAL EMAIL CONTACT WITH TEACHERS ..........................154

APPENDIX B: SURVEY PREAMBLE, CONSENT, and

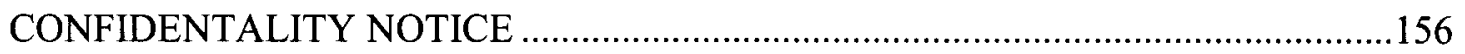

APPENDIX C: BEM SEX ROLE INVENTORY SAMPLE ITEMS ...........................158

APPENDIX D: MULTIFACTOR LEADERSHIP QUESTIONNAIRE

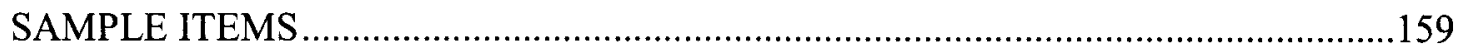

APPENDIX E: SCHOOL/PRINCIPAL INFORMATION SURVEY ITEMS ..............160

APPENDIX F: INSTITUTIONAL REVIEW BOARD APPROVAL LETTER ............161

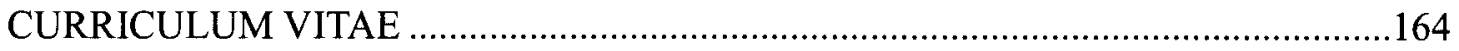




\section{LIST OF TABLES}

TABLE

PAGE

1. Bass's Full Range Leadership Model Components and Factors ...............................31

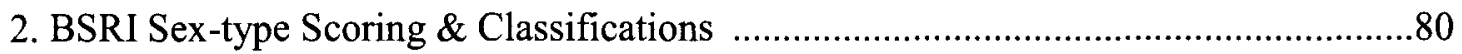

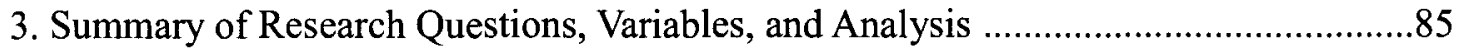

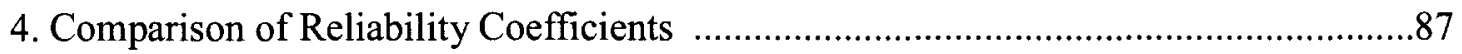

5. Means and Standard Deviations for Perceived Principal Psychological Gender Role, Perceived Principal Leadership Behavior, and Leadership Outcome Variables ...........89

6. Perceived Principal Psychological Gender Role Group Breakdown .........................90

7. Perceived Psychological Gender Role Group by Principal Biological Gender

Breakdown

8. Perceived Principal Leadership Behavior by Perceived Psychological Gender Role ..92

9. Perceived Principal Leadership Behavior by Principal Biological Gender

10. Perceived Leadership Behavior and Leadership Outcomes by Perceived Principal

Psychological Gender Role Group by Principal Biological Gender . .96

11. Leadership Outcomes Means and Standard Deviations by Perceived Principal

Psychological Gender Role Group by Principal Biological Gender

12. Intercorrelations 101

13. Multivariate Test of Significance 103

14. Canonical Structure of the Two Canonical Functions 105 


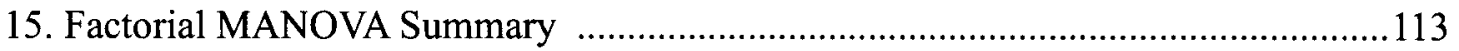

16. Comparisons of All Possible Variable Combinations ...............................................114

17. Means and Standard Deviations for Leadership Outcomes ................................115 


\section{CHAPTER I}

\section{INTRODUCTION}

Effective leadership, including principals' leadership of schools, remains an ambiguous concept associated with an extensive body of research literature. Over the past several decades, the concept of effective principal leadership has evolved with changing public school reform efforts. For example, A Nation at Risk (National Commission on Excellence in Education, 1983) called for centralization of schools to improve student achievement, promoting principals as instructional leaders; however, A Nation Prepared (Carnegie Task Force on Teaching as a Profession, 1986), called for decentralization of school decision-making to improve school effectiveness, promoting school principals as transformational leaders - that is, leaders who inspire, challenge, help, and encourage teachers (Stobaugh, 2003). With A Nation Prepared, educational researchers began investigating the effects of principal leadership (Hallinger \& Heck, 1998), bringing transformational leadership to the forefront of education research. Transformational leadership is a leadership style that concentrates on stimulating and inspiring followers to surpass expectations, as well as motivating followers to transcend self-interest to reach organizational goals. Transformational leadership is a process-centered perspective of leadership implying the leader and follower influence each other in a group context to achieve a common goal. 
Research literature supports transformational leadership as an effective leadership behavior. Research has shown that various leadership styles have different impacts on leader outcomes such as satisfaction, extra effort, and effectiveness. Specifically, researchers have found that transformational leadership positively impacts follower perceptions of satisfaction, extra effort, and leader effectiveness (Avolio, Bass, \& Jung, 1995; Philbin, 1997; Yammarino, Spangler, \& Bass, 1993). Furthermore, research posits that the effects of leadership behavior on student achievement and engagement are partly mediated by school culture stemming from perceptions of extra effort, leader effectiveness, and satisfaction (Leithwood \& Jantzi, 2005), with all leader outcomes linked positively to transformational leadership. Specifically, empirical research has shown that a principal's expression of transformational leadership behaviors can positively influence student achievement and engagement (Leithwood, Jantzi, Silins, \& Dart, 1993; Binkowski, Cordeiro, \& Iwanicki, 1995; Silin, 1994). For example, Binkowski, Cordeiro, and Iwanicki's (1995) qualitative study showed that schools with high student achievement had principals who employed a transformational leadership style. Specifically, high-performing schools showed a common theme of visionary principals who energized the staff and organized academic decision-making teams. Furthermore, Leithwood, Jantzi, and Steinbach's (1999) work suggests a link between transformational leadership practices and school conditions $(r=.68, p<.01)$ and behavioral (participation) $(r=0.19, p<.05)$ and cognitive (identification) $(r=.23, p<$ .05) dimensions of student engagement. Higher levels of teacher satisfaction, commitment, extra effort and effectiveness have been attributed to transformational 
principals' actions of developing shared goals and establishing high expectations (Leithwood, Jantzi, Silins, \& Dart, 1993).

Moreover, the work of Kirby, King, \& Paradise (1992) and their colleagues (Bass, 1985; Hoover, 1987; Binkowski, Cordeiro, Iwanicki, 1995; Silin, 1994) have revealed teachers prefer principals who express transformational leadership behaviors.

However, research has shown that not all leaders display transformational leadership. In fact, Eagly, Karau, \& Johnson (1992) and their colleagues have shown transformational leadership in education to be linked to the extent to which male and female principals carry out their gender roles - a set of beliefs and perceptions about men and women (Biddle, 1979; Deaux \& Kite, 1987; Eagly \& Karau, 2002; Sarbin \& Allen, 1968; Whitley, 2001)-referring to role congruity. Role congruity occurs when an individual's socially desirable psychological role matches his or her socially expected leader role. Role incongruity occurs when an individual's socially desirable psychological role does not match his or her socially expected leader role. For example, the cross pressures of gender role and female role are prominent in male-dominated and culturally defined masculine leadership roles, such as that of a military officer. In such contexts, women face the challenge of incapability between society's expectations of leaders and expectations of females. Consequentially, some suspect women are not qualified for such leadership roles and may resist female authority (Carli, 1999; Eagly \& Karau, 2002). The same experience occurs with a male in a female-dominated role, such as human resources or nursing. One leader role in which both men and women potentially have experienced role incongruity is the elementary school principal. Role incongruity in the principalship is due to continual change in the gender composition of 
elementary school principals (Loder \& Spillane, 2005). However, one can surmise men experience such role incongruity as the prinicpalship is currently a female-dominated role (Eagly \& Johnson, 1990; Eagly, Karau, \& Johnson, 1992).

Role incongruity has been substantiated in leadership studies in the private sector, but not in public education. As recommended by Eagly, Karau, \& Johnson (1992), gender differences in elementary school principal leadership should be interpreted with caution and therefore treated as a hypothesis for further testing. Currently, from the literature that was reviewed it was deduced not much is known empirically about the relationship between the role of the elementary school principal leadership and gender roles and its combined effects on teachers' perceived satisfaction, perceived effectiveness of their principals, and their assessment of extra effort put forth towards their job. The current study aims to add such empirical research to the extant literature. A study designed to examine the relationships among leadership, psychological gender, biological gender, and leader outcomes (effectiveness, satisfaction, and extra effort) would add significantly to research and to a new conceptual understanding of principal leadership.

The purpose of this study was to further examine the relationship between leadership style (transformational, transactional, and laissez-faire) and psychological gender role group (masculine, feminine, undifferentiated, androgynous) of elementary school principals. The correlational study represented a unique investigation of the effect of the relationship between leadership style and psychological gender on principals' effectiveness, teacher satisfaction, and teacher extra effort. Exploration of this topic filled a void in empirical investigations of the psychological gender perspective of school leadership. The aims of the study were addressed by MANOVA and canonical 
correlation statistical techniques. First, the use of MANOVA techniques tested the relationships between and among principal psychological gender role, biological gender, principal effectiveness, teacher satisfaction, and teacher extra effort. Second, canonical correlation was used to examine the relationship between leadership factor variable set and psychological gender role variable set. The factors and dimensionality of leadership and psychological gender role will be discussed in further detail in the following chapter.

\section{Problem Statement}

Despite their evolving roles, school principals still figure prominently in school reform efforts. Educational researchers continually identify principals as an essential force in school effectiveness and school improvement (Bryk, Sebring, Allensworth, Luppescu, \& Easton, 2010; Herman et al., 2008; Teddlie \& Reynolds, 2000). According to Leithwood, Seashore-Louis, Anderson, and Wahlstrom (2004), effective or successful educational leadership is necessary for school reform. For this reason, national and statewide reform initiatives to improve school leadership have been adopted. Despite continual reform initiatives, empirical research in the last 30 years has shown that a principal's expression of transformational leadership positively influences student outcomes, school climates, and instructional organization indirectly through teacher satisfaction, extra effort, and leader effectiveness (Bass, 1985; Leithwood, Jantzi, Silins, \& Dart, 1993; Binkowski, Cordeiro, \& Iwanicki, 1995; Silin, 1994). Thus, as states continually rethink leadership, transformational leadership emerges as a conceptual framework useful for motivating teachers and promoting student success. However, while there is much discussion on transformational school leadership, empirical evidence is thin (Leithwood \& Jantzi, 2006). Efforts to understand transformational school leadership 
should begin with research-based questions addressing transformational leadership outcomes.

Many research avenues of principal leadership exist; however, the lack of empirical data on the relationship between psychological gender role, leadership style, and leader outcomes of principals represents a gap in empirical literature this study addresses. Research concerning the potential gender-based differences in principal leadership reflects educational researchers' desire to understand gender equality within the administrative position. One perspective that predicts differences between male and female principal leadership is gender role expectations of men and women - that is, the extent to which male and female principals carry out their gender roles as desired by society. The extent to which male and female school principals carry out their leader role in a manner consistent with gender expectations causes differences in their respective leadership styles (Eagly, 1992; Johnson, Busch, \& Slate, 2008; Smulyan, 2000). Research has shown that men, in female-dominated or -defined roles (e.g. elementary school principal), face the challenge of incompatibility between individuals' expectations of the male role and of the female leader role. Consequently, society deems men unqualified for such female-defined leadership roles and men potentially experience a disadvantage. A focus on role congruity in the elementary school principalship presents a unique study to fill a gap in extant literature.

\section{Study Significance}

The goal of this research was to examine the relationship between leadership, psychological gender, and leadership outcomes in Kentucky principals. This study was meant to explain principal leadership, the relationship to psychological gender, and the 
relationship with leader effectiveness, teacher satisfaction, and teacher willingness to exert extra effort. Examining these effects has the potential to add to several important areas of study in educational leadership including the study of principals, teachers, principal behavior, principal leadership, and psychological gender of principals, to name a few.

The importance of this research is highlighted in three spheres. First, the findings of this research should interest scholars who focus on educational leadership, general leadership, educational administration, and other related academic topics. Since effective school leadership has received considerable research attention during the last several decades, research concerning the potential predictors of leader outcomes is relevant. This study will add to the literature by further clarifying the changing nature of elementary school leadership.

Second, this study's findings should also have implications for principal hiring with gender leadership behaviors in mind. According to Bass \& Riggo (2006), research that addresses personality differences in relation to leadership can help in leader identification, selection, and development. Investigating and understanding gender differences may contribute to matching candidates to schools. Third, if psychological gender role differences are critical to the ways in which one experiences and make sense of the world (Bem, 1974, 1983), there exists an important relationship between gender and leadership behavior (Eagly \& Johannesen, 2001). Specifically, because leadership is such an important aspect of school achievement and reform, investigating the correlation between leadership and psychological gender in schools is warranted. The findings of this research will prove useful to specialists and researchers who focus on psychological 
gender. This will be especially true for those who specialize in role congruity. More specifically, the findings of this project will add to the understanding of role congruity in a new domain - the public elementary school principalship, a topic not often addressed in the field of education or psychology.

\section{Research Questions}

To achieve the study's purpose, the following four research questions were addressed: (a) is there a significant canonical correlation between the leadership variables set (idealized influence-attribute, idealized influence-behavior, inspiration motivation, intellectual stimulation, individualized consideration, contingent reward, managementby-exception-active, management-by-exception-passive, and laissez-faire) and the psychological gender role variable set (masculinity and femininity)? (b) is there a significant interaction effect of principal biological gender and principal psychological gender role on teachers' perceived principal effectiveness, teachers' perceived satisfaction, and teachers' perceived extra effort? (c) is there a significant main effect of principal biological gender on teachers' perceived principal effectiveness, teachers' perceived satisfaction, and teachers' perceived extra effort? (d) is there a significant main effect of principal psychological gender role group (androgynous, femininity, masculinity, and undifferentiated) on teachers' perceived principal effectiveness, teachers' perceived satisfaction, and teachers' perceived extra effort?

\section{Limitations and Delimitations}

Several limitations and delimitations exist with the study. First, the study focused on a single metropolitan school district, restricting generalizability. Generalizing the results to other school districts and states with different gender compositions and 
systemic reform legislation is limited. Additionally, teachers residing in other school districts and U.S. regions may have responded differently to survey questions compared to those in sampled.

Second, the study examined the relationship between psychological gender and leadership style on teachers' perceived principal effectiveness, teachers' perceived satisfaction, and teachers' perceived extra effort, yet other variables may influence the dependent variable not accounted for in the current study. For example, school size and school culture relate to perceived leader effectiveness (Cross \& Rice, 2000; Hoy \& Hoy, 2003; Leithwood \& Levin, 2005). However, leadership style and psychological gender were deemed the most essential as the study focused on role congruity; specifically, how congruent is an elementary school principal's leader role and psychological gender role.

Third, the study used a cross-sectional survey design; thus, teachers were surveyed at a particular point in time. Thus, perceptions may change over time and throughout the school year. Additionally, as in all survey research, self-selection bias is a limitation. It is possible that those teachers who did not respond differ in some way from respondents in their perceptions of psychological gender, leadership style, and effectiveness of principals.

Despite the delimitations and limitations of the research, this study has great significance and implications for educational leadership, as previously discussed.

\section{Organization of the Study}

The study is organized into several sections. Preceding an introduction that explains the framework and purpose of the study, the body of literature on leadership and psychological gender is presented in Chapter 2. The theoretical framework guiding this 
study is also presented in this chapter. The study methodology is presented in Chapter 3 . This chapter includes details on the primary method of investigation, research design, study participants, sampling and data collection procedures, and analyses. The results of all analyses will be presented in Chapter 4. Finally, a discussion of the study findings, implications, and future research will be put forth in Chapter 5.

\section{Definitions}

The primary terms used in this study are defined as follows:

1. Effectiveness- Effectiveness is a leadership outcome conceptualized by Bass (1985) and determined by the Multifactor Leadership Questionnaire 5X form. A continuous variable, effectiveness refers to the belief that principals are efficient: specifically, principal efficiency in organizational objectives and all organizational structures in which a leader is involved (Bass, 1985; Bass \& Riggio, 2006).

2. Extra Effort - Extra-effort refers to the ability a leader (principal) has to motivate others to achieve beyond what is expected of him or her as a teacher in his or her school; particularly leaders (principals) heighten followers (teachers) desire for success and promote a willingness to try harder (Bass, 1985; Bass \& Riggio, 2006).

3. Laissez-Faire Leadership- Laissez-Faire leadership is the avoidance of responsibility and decision-making. Such leaders delay actions, do not make urgent decisions, and avoid using authority (Bass \& Riggio, 2006).

4. Leadership - Leadership is a process in which an individual (leader) influences a group (followers) with the purpose to achieve a common goal. Literature suggests four components as central to the phenomenon: (a) it is a process, (b) it involves influence, (c) it occurs in a group context, and (d) it involves goal attainment (Northouse, 2007). 
5. Psychological Gender Role - Psychological gender is a set of beliefs and perceptions about men and women and about characteristics of masculinity and femininity (Deaux \& Kite, 1987; Whitley, 2001). Psychological gender is a function of both biological and social influences.

6. Role Congruity- Role congruity occurs when an individual's socially desirable psychological gender role matches his or her socially expected leader role.

7. Satisfaction - Satisfaction refers to followers' (teachers) perceptions on whether they are content with leadership behavior of their leader (principal) and pleased with the way leaders (principal) work with others.

8. Transformational Leadership- Transformational leadership is a teaching/mentoring model of leadership. This leadership approach is a process that stimulates and inspires followers to surpass expectations, as well as motivating followers to transcend self-interests to reach organizational goals. The transformational approach raises the level of motivation and morality in both leaders and followers (Avolio \& Bass, 1987; Bass \& Riggio, 2006, Burns, 1978).

9. Transactional Leadership - Transactional leadership behavior is a transaction between leaders and followers, seen as a lower order exchange process. Transactional leadership is as one of contingent reinforcement, leaders and followers perceive one another as instrumental to the completion of a task (Bass, 1985, Burns, 1978). 


\section{CHAPTER II \\ LITERATURE REVIEW}

The study explored elementary school principal leadership in Kentucky through examining constructs of leadership style (transformational leadership, transactional leadership, and laissez-faire leadership) and psychological gender (feminine, masculine, androgynous, and undifferentiated) on principal effectiveness. To contextualize the current study, several relevant areas of literature are reviewed. First, the development of leadership is presented. This includes a description of different leadership perspectives (leader-centered, situation-centered, follower-centered, and process-centered), leadership trends, and characteristics of leaders and followers. Second, the discussion turns to Bass's conceptualization of Multifactor Leadership Theory and its associated Full Range Leadership Model. A brief review of the link between Multifactor Leadership Theory and leader outcomes (follower satisfaction, follower commitment, and leader effectiveness) is presented. Third, a review of Multifactor Leadership Theory in public education is discussed.

Following the theoretical frameworks that under-gird leadership in this research study, psychological gender is explicated. This includes a discussion on traditional and modern perspectives of psychological gender, and gender role development. Next, the review turns to a discussion on the congruity between gender roles and leader roles. In 
the final portion of this review, the researcher underscores the current gaps in the research literature.

\section{Leadership}

Leadership is an ambiguous term associated with an extensive body of research literature explained through a wide variety of theoretical approaches. Between the $1930 \mathrm{~s}$ and 2000 s, leadership was conceptualized into as many as 65 different classification systems (Fleishman, Mumford, Zaccaro, Levin, Korotkin, \& Hein, 1991). Various social scientists have conceived leadership through the multiple perspectives of leader traits, leader behaviors, leader skills, and reciprocal processes. Despite various ways leadership has been conceptualized, literature suggests four components as central to the phenomenon: (a) it is a process, (b) it involves influence, (c) it occurs in a group context, and (d) it involves goal attainment (Northouse, 2007). Based on the aforementioned components, leadership in the current review is defined as a process in which an individual (leader) influences a group (followers) with the purpose to achieve a common goal. Leaders are defined as those who direct leadership and followers as those toward whom leadership actions are directed.

The current definition indicates that both leaders and followers are engaged in a nonlinear-interactive process which often involves restructuring of situations, perceptions, and expectations of followers. According to Burns (1978), Heller \& Van Til (1983), and Hollander (1992), both leaders and followers need each other, both are part of the leadership process. Thus, it is essential to understand leaders and followers in relation to one another (Burns, 1978; Hollander, 1992). Though leaders and followers are engaged in reciprocal interactions, leaders establish and maintain the leader-follower relationship 
(Heller \& Van Til, 1983). The process-center perspective suggests leadership is available to and can be learned by anyone. This perspective provides the leadership framework in the current study.

Leadership perspectives. In addition to definition and conceptual issues, it is important to discuss the various leadership perspectives beyond the process-center viewpoint. Specifically, scholars of leadership need to be able to distinguish between leader-centered (trait theories, skill theories, style theories), situation-centered (situational theory, contingency theory), follower-centered (path goal theory), and process-centered perspectives (social exchange theories, transformational theory). Knowledge of leadership development and variation of perspectives aids in the understanding of how leadership theory relates to leadership practice.

Leader-centered perspective. According to Bass (1990), the earliest leadership perspective started with the qualities of unique individuals. The leader-centered perspective suggests leadership is bestowed on individuals with special traits, characteristics, and skills. These individuals have superior qualities and the ability to influence others to complete tasks (Bass, 1990). This classic perspective is categorized into trait, skills and behavioral approaches to leadership.

Trait approach. Arguably, the earliest leadership research started with the qualities of great men in the early $20^{\text {th }}$ century. It was during the $20^{\text {th }}$ century, leadership research started to focus on identifying specific traits that separated leaders from followers (Bass, 1990; Jago, 1982). The trait perspective conceptualizes leadership as residing in select people, as well as restricting leadership to individuals believed to have special, inborn talents. The trait perspective focuses solely on the leader, particularly concerned with 
identifying the innate characteristics posed by "great men" - that is, leaders of nations, military leaders, and men of great wealth (Bass, 1990). The trait perspective of leadership suggests only leaders with certain innate traits are effective. The mid- $20^{\text {th }}$ century brought much criticism to the trait perspective. Stodgill (1948) criticized trait theories in his review of leadership studies from 1904 to 1947. Stogdill's review of 124 trait studies began a line of research asserting that traits required of leaders varied across situations. Specifically, individual leaders with a set of traits who is a leader in one situation might not be a leader in another. Researchers began to proffer the trait perspective failed to set forth concrete leadership traits, or take into account leadership outcomes (Bass, 1990). Therefore, leadership later was re-conceptualized into a situationcentered perspective, which focuses on the relationship between leaders and situations. The dynamics of the situation-centered perspective is discussed in greater detail later in this review.

Skill approach. A second leader-center perspective is the skills approach. The skills perspective stresses abilities exclusive to unique leaders, highlighted in the work of Katz (1955). Katz's work was a new breed of leadership research moving scholars away from seeing leadership as a trait, but rather as a learned skill. Katz proposed a skills approach suggesting three basic personal skills necessary for administrative effectiveness- technical skills, human skills, and conceptual skills. A technical skill is defined as proficiency in a specialized type of work. Human skills are interpersonal skills - the ability to work with followers, peers, and superiors to achieve organizational goals. A conceptual skill is the ability of a leader to articulate organizational objectives (Katz, 1955). Katz proposed a leader's technical skills, human skills, and conceptual skills vary 
depending on a leaders' placement in the organization's hierarchy. For example, board members and vice presidents (higher-level leaders) will posses higher levels of conceptual skills versus front line managers (lower-level leaders) who will pose higher levels of technical skills.

Advancing the work of Katz, the $21^{\text {st }}$ century experienced an increase in research studies proposing effective administration is the result of a leader's ability to problem solve. Mumford, Zaccaro, Harding, Jacobs, \& Fleishman (2000) formulated a skillsbased model of leadership that examined the relationship between leader knowledge, skills, and performance. Mumford, Zaccaro, Harding, Jacobs, \& Fleishman (2000) skillsbased model highlighted leader competencies in problem solving skills, social judgment skills, and knowledge generating skills. Although the leadership field saw a raise in empirical research for the skills perspective, the model received much criticism. Researchers criticized the skills approach for not providing clarity on how differences in judgment and problem solving affect leader performance. Additionally, the skills approach received much criticism because of its similarity with the leader trait approach, that is -skills based models include trait-like attributes such as motivation and personality. Furthermore, the skills approach is criticized for its weak generalizability, most empirical research continually relies on military samples.

Behavior/style approach. The behavior approach, referred to as the style approach, is a leader-center approach that arose following Stodgill's 1940 research. Rather than emphasize personal characters (trait approach) or leader capacities (skills approach), the behavior/style approach emphasizes leader behavior (actions) towards followers. This approach provides a framework for defining leader behavior as either task 
or relations oriented. Moreover, the style approach assesses how to combine task and relational behaviors to influence followers' efforts toward goal attainment. On the one hand, task behaviors facilitate follower accomplishments (Bass, 1990). On the other hand, relational behaviors foster followers' sense of comfort with each other and with situations. Situations determine if a leader expresses task or relational behavior. Certain situations call for leaders to express more task behaviors, while others call for relational behaviors. Many studies were conducted throughout the 1940s to 1960 s investigating the style approach to leadership; particularly the Ohio State University studies (Hemphill \& Coons, 1957), the University of Michigan studies (Katz, Maccoby \& Morse, 1950) and the Managerial Grid (Blake \& Mouton ,1964). First, the Ohio State University studies emphasized the need for more leader behavior research. Second, the University of Michigan studies (Cartwright \& Zander, 1960; Katz \& Kahn, 1951) focused on leadership in small groups. Third, the Managerial Grid (Blake and Mouton, 1964) stressed the application of task and relational behaviors linked to organizational settings. These three lines of research emphasized leader behavior (actions) towards followers, stressing certain situations call for leaders to express certain behaviors. Specifically, not all leader behaviors are appropriate or effect in all situations.

Researchers at The Ohio State University analyzed how individual leaders behaved when leading a group or organization (Bass, 1990). Hemphill \& Coons (1957) developed the Leader Behavior Description Questionnaire (LBDQ) that asked followers to identify the number of times their leader engaged in a certain behavior. The researchers found follower responses clustered around two behavioral factors consideration and initiating structure. The consideration factor is a relationship behavior 
including qualities that express concern for the welfare of others such as: building interpersonal relationships, strengthening member self-esteem, and recognizing staff accomplishments (Bass, 1990). The initiating of structure factor is a task behavior emphasizing a leader's intent of activity such as: organizing, communicating, arranging, and defining role expectations (Bass, 1990). Initiation and consideration factors are seen as independent and distinct - a leader exhibiting one behavior is not related to exhibiting the other.

Congruent with The Ohio State University studies, researchers at The Survey Research Center at the University of Michigan explored the impact of leader behavior on small groups. The research differentiated between employee orientated and production orientated leader behavior. Employee orientated leaders (often referred to as relationsoriented) have a strong concern for others (Katz, Maccoby \& Morse, 1950). Employeeoriented leaders take interest in followers' needs and individuality (Bowers \& Seashore, 1966). Production oriented leaders (often-termed task-oriented leaders) have a strong concern for task completion; specifically, leaders stress followers are a means to getting the technical production of jobs completed (Bowers \& Seashore, 1966). Originally, employee orientated behavior and production orientated behavior were seen as two ends of spectrum. As a leader displayed more employee-oriented behavior, s/he displayed less production-oriented behavior. However, recent research suggests a leader can equally express both employee-oriented and production-oriented behaviors (Northouse, 2007).

In 1964, Blake and Mouton built upon the Ohio State University and University of Michigan studies. Blake \& Moutone prescribed an integration of task and relations oriented leadership. The Managerial Grid (also referred to as the Leadership Grid) 
explains how leaders promote reaching organizational objectives through a concern for production and a concern for people. The first factor, concern for production, refers to leaders concerned with achieving organization tasks (i.e. attention to policy, product development, and workload). The second factor, concern for people, refers to leaders concerned the people in the organization (i.e. building trust, maintaining fair salary structures, promoting good social relations). The Managerial Grid contains a scale ranging from 1 to 9 along a vertical (leaders concern for people) and horizontal (leader concern for production) axis. One indicates low concern and nine indicates high concern. Blake and Mouton introduced five leaders' styles in the grid: authority- compliance management, country club management, improvised management, middle of the road management, and team management. The authority compliance management expresses a leader with maximum concern for production and minimum concern for people. The country club management stresses a leader with a high concern for people (1), but low concern for production (9). The improvised management expresses leaders have minimal concern for people (1) and production (1). The middle of the road management stresses adequate concern for people (5) and production (5). The team management expresses the leader has a high concern for people (9) and production (9) people.

The behavior/style approach has received two major criticisms in research literature. First, the style approach does not adequately demonstrate how leaders' styles relate to performance outcomes (Yukl, 1999). Second, the approach implies effective leadership occurs when leaders display both a high concern for people and production, ignoring that variability among situations. Ultimately, the approach suggests one behavior (high concern for people and production) is effective in all situations. Specifically, the 
style approach does not acknowledge that certain situations require different leadership behaviors.

Situation-centered perspective. Following much criticism of the leader-center approach, leadership research turned to situation-center perspectives. Rather than seeing leadership as a trait, skill, or behavior, leadership was re-conceptualized as a relationship between leaders and the situation in which a leader functions. The most prominent of the situation-centered perspectives are the situational and the contingency leadership frameworks.

Situational approach. One of the most widely recognized situation-centered approach to leadership is the situational approach. The emergence of situational leadership enabled the idea that situations determine leadership behavior. For example, expectations of leadership in unstable, chaotic environments are different from those in stable, calm environments. According to Bass (1990), a leader can change environments to fit his/her own disposition; in turn, situations or changes in situations affect a leader's behavior. Additionally, a leader must adapt his or her style to the demands of a situation to be effective. The most prominent situational model discussed in the research literature is the Hersey-Blanchard Situational Leadership Model (Hersey \& Blanchard, 1969).

The Hersey-Blanchard Situational Leadership Model prescribes a leader as either task oriented - telling followers what to do or as relation-oriented -sharing decisionmaking. Hersey and Blanchard's model is composed of four components of leadership behavior: telling, selling, participating (sharing in decision-making), and delegating. In a telling behavior, followers new to a task seek task-oriented leadership and are told what to do. In a selling behavior, as follower experience increases, he/she needs to be sold on 
continuing their experiences. In participating behavior, relations-oriented leadership is necessary to engage both followers' knowledge and maturation. In a delegating behavior, fully experienced followers perform better when leaders delegate tasks to be completed. Hersey and Blanchard's Situational Model has received much criticism regarding the model's conceptual ambiguities and lack of theoretical justification (Graeff, 1983, 1997).

One criticism of the model is its lack of recognition for one-on-one versus group leadership in organizations- does a leader match his/her style to the overall group or to the level of individual members in a group? A second criticism raises the question, should leaders vary their orientation and behavior to fit the demands of the situation or try to be consistent in their styles (Bass, 1990)? Fielder addressed this question with his contingency model (Fielder, 1967). Fielder indicated that different leader styles are appropriate for different situations. Furthermore, Fielder stressed leaders need to change situations to appropriately fit their style (Bass, 1990).

Contingency theory. The Fielder Contingency Model is a leader-match theory indicating leader effectiveness is dependent on how well a leader's style fits the given situation. Contingency theory ultimately postulates no best leadership theory exists. Rather, effective leadership is contingent on matching a leader's style to the right situation. The contingency model describes leadership as either task motivated or relationship motivated. Task motivated leaders are interested primarily in completing task, while relationship motivated leaders are interested in developing leader-follower relationships. Fielder's research suggests that under extremely favorable or extremely unfavorable conditions, task-motivated leadership works best, but that moderately favorable and unfavorable conditions called for relationship-motivated leadership. 
Furthermore, Fielder advocated the type of leadership needed in a given situation depends on the following three situational variables: 1) the degree to which the group aligns with the leader, 2) the degree to which tasks have clearly identified procedures, and 3) the leader's use of positional power to supervise followers. Much empirical research has supported contingency theory, extending the leadership field to include the impact of situations on leaders. However, the theory has received some criticism.

First, the theory does not adequately link leadership styles and situations; specifically the theory does not clarify why certain leadership styles work in some situations and not others. Second, the theory does not provide an explanation on how to teach leaders to adapt their styles to situations. Contingency theory promotes the changing of a situation to fit a leader; however, there is no explanation on how a leader can engineer such a task (Northouse, 2007).

Follower-centered perspective. In the 1970s, scholars began to draw heavily on follower motivation as the center of leadership. Evans (1970), House (1971), House and Dessler (1974) and House and Mitchell (1974) introduced the concept of leaders matching their style to follower motivational needs. Unlike the situation-centered perspective, the follower-centered perspective focuses on the relationship between a leader's style and follower characteristics. The most prominent follower-center perspective is Path Goal Theory (Evans, 1970; House, 1971).

Path Goal Theory. Path goal theory arose as a way to explain how leaders influence follower motivation and satisfaction. In addition, the theory stemmed from the need for leaders to point out paths (behaviors) for successful goal completion (Georgopolous, Mahoney, \& Jones, 1957). Path-goal theory derived from expectancy 
theory, which suggests follower motivation is the result of believing task completion leads to beneficial payoffs (House \& Mitchell, 1974). The theory stresses that a leader's responsibility is to choose a leadership style that best meets followers' needs. In addition, leaders must clearly define followers' goals, and the paths to attain such goals increase follower motivation and performance (Bass, 1990). Furthermore, path-goal theory consists of the following components: leader behaviors, follower characteristics, task characteristics, and motivation.

First, leaders express directive-oriented, supportive-oriented, participativeoriented, or achievement-oriented behaviors. Directive leadership behavior emphasizes task structure, expectations, processes, and timeliness for task completion. Participative leadership behavior emphasizes collaborative decision-making. Supportive leadership behavior advocates treating followers as equals. Achievement-oriented leadership stresses high expectations for followers (House \& Mitchell, 1974). Leader expression of any one the aforementioned behaviors is based on situational factors such as: (a) task variables (i.e. role clarity and/or routine), (b) environmental variables, and (c) individual differences (i.e. preferences and/or personality) (House \& Mitchell, 1974).

Second, follower characteristics determine the interpretation of leader behaviors. Follower characteristics such as the need for affiliation, preferences for structure, desires for control, and self-perceived level of task ability determine if a leader's behavior is satisfactory. A follower need for affiliation refers to a need for structure, clarity, certainty, or friendliness in the work setting; specifically those followers with a strong need for affiliation perform better in friendly environment versus dogmatic followers who prefer structure. Desire for control is concerned with followers having internal (belief they are 
in charge) or external (belief that outside sources determine events) locus of control. Selfperception of task ability refers to a followers' self-efficacy in task completion; specifically followers that believe they can complete a task require less directive leadership.

Third, task characteristics affect how leader behaviors influence follower motivation. Task characteristics are divided into design of follower task, authority system of an organization, and follower work groups. When situations provide clear structured task, strong work groups, and clearly established authority systems, followers perceive the paths to complete goals as clear. As a result, followers tend to complete goals without coaching from leaders and feel their work is of value (House \& Mitchell, 1974).

Fourth, leaders can affect follower motivation by adopting the following reforms: (a) clarification of follower roles, (b) dependency of rewards on follower success, and (c) the increase in size and value of rewards. Leaders can strengthen followers' attainment of goals by: (a) providing support, (b) alleviating frustration in time of stress, (c) coaching and mentoring, and (d) providing direction (Bass, 1990; Fielder \& House, 1988).

The four points highlight the strengths of Path Goal Theory. The theory provides a framework of understanding just how leader behavior affects follower satisfaction and performance. Additionally, the theory integrates motivation and leadership and is one of the most practical of all leadership theories (Jermier, 1996). Though path goal theory has received support, researchers have criticized the lack of empirical evidence supporting its validity (Schriesheim \& Kerr, 1977; Schriesheim \& Schriesheim, 1980). Furthermore, the theory involves so many different aspects that it is difficult to interpret and hard to incorporate into practice. Moreover, the empirical research findings to date fail to explain 
the link between leadership and follower motivation; specifically path goal theory does not clarify how leaders can promote competency and success (Evans, 1996; Jermier 1996).

Process-centered perspective. The review thus far has discussed leadership approaches from the leader-centered, situation-centered, and follower-centered perspectives. Yet, still leadership can be conceptualized as a process. Leadership as a process implies the leader and follower influence each other in a group context to achieve a common goal. The prominent leadership theories housed under the process-centered perspective are social exchange theory, transformational leadership, and Multifactor Leadership Theory. The process-center perspective of leadership derives from leadermember exchange theory.

Leader-Member Exchange Theory (LMX) is an interaction theory advocating a dyadic relationship between leader and followers (Graen, 1976; Graen \& Cashman, 1975). LMX is in opposition to earlier theories because it stresses leaders have distinct unique relationships with followers. LMX bridges the gap between leadership behavior and follower outcomes. "Hence, drawing from LMX research, it can be asserted that the development of the relationship between superiors and subordinates is critical to leader and managerial effectiveness" (May-Chiun, Ramayah, \& Ling, 2009, p. 575). LMX ultimately is used to elaborate the reciprocal relationship between a leader and follower, a concept present in social exchange theory, transformational leadership theory, and Multifactor Leadership Theory.

Social exchange theory. The exchange process approach between leaders and followers most often describes leadership dynamics in recent history (Bass, 1990). Social 
Exchange Theory takes a different approach to leadership than early theories in the 1940s to early 1970s. Early theories advocated leadership approaches that were unidirectional focusing on leaders actions toward followers; however, social exchange theory advocates leadership is a bidirectional dyadic relationship between a leader and each of his/her followers. The bidirectional relationship proposes a follower expects a leader will provide rewards in exchange for successful task completion (task defined by a leader). Rewards, for example, can be a sense of direction, values, or recognition (Hollander, 1992). Hollander's (1978) study suggested leaders and followers enter into agreement on satisfactory exchanges - a follower's compliance in exchange for leaders clarifying the paths to receive rewards. Central to social exchange theory is the idea of contingent reinforcement. Leaders serve as reinforcing agents for followers. For the exchange process to be effective, leaders and followers must perceive each other as instrumental in fulfilling each other's needs. Social exchange theory is often criticized for promoting inequality in the workplace; specifically, problems can arise if certain followers are treated differently than others. Another prominent process-centered theory on leadership is transformational leadership.

Transformational leadership theory. Many theories of leadership exist. Yet, transformational leadership theory has increasingly become the leadership approach of choice for various researchers and scholars since the 1980s (Bass \& Riggio, 2006). According to Bass \& Riggio (2006), transformational leadership's popularity is due to its emphasis on intrinsic motivation and follower development. Transformational leadership is a process that stimulates and inspires followers to surpass expectations (Avolio \& Bass, 1987; Bass \& Riggio, 2006). Though the term "transformational leadership" was first 
coined by Downtown (1973), arguably the approach's popularity started with Burns (1978). In his seminal piece Leadership, Burns (1978) wrote of leaders raising followers' lower levels of consciousness and motivating them to transcend self-interests to reach organizational goals. Unlike the bulk of leadership approaches, the transformational approach raises the level of motivation and morality in both leaders and followers. Transformational leadership is an extension of charismatic leadership theories.

Often, transformational leadership is described in such a way to make it similar, if not identical, to charismatic leadership (House, 1976). House proposed charismatic leaders, either socialized or personal, have very distinct effects on followers. Socialized charismatic leaders are participatory and committed to serving others (House, 1996). Socialized charismatic leaders, synonymous with "socialized transformational leaders", experience close psychological connections to followers, express strong moral values, and develop shared goals. According to Howell \& Avolio (1993), true socialized transformational leaders place follower interest above their own. Often, Martin Luther King Jr. and John F. Kennedy are cited as examples of socialized charismatic or socialized transformational leaders.

Unlike socialized charismatic leaders, personalized charismatic leaders are directive, self-serving, self-aggrandizing, exploitative of others, and focus on personal goals (Bass \& Riggo, 2006). This type of charismatic leader relishes control and uses persuasion to obtain follower submission, thus giving birth to the idea of dark charisma (Bass \& Riggo, 2006). Personalized charismatic leaders use their abilities to inspire others in negative ways leading followers to destructive ends (Bass \& Riggo, 2006). The notion of personalized charismatic leadership is similar, if not identical to pseudo- 
transformational leadership. Pseudo-transformational leaders are self-oriented, selfaggrandizing, exploitative, and narcissistic (Popper, 2002). Adolf Hitler and Saddam Hussein are referred to as personalized charismatic and pseudo-transformational leaders (Avolio \& Bass, 2002).

Burns termed the opposite of transformational leadership as transactional leadership. Transactional leadership focuses on the exchange between a leader and a follower based on the promises of rewards or avoidance of punishment. More specifically, the transactional approach encompasses leaders bargaining with rewards in exchange for follower performance (Burns, 1978). In the mid-1980s, Bass (1985) extended the work of Burns describing transformational and transactional leadership approaches as a single continuum, rather than in opposition. Bass's conceptualization became the Multifactor Leadership Theory. Multifactor leadership leader prescribes leaders can express both transformational and transactional leadership behaviors; specifically transformational behaviors augment the effect of transactional behaviors. The Multifactor Leadership Theory is the framework for leadership in the present study.

\section{Multifactor leadership theory and full range leadership model.}

Transformational and transactional leadership behaviors have been the primary focus of leadership theory over the past twenty years (Powell, Butterfield \& Bartol, 2008). Bass (1985; 1988; 1990) and his colleagues (Bass, Avolio, \& Goodheim, 1987; Bass \& Riggio, 2006; Waldman, Bass, \& Yammarino, 1990), developed the most comprehensive theory of the conceptualization of transformational and transactional leadership known as the Multifactor Leadership Theory. In 1985, Bass extended Burns' transactionaltransformational leadership paradigm describing three components of leadership: 
transformational, transactional and laissez-faire leadership. Unlike Burns, Bass posits transformational leadership augments transactional leadership, and laissez-faire leadership is the lack of leadership. Multifactor Leadership Theory proposes every leader is capable of displaying all three leadership behaviors (transformational, transactional, and laissez-faire); one behavior does not replace the other (Bass, Avolio \& Goodheim, 1987; Avolio \& Bass, 1987). However, research has presented a hypothetical hierarchy to the leadership behaviors. According to Waldman, Bass and Yammarino (1990), a leader performing poorly most frequently displays laissez-faire leadership and least frequently exhibits transformational leadership. In contrast, optimal leaders infrequently display laissez-faire behaviors, show higher frequencies of transactional behaviors and display the highest levels of transformational behaviors.

Transactional leadership behavior is a transaction between leaders and followers, seen as lower order exchange process. Bass (1985) described transactional leadership as one of contingent reinforcement, leaders and followers perceive one another as instrumental to the completion of a task. If necessary, leaders clarify what followers must do to obtain rewards. Followers' receipt of reward or punishment is contingent on completing a task in the manner the leader prescribes. However, transactional leadership is viewed as a necessary for transformational leadership to be effective. Transactional behaviors provide direction, focus, and clarity to what confusion and ambiguity would result from the sole use of transformational behaviors (Bass, Avolio, Jung, \& Berson 1999; Hinkin \& Schriesheim, 2008).

An extension of transactional leadership, transformational leadership involves leaders raising followers' motivation to transcend their own self-interests for shared 
organizational visions and goals (Bass 1985, 1988; Bass, Avolio, Jung, \& Berson 1999). Through coaching and mentoring, transformational leaders promote followers' own leadership abilities, while encouraging followers to take on more challenging roles and become innovative problem solvers (Avolio, Waldman, \& Einstein, 1988; Bass \& Riggo, 2006). When transformational leadership is practiced, followers feel leaders care and see themselves as more than such a means to an end (Albulushi \& Hussain, 2008).

Based on studies completed in 1985 to 1990, Bass and his colleagues (Avolio, Bass, \& Jung, 1991; Bass, 1985; Bass \& Avolio, 1993; Bass, 1998; Hater \& Bass, 1988) conceptualized Multifactor Leadership Theory with the Full Range Leadership Model. Bass's Full Range Leadership Model consists of five transformational factors, three transactional factors, and one laissez-faire leadership factor.

The Full Range Leadership Model is composed of three components and nine factors, refer to Table 1. As a way to explore the model, Bass developed the Multifactor Leadership Questionnaire (MLQ) (1985). The MLQ a 45-item questionnaire measuring the Full Range Leadership Model's components as well as leadership outcomes (extra effort, effectiveness, and satisfaction) on a 5-point likert scale.

Transformational component. Transformational leaders encourage followers to take on more challenging roles while contributing to organizational innovation (Avolio, Waldman, \& Einstein, 1988). Transformational leaders are proactive in helping followers achieve extraordinary goals. Self-reinforcement is an underlying construct of the following five transformational factors: idealized influence (attribute), idealized influence (behavior), inspirational motivation, intellectual stimulation, and individual consideration (Bass, Avolio \& Goodheim, 1987). 
Table 1

Bass's Full Range Leadership Model Components and Factors

\begin{tabular}{ll}
\hline Leadership Component & Underlying Factors \\
\hline & Idealized Influence (attribute) \\
& Idealized Influence (behavior) \\
Transformational & Inspiration Motivation \\
& Intellectual Stimulation \\
& Individualized Consideration \\
\hline Transactional & Contingent Reward \\
& Management by Exception (active) \\
\hline Non-leadership & Management by Exception (passive) \\
\hline
\end{tabular}

Idealized influence (attribute and behavior). The first transformational factor is idealized influence, an interaction between leader behavior and leader attributes.

Idealized influence -attribute describes distinctive features of leaders, specifically leaders have high standards of ethical and moral conduct and as result are seen as role models (Avolio \& Bass, 2002; Bass \& Riggo, 2006,). Idealized influence -behavior describes leaders' actions that promote organizational goals, missions and values. Bennis and Nauis (1985) assert that leaders expressing both distinctions of the idealized influence factor create an intense commitment from followers.

Collins and Porras (1994) found such leaders to have followers that felt a sense of belonging and pride in the organization. 
Inspirational motivation. The second transformational factor is inspirational motivation. It describes leaders who motivate followers through meaningful and challenging work. Bass and Avolio (2004) describe such a leader as one who communicates high expectations, provides encouragement, and demonstrates commitment to goals. Leaders and followers develop a relationship fostering higher levels of motivation and morality in each other. Both inspirational motivation and idealized influence indicate a leader's ability to articulate and share visions.

Intellectual stimulation. The fourth transformational factor is intellectual stimulation. It describes leaders who encourage followers to be creative and innovative by trying new approaches and questioning old assumptions. Leaders solicit ideas and creative problem-solving solutions from followers as well as promote intelligence and rationality. Leaders facilitate opportunities for professional growth and learning. With constructive criticism, leaders enhance followers' professional skills and never publicly criticize follower mistakes. Furthermore, leaders value follower opinions and decisionmaking ideas, even if such opinions and ideas are different from their own (Bass \& Avolio, 2004).

Individualized consideration. The fifth transformational factor is individualized consideration. It describes leaders who help followers reach their potential, recognizing individuals' needs and desires. Such leaders act as mentors, fostering a supportive climate that stimulates learning opportunities. Such considerate leaders listen and delegate tasks for the sole purpose of follower development. Additionally, leaders encourage 
two-way communication, personalized interactions, and are aware of follower concerns (Bass \& Riggio, 2006).

Transactional component. Transactional leadership posits a fundamental psychological contract between leaders and followers (Hollander, 1978). Leaders and followers perceive one another as instrumental to completion of a task (Bass, 1985). If necessary, leaders clarify what followers must do for successful task completion to obtain rewards. The exchange cycle lays the foundation for the three theorized transactional leadership factors: contingent reward, management-by-expectation active and management-by-exception passive.

Contingent reward. The first transactional factor is contingent reward. It describes leaders who contract exchanges for what the leader perceives as satisfactory performance in return for promised rewards. In such an exchange, leaders attempt to obtain agreement from followers on task that must be completed and the benefits to completing such task. Contingent reward does motivate followers (through rewards), as well as produce a positive effect on organizational outcomes.

Management-by-exception (active and passive). The second and third transactional factors are corrective and negative dimensions of management-byexception. Management-by-exception can be either active (factor 2) or passive (factor 3). Management-by-exception active is corrective, involves a leader actively monitoring for mistakes and errors, and intervenes when necessary or when standards are not met. Management-by-exception passive is negative reinforcement and leaders wait for deviations to occur or fail to intervene until problems become serious and are brought to 
his/her attention. According to Bass \& Riggio (2006), management-by-exception passive is practiced more often when leaders supervise large numbers of followers.

Laissez-faire component. The final leadership factor in the Full Range Leadership Model is laissez-faire leadership. It describes leaders that avoid responsibilities and decision-making. Such leaders delay actions, do not make urgent decisions, and avoid using authority (Bass \& Riggio, 2006). By definition, laissez-faire leadership is inactive and is the most ineffective (Hater \& Bass, 1988). Additionally, laissez-faire leadership is most often associated with lower levels of performance and lower levels of follower satisfaction (Hater \& Bass, 1988). The current study views laissez-faire as passive leadership. The act of delaying action, lack of urgent decisions, and avoidance of authority are passive rather than active leadership behaviors. Leaders are still taking part in some type of behavior, just not behaviors followers view as satisfying or productive (Hater \& Bass, 1988).

A large growing body of research supports the effectiveness of the dimensionality of the Multifactor Leadership Theory and the associated Full Range Leadership Model. Additionally, the research literature supports a relationship exist between the Full Range Leadership model and the three leader outcomes that are also measured by the MLQ (follower extra effort, leader effectiveness, and follower satisfaction). The research is reviewed to provide empirical support for it use of three leader outcomes as dependent variables in the current study.

Research supporting multifactor leadership theory. According to Bass \& Riggio (2006), there is much generality to Multifactor Leadership Theory as well as the Full Range Leadership Model. Multifactor Leadership Theory has been studied in various 
research settings such as military, governmental, health care, and nonprofit sittings (Bass, 1985, 1997; Hater \& Bass, 1988). Since its development, the Multifactor Leadership Theory, and particularly transformational leadership, has received much research attention; particularly focused on examining the models effectiveness. Researchers have found transformational leadership and the transactional contingent reward factor to positively impact follower perceptions of satisfaction, extra effort, leader effectiveness, and organizational performance (Avolio, Bass, \& Jung, 1995; Philbin, 1997; Yammarino, Spangler, \& Bass, 1993). The empirical research reviewed examines the relationships between the transformational leadership, transactional leadership, and laissez-faire leadership and follower perceptions of satisfaction, extra effort, effectiveness, and performance. The studies reviewed substantiate a positive relationship exists between the variables.

Bass (1985) published one of the first empirical pieces showing the transformational leadership factors and the transactional leadership factor of contingent reward are significantly related to follower satisfaction, extra effort, and work effectiveness. In a correlational study, Bass sampled New Zealand professionals and managers $(N=45)$, administering the MLQ to each participant. The study revealed that the more leaders displayed idealize influence $(r=.50, p<.01)$, intellectual stimulation $(r=.49, p<.01)$, and contingent reward $(r=.38, \mathrm{p}<.01)$ leader behaviors, the more followers are willing to exert extra effort. The transformational factors intellectual stimulation $(r=.51)$, idealized influence $(r=.41)$ and individual consideration $(r=.36)$ were positively correlated with perceptions of effectiveness, along with the transactional factor of contingent reward $(r=.29)$. All transformational leadership factors and transactional leader factor of 
contingent reward were correlated with perception of leader satisfaction. The more a follower felt his or her needs were met, the more satisfied he or she was with his or her leader.

Following Bass's initial study, Hater and Bass (1988) explored the relationship between leadership behavior and leader effectiveness, follower satisfaction, and follower performance with air delivery managers. The study administered the Multifactor Leadership Questionnaire (Bass, 1985) to measure the five factors of transformational leadership, the three factors of transactional, laissez-faire leadership and leadership outcomes (effectiveness, satisfaction, and performance). Study findings revealed transformational leadership was highly correlated with follower perceptions of effectiveness $(r=.82)$ and satisfaction $(r=.88)$. Thus, the more a leader displays transformational leadership behavior, the higher the levels of follower satisfaction and perceived leader effectiveness. However, transactional leadership was weakly correlated with effectiveness and satisfaction $(r=.48$ and $r=.41, p<.01)$. Additionally, the study showed significant, positive relationships between transformational leadership and follower work performance ( $r=.48$ to $r=.60, p<.01$ ) as compared to nonsignificant relationships between work performance and transactional leadership factors. This study supports the argument transformational leadership factors are significantly related to perceptions of leader effectiveness, follower satisfaction, and follower willingness to exert extra effort. Hater and Bass findings were later supported with by the work of Seltzer \& Bass (1990).

According to Seltzer and Bass (1990), the leadership behaviors of initiation and consideration are not sufficient in explaining the range of leadership behaviors commonly 
associated with the best and worst leaders. Initiation scales are concerned clarification of task. The consideration scale is concerned with followers' welfare. Although initiation and consideration are related to performance, Seltzer \& Bass (1990) hypothesized transformational leader behaviors augment the effects of initiation and consideration on performance. Moreover, the authors hypothesized transformational leadership results in higher levels of follower performance and satisfaction beyond that of initiation and consideration behaviors. To test the hypotheses, Seltzer \& Bass conducted a study with 55 managers and 138 followers; followers of each manager completed the MLQ describing leader styles and their willingness to exert extra effort, leader effectiveness, and satisfaction. A hierarchical regression analysis showed transformational factors of idealized influence, individualized consideration, and intellectual stimulation accounted for an additional $8 \%$ to $28 \%$ more variability in study outcome measures (extra effort, effectiveness, and satisfaction) beyond initiation and consideration. Researchers found the intellectual stimulation factor of transformational leadership had the highest correlations with follower perceptions of satisfaction $(r=.70)$ effectiveness $(r=.56)$ and effort $(r=64)$. The individual consideration factor of transformational leadership had the next highest correlations with follower perceptions of effectiveness $(r=.49)$ and satisfaction ( $r=.63$ ). Seltzer \& Bass' (1990) study findings provide further empirical evidence that the transformational leadership factors individual consideration and intellectual stimulation are related to the MLQ's three leader outcome measures. Further, changes in two transformational leadership factors, intellectual stimulation and individual consideration, reflect a moderate change in follower willingness to exert extra effort, follower satisfaction, and follower perceptions of leader effectiveness. 
Furthermore, Podaskoff, MacKenzie, Moorman, \& Fetters (1990) work supported Bass (1995), Hater \& Bass (1997), and Seltzer \& Bass (1990). Podaskoff, MacKenzie, Moorman, \& Fetters (1990) further investigated the effect of transformational leadership behavior on followers' satisfaction. The Minnesota Satisfaction Questionnaire was administered to 988 employees of a petrochemical company. Study results showed the transformational leadership component significantly correlated with follower satisfaction $(r=.77)$. Specifically, results indicated transformational leadership accounts for $59 \%$ of the variance in follower satisfaction. The transformational leadership factors individualized consideration and intellectual stimulation were positively correlated with satisfaction ( $r=.77$ and $r=.65$ ); individualized consideration accounts for $59 \%$ of variance in satisfaction and intellectual stimulation accounts for $42 \%$ of variance in satisfaction. The more a leader displays individual consideration and intellectual stimulation behaviors, the more followers are satisfied.

Additionally, researchers have found transformational and transactional leadership impact organizational performance, such as goal attainment, productivity, and financial outcomes. In several research studies, transformational leadership has been highly correlated with organizational performance compared to the transactional and laissezfaire leadership components. For example, Altieri (2008) found a statistically significant relationship between idealized influence (transformational factor) and nurse unit performance. Howell \& Avolio (1993) found transformational leadership of middle managers to predict organizational performance (financial success).

Furthermore, Avolio, Waldman, and Einstein (1988) examined the effects of transformational and transactional leadership on organizational performance in a game 
stimulation with MBA students. Specifically, in a three-month period authors explored the effects of the transformational and transactional leadership factors on group performance. Information on group presidents' leadership, as measured by the MLQ, and organizational performance, as measured by team financial outcomes, was gathered. Financial outcomes included data on market shares, return to assets, stock prices, earnings per share, and debt-to-equity ratios. Findings from a stepwise regression showed that individualized consideration and idealized influence (transformational factors) accounted for $31 \%$ of the variance in the outcome measures. Transformational leadership factors (idealized influence, individual consideration, and intellectual stimulation) were positively correlated with market shares, return to assets, stock prices, and earnings per share. The individual consideration factor showed the strongest relationship to market shares $(r=.60, p<.01)$, return to assets $(r=.45, p<.01)$, stock prices $(r=.36, p<.05)$ and earnings per share $(r=.45, p<.05)$. The transformational leadership factors were negatively correlated with debt-to-equity ratio. In addition, study findings revealed the transactional factor of contingent reward positively correlated with market shares $(r=.55, p<.01)$, return to assets $(r=.37, p<.01)$, stock prices $(r=.50, p<.05)$ and earnings per share $(r=.46, \mathrm{p}<.05)$. The correlations between the leadership factors and financial outcomes show moderate to strong associations. Overall, the study findings support both the transformational leadership factors and the transactional leadership factor of contingent reward relate to organizational performance.

Additionally, in a meta-analytic review of 75 transformational leadership studies, Lowe, Kroeck, \& Sivasubramaniam (1996) found the transformational leadership factors idealized influence, individual consideration, and intellectual stimulation to be significant 
predictors of organizational performance. Authors found leader position in the organizational hierarchy and organizational settings have differential effects on the correlations between leader behavior and organizational effectiveness. Specifically, leaders higher in the organization hierarchy (i.e. board members, division heads) express less transformational behaviors than leaders positioned lower in the organization hierarchy (i.e. front line managers). Furthermore, Lowe, Kroeck, \& Sivasubramaniam (1996) found idealized influence accounted for $48 \%$ of variance in organizational and individual considered accounted for $46 \%$ of variance in organizational performance. Thus, there exists a positive relationship between idealized influence and organizational performance as well between individual consideration and organizational performance. Results showed follower perceptions of the transactional leadership factors contingent reward ( $r=.56)$ to be positively correlated with organization performance, yet weaker than the transformational factors.

The empirical research reviewed posits that transformational leadership and contingent reward (transactional leadership factor) behavior compared to the transactional management-by --exception factor and laissez-faire leadership positively impact follower satisfaction, extra effort, and leader effectiveness (Waldman, Bass \& Einstein, 1986; Avolio, Bass, \& Jung, 1995). The similarity between the transactional factor of contingent reward and the transformational factors is supported by several factorial analysis studies showing high validity between the transformational factors and the contingent reward factor (Antonakis, Avolio, \& Sivasubramaniann, 2003; Podaskoff, MacKenzie, Moorman \& Fetter, 1990; Tejada, Scandura, \& Pillai, 2001). 
Early studies of the Multifactor Leadership Theory and the Full Range Leadership Model focused on military or private organization samples; however, in the last two decades, examination of transformational and transactional leadership behaviors in public education has emerged. Specifically, educational researchers have found transformational leadership to positively affect culture, teacher satisfaction, teachers' perceptions of principal effectiveness, and extra effort in public school settings (Leithwood, Jantzi, Silins, \& Dart, 1993; Binkowski, Cordeiro, Iwanicki, 1995; Silin, 1994).

Multifactor leadership theory and public education. With growing pressure toward national and state standards, the U.S. continues to see the rise in educational standards as a means to improve school accountability. As a result, rigorous curriculum content, instructional methods, high quality teachers and assessment have been emphasized in educational reform movements. According to Leithwood, Seashore-Louis, Anderson, \& Wahlstrom (2004), the possibility of any reform improving student learning is moot unless school leaders are in agreement on its purposes. It is no mystery that effective or successful educational leadership is necessary for school reform (Leithwood et al., 2004). For this reason, leadership must be better understood; specifically, principal leadership has been linked to student outcomes, school climates, and instructional organization of a school (Cross \& Rice, 2000, Hoy \& Hoy, 2003; Leithwood \& Levin 2005).

Research literature has seen an increase in studies examining the association between the multifactor leadership model and education. However, while there is much discussion, both supportive and critical of transformational school leadership, empirical evidence is thin (Leithwood \& Jantzi, 2006). Thus, much of the research currently 
reviewed dates to the late 1980s and 1990s when the FRL Model was developed. The lack of evidence about transformational leadership in education, in the $21^{\text {st }}$ Century, is potentially due to the federal governments passing of The No Child Left Behind Act of 2001 (NCLB) to influence curriculum. Due to its high-stakes testing and demand for adequate yearly progress, the principal role has been redefined as an instructional leader (Sergiovanni, 2009). State boards of education, university researchers, and scholars began to investigate discrepancies between principals' responsibilities as a manager and instructional leader. Thus, much research on principal leadership following the passing of NCLB was focused on investigating meditating and moderating effects of principals as instructional leaders in their schools, moving research away from studying principals as leaders in the traditional sense.

However, the extant literature supports transformational leadership factors suggest the transactional leadership factor of contingent reward leads to high levels of teacher satisfaction, principal effectiveness, and teacher extra effort (Bass, 1985; Hoover, 1987; Kirby, King \& Paradise, 1992) For example, Bass (1985) explored the relationship between transformational leadership, and teacher perceptions of extra effort, leader effectiveness, and satisfaction. The Multifactor Leadership Questionnaire was administered to 23 New Zealand educational administrators to rate their perceptions of principals. Study findings revealed transformational leadership factors of idealized influence $(r=.72, p<.01)$, intellectual stimulation $(r=.76, p<.01)$, and individual consideration $(r=.60, p<.01)$ were positively correlated with teacher perceived willingness to exert extra effort. The more a leader is perceived to display transformational leadership factors the higher levels of teacher satisfaction. Additionally, 
the transformational leadership factor of individual consideration was the only factor related to perceived leader effectiveness in schools $(r=.40, p<.05)$. All transformational leadership factors (idealized influence, inspiration, intellectual stimulation, and individualized consideration) and the transactional leadership factor of contingent reward were positively correlated with teacher satisfaction. Bass findings parallel those in the private sector - the transformational leadership factors and transactional leadership factor contingent reward leads to more satisfied followers, increased perceptions of leader effectiveness, and increased willingness to exert extra effort.

Hoover's (1987) work supports that teachers' perceptions of principal effectiveness, satisfaction, and willingness to exert extra effort are related to transformational leadership. Specifically, Hoover (1987) investigated perceived teacher satisfaction, extra effort, and leader effectiveness in relation to transformational and transactional leadership behaviors in U.S. secondary private schools. In sample of 45 principals and their teachers $(N=151)$, teacher participants responded to items regarding their perceptions of principal leadership on the Multifactor Leadership Questionnaire (5X form). Study results revealed positive associations between the transformational leadership factors of idealized influenced, individualized consideration, and intellectual stimulation and leader effectiveness. In addition, the transformational leadership factors of idealized influenced and individual consideration were significantly correlated with perceived teacher satisfaction. There were no significant correlations found between perceived leader effectiveness and transactional leadership factors or between perceived teacher satisfaction and the transactional leadership factors. 
Furthermore, transformational leadership and the transactional contingent reward factor are hypothesized as significant predictors of follower satisfaction and principal effectiveness. In 1992, Kirby, King \& Paradise explored the degree to which educational leaders were perceived to use transformational and transactional leadership behaviors, as well as examined which factors were predictors of follower satisfaction and leader effectiveness. Using the Multifactor Leadership Questionnaire, 103 educators (teachers, principals, and assistant school administrators) responded to items about their immediate supervisors. Stepwise regression analysis (entering transactional factors first) revealed transformational leadership to be associated with higher levels of performance and satisfaction. Specifically, the $R^{2}$ for transactional factors $\left(R^{2}=.34, p<.001\right)$ increased to $.78(p<.001)$ with the addition of five transformational leadership factors for follower satisfaction. For effectiveness, the $R^{2}$ for transactional factors $\left(R^{2}=.27, p<.001\right)$ increased to $.62(p<.001)$ with the addition of all five transformational leadership factors. Forward regression analysis revealed the idealized influence factor of transformational leadership $(t=15.81, p<.001)$ and laissez-faire leadership behavior $(t=-2.44, p<.05)$ were significant predictors of follower satisfaction. The transformational leadership factors of idealized influence $(t=9.98 p<.001)$ and intellectual stimulation $(t=2.27, p<.001)$ were significant predictors of perceived leader effectiveness. The work of Kirby, King, \& Paradise (1992) and their colleagues (Bass, 1985; Hoover, 1987; Binkowski, Cordeiro, Iwanicki, 1995; Silin, 1994) have revealed teachers prefer principals who express transformational leadership behaviors as well as transactional contingent reward behavior. 
Summary of leadership literature. The current review presented a multitude of different constructs to conceptualize leadership. The presentation of a succinct list of relevant findings is believed the most efficient method to summarize the present literature review.

1. Between the 1930 s and 1990 s, leadership was conceptualized into as many as 65 different classification systems (Fleishman, Mumford, Zaccaro, Levin, Korotkin, \& Hein, 1991).

2. Consistent with the works of Burns (1978), Heller \& Van Til (1982), Hollander (1992), and Bass $(1985,1997,1999)$ and his colleagues (Bass, Avolio, \& Goodhiem, 1987; Bass \& Riggio, 2006), the current study adapts the process-center perspective. Leadership as a process implies that leadership is a nonlinear- event in which the leader and follower influence each other in a group context where individuals attempt to achieve a common goal.

3. Bass $(1985,1987,1990)$ and his colleagues developed the most comprehensive theory of the conceptualization of transformational and transactional leadership Multifactor Leadership Theory.

4. In 1985, Bass extended Burns transactional-transforming leadership paradigm describing three components of leadership: transformational, transactional and laissezfaire leadership. Unlike Burns, Bass posits transformational leadership augments transactional leadership.

5. According to Waldman, Bass and Yammarino (1990), a leader performing poorly most frequently displays laissez-faire leadership and least frequently exhibits transformational leadership. In contrast, optimal leaders infrequently display laissez- 
faire behaviors, show higher frequencies of transactional behaviors and display the highest levels of transformational behaviors.

6. Based on studies completed in 1985 to 1990, Bass and his colleagues (Avolio \& Bass, 1991; Avolio, Waldman, \& Yammarino, 1991; Bass, 1998; Bass \& Avolio, 1994; Hater \& Bass, 1988) framed the Multifactor Leadership Theory into the Full Range Leadership Model (FRL). The model consists of five transformational factors, three transactional factors, and one laissez-faire factor.

7. Empirical research supports that transformational leadership leads to higher levels of follower satisfaction and commitment, as well as increased organizational performance and effectiveness (Bass \& Riggio, 2006; Lowe \& Sivasubramanian, 1996) in the private sector.

8. Research literature has seen an increase in studies examining the association between the transformational and transactional leadership behavior and education. Leithwood \& Jantzi (1999) and their colleagues have shown transformational leadership to be effective in K-12 education. Specifically, idealized influence, intellectual stimulation, and individual consideration (transformational factors) are significantly correlated with higher levels of teacher perceptions of leader effectiveness (Hoover, 1987).

9. In a meta-analytical review of studies from 1996 to 2005 Leithwood \& Jantzi (2005) found the indirect effects of such leadership behaviors on student achievement and engagement are mediated by school culture, teacher commitment and teacher job satisfaction. 
10. Higher levels of teacher satisfaction, commitment, and effectiveness are effects of transformational principals' actions of developing shared goals and establishing high expectations (Leithwood, Jantzi, Silins, \& Dart, 1993). Unlike transformational leadership, transactional leadership factors, with the exception of contingent reward, are not perceived as effective in education (Hoover, 1987; Leithwood et al., 1993). The lack of principals' expression of transactional leadership can be attributed to the limited resources principals have to exchange in return for performance (Leithwood et al., 1993).

\section{Psychological Gender Role}

This section reviews a portion of the literature surrounding psychological gender roles. Psychological gender role will be presented first, followed by a discussion of psychological gender role development, gender role congruity, and psychological gender role and the elementary school principalship. The terms psychological gender and gender role are used interchangeably throughout this section and the remainder of the dissertation. Psychological gender has been defined as a set of beliefs and perceptions about men and women and about characteristics of masculinity and femininity (Deaux \& Kite, 1987; Whitley, 2001). Psychological gender is a function of both biological and social influences, traditionally seen as enduring and unchanging. Both men and women from an early age acquire, internalize and are socialized to behave in socially appropriate and desirable manners for their respective genders.

Prior to discussing two theoretical perspectives of psychological gender roles, it is first necessary to establish definitions of the terms masculinity and femininity. Bakan (1966) proposed that masculinity is associated with an agentic orientation-a cognitive focus on "getting the job done" — and a concern for oneself. Conversely, femininity is 
associated with a communal orientation - an affective concern for others. Psychologists posit masculinity and femininity are equivalent to traits that correspond to socially approved behavioral differences between men and women (Spence \& Helmrich, 1978). Psychological gender role has a lengthy psychological discourse; however, it has been among the most difficult concepts to define (Constantinople, 1973). The belief in unidimensionality of gender roles was axiomatic during the $1960 \mathrm{~s}$-termed the traditional perspective of psychological gender in the current study. Conversely, the belief in the multidimensionality of gender roles gained considerable attention in literature as researchers began to examine the accuracy of the traditional perspective in the $1970 \mathrm{~s}$ (Constantinople, 1973). The current study refers to the multidimensional view of psychological gender roles as the modern perspective.

Traditional perspective of psychological gender role. Traditional psychological theorists, prior to the early 1970 s, suggested psychological gender is a single bipolar dimension. Psychological gender, as a unidimiensional construct, refers to an inverse relationship between masculinity and femininity. As people become less feminine, they are perceived to become more masculine. Likewise, as people become less masculine, they are perceived to become more feminine. The bipolarity of psychological gender refers to masculinity and femininity in opposition-specifically, the opposite of feminine behavior is masculine behavior-such that femininity and masculinity are negatively correlated. English and English (1958) implied that bipolarity refers to a single continuum ranging from one extreme through a zero point to another extreme, and the behaviors defining one end point are opposite to those at the other end point. Constantinople (1973) suggested the traditional view was evidenced in at least three ways 
in test construction during the time period: (a) the dependence on biological sex alone as the appropriate criterion for an item's masculine-feminine relevance, as item selection is usually based solely on its ability to discriminate the responses of the two sexes; (b) the implication that the opposite of a masculine response is necessarily indicative of femininity, especially in tests where only two options are provided; and (c) the use of a single masculine-feminine score that is based on the algebraic summation of masculine and feminine responses and places the individual.

Constantinople's (1973) study of major existent masculinity-femininity (M-F) measurement scales showed M-F potentially as a multidimensionality. Specifically, the results revealed medium to low correlations in support of multidimensionality-that is, if it were believed to support unidimensionality of psychological gender, correlations between existing scales would be high. Furthermore, her meta-analytical review of various factor analysis studies substantiated the possibility of multidimensionality of masculinity and femininity. Constantinople reported researchers repeatedly extracted multiple factors from data using both men and women; hence, a researcher could derive different levels of masculinity and femininity in a sample depending on the behaviors sampled at a given time. As a result of her findings, Constantinople contended masculinity and femininity could possibly be multidimensional in nature. Likewise, a number of studies were completed in the 1970 s to further understand the dynamics of the psychological gender construct. Carlson (as cited in Constantinople, 1973) made particular reference cautioning against the simplistic notion of a single bipolar continuum; rather, she urged that many of the dualities inherent in human nature are interactive forces potentially working toward integration. Carlson, Constantinople, and 
others' views of psychological gender as multidimensional in nature generated a more modern view of the construct, proposing two distinct dimensions of masculinity and femininity.

\section{Modern perspective of psychological gender role. Supporting modern} psychological theorists, Bem (1974) theorized that perhaps the belief in a single bipolar dimension of psychological gender did not truly capture the actual dynamics of the construct. Rather, Bem theorized about a single individual who could be androgynous, displaying both masculine and feminine traits. Bem's theory suggests exhibited traits differ based upon specific ambience. For example, a male is capable of displaying desirable male traits at a sporting event and desirable female traits at a funeral. Similarly, a female can display desirable feminine traits at a wedding and desirable male traits in a court room. Bem argued that the dichotomy of gender roles ignores two plausible hypotheses: (a) many individuals might be "androgynous," and (b) conversely, strongly sex-typed individuals might be seriously limited in the range of behaviors available during different situations. First, sex-typed individuals are those having deeply ingrained gender role expectations. Sex-type is a social and biological function. A sex-typed male is a biological male with deeply ingrained desirable male traits - that is, males who display only traits perceived as acceptable for men and reject traits associated with females. A sex-typed female is a biological female displaying only socially desirable feminine traits, while rejecting traits perceived as stereotypically masculine. Second, an androgynous person is capable of incorporating both masculinity and femininity into his or her personality. Theoretically, such an individual does not limit his or her behaviors to only those traditionally defined as sex appropriate, but possesses the psychological freedom to 
engage in behaviors most effective given the situation. Androgyny increasingly emerges as an ideal gender role in contemporary research due to high levels of sex-typing characterized as undesirable (Wood, Christensen, Hebl, \& Rothgerber, 1997). Several researchers have claimed androgynous individuals potentially possess the strengths of both masculine and feminine characteristics (O'Connor, Mann \& Bardwick, 1978; Spence, Helmreich, \& Strapp, 1975).

Furthermore, research literature implies androgynous individuals are more adaptable and do not experience turmoil or great distress when gender-incongruent behavior is incumbent (Bem, 1975; O’Neil, Helms, Gable, David, \& Wrightsman, 1986). Research substantiates that when a sex-typed individual is called upon to exhibit traits associated with the opposite sex, significant psychological distress can ensue (Good \& Mintz, 1990). Psychological distress often results in negative mental health, such as low self-esteem and loneliness in both sexes (Good \& Mintz, 1990). Additionally, high femininity in females has been repeatedly correlated with high levels of anxiety, low selfesteem, and low social acceptance (Cosentino \& Heilbrun, 1964; Sears, 1970). High masculinity in males has been correlated with high anxiety, high neuroticism, and low self-acceptance (Harford, Willis, \& Deabler, 1967; Mussen, 1962). Furthermore, research has shown sex-typed individuals to have lower overall intelligence, lower spatial ability, and lower creativity (Maccoby, 1966). Overall, research has shown androgynous individuals to have better psychological outcomes compared to sex-typed individuals (Sanchez \& Crocker, 2005).

Measurement of androgyny. To provide construct validity for the concept of androgyny, Bem developed the Bem Sex Role Inventory (BSRI), an instrument that- 
unlike traditional measurements-would not automatically build an inverse relationship between masculinity and femininity. The BSRI measures the extent to which an individual divorces his/her self from characteristics deemed appropriate or desirable for the opposite sex. According to Bem, because the BSRI was founded on the conception of sex-typed individuals, masculine and feminine personal characteristics were selected traits considered desirable for males and females, respectively. Specifically, the BSRI classifies individuals into four gender role categories: masculine, feminine, androgynous, and undifferentiated. Scholars have used the four categories on numerous occasions to gain a better understanding of psychological gender roles. Research has shown there is a social and biological component to each gender role classification (Bem, 1974).

Masculine. A respondent scoring low on the BSRI femininity scale and high on the BSRI masculinity scale is categorized as masculine. It is possible for a biological male or biological female respondent to fall into the masculine category. An individual with a high masculine score posses stereotypical masculine traits, such as independence, assertiveness, and forcefulness (Bem, 1974).

Feminine. A respondent scoring low on the masculine scale and high on the feminine scale is categorized as feminine. Biological females and biological males can potentially fall into this category. A respondent scoring high on the feminine scale and low on the masculine scale possesses stereotypical feminine traits, such as compassion, nurturing, and sensitivity (Bem, 1974).

Undifferentiated. It is possible for a respondent to score low on the feminine and masculine scales of the BSRI. When this occurs, individuals are classified as undifferentiated (Bem, 1975). An undifferentiated individual possesses low levels of 
both stereotypical male and stereotypical female traits. It is rare for an individual to be classified as undifferentiated in comparison to being classified as masculine, feminine or androgynous (Herdman, 2007).

Androgynous. An individual scoring high on both the masculine and feminine scale of the BSRI is classified as androgynous. Researchers have argued that for healthy human functioning, the masculine and feminine traits must be balanced in a true androgynous personality (Bem, 1976).

Developmental perspective of psychological gender role. From an early age, American boys and girls are expected to exhibit socially desirable traits associated with his or her gender role. Children are taught appropriate gender role behavior early in life (Bem, 1974). For example, often in American culture, boys learn to wear blue and girls learn to wear pink. Likewise, boys are rewarded for being strong and girls are rewarded for being nurturing (Bem, 1974). Such gender roles developed at an early age are sustained throughout adulthood (Eagly \& Karau, 2002). For example, homemaker roles are often attributed to women and executive roles are often attributed to men. Eagly and her colleagues argue that gender role differences are reinforced in adulthood through social role theory. Specifically, social role theory posits that the desirable attributes of males and females (males oriented to be agentic and females oriented to be communal) can be explained by different social roles ascribed to men and women. Social role theory stresses the division of labor, power, and status, maintaining society's social construction of gender; thus, social role theory is proposed as a social-structural perspective of psychological gender. To explain why women and men are perceived differently, Eagly, 
in addition to others, examined gender differences that regulate and reinforce behavior in adult life.

Eagly, Woods, \& Steffen (1982) completed a study to examine the major differences in social roles of men and women in regards to social status. The purpose of the study was to determine whether higher status positions are perceived as agentic, whether homemakers are perceived as more communal compared to those who are employed, and whether women are perceived as holding lower status positions (i.e., homemaker) and perceived as more communal. In a series of experimental studies, randomly selected college students read descriptions of individuals (male and female) and rated these individuals on 18 gender-stereotypical traits as measured by the Personal Attributes Questionnaire (Spence \& Helmriech, 1978). Study findings showed, overall, that women were perceived to hold lower status positions, and homemakers were perceived as more communal compared to those who are employed. It was further reported that employed females were perceived as more agentic than employed males. This perception was accounted for by a significant interaction effect of sex by choice $\left(\mathrm{F}_{(2 \text {, }}\right.$ 236) $=3.46, \mathrm{p}<.05)$, specifically, the belief that women freely choosing to be employed was significantly related to perceived agency.

Further evidence that desirable attributes of males and females are explained by different social roles ascribed to men and women was more recently provided by Harrison \& Lynch (2005). Harrison \& Lynch (2005) predicted that athletic role (the type of sport played) rather than an athlete's gender would guide perceptions of an athlete's gender role orientation. For example, athletes who engage in stereotypically "masculine" athletic roles (i.e., football) are more likely to be perceived as having a masculine gender 
role orientation. Athletes who engage in stereotypically "feminine" athletic roles (i.e., cheerleading) are more likely to be perceived as having a feminine gender role orientation. In this study, participants ( $N=148$ students) were randomly selected to read from one of six fictional news articles. Each article described a successful high school athlete with a different biological sex (male or female name) and sport played (football, basketball, or cheerleading). Participants were then administered the Bem Sex Role Inventory to measure the perceived agentic and communal traits of the athletes described in the articles. Results revealed a significant main effect of sport for the feminine (communal) index $\left(F_{(2,133)}=8.16 ; \mathrm{p}<.05\right)$-that is, there exists a significant difference between football, basketball, and cheerleading on the feminine index. Additionally, there exist a difference between football, basketball, and cheerleading on the masculine (agency) index $\left(F_{(2,133)}=4.37, p<.05\right)$. Follow-up analyses revealed cheerleaders were perceived to have more communal traits compared to football players. Football and basketball players were perceived as higher in agentic traits compared to cheerleaders. Overall, the findings support the argument that athletes' gender role orientations are influenced by stereotypes of athletic roles. The major findings from this study supports social role theory, in that perceived gender role orientations resulted from beliefs regarding the social roles fulfilled. Individuals who are perceived to engage in a stereotypical feminine athletic role (cheerleader) were viewed as feminine. Likewise, individuals perceived to engage in a stereotypical masculine athletic role (football player) were viewed as masculine.

Several research study findings point out that distribution of men and women into different social roles starts as early as childhood. For example, Wilburn \& Kee (2010) 
examined occupational stereotypes of women and men with a sample of children. Fiftyseven children, between the ages of eight and ten years old, were asked to create sentences from randomly-selected lists of female and male name-occupation pairings. Subjects were presented with one of two lists comprising 20 names and 20 occupations: 10 stereotypical female names, 10 stereotypical male names, 10 stereotypical female occupations, and 10 stereotypical male occupations. The lists contained either a female name matched to a stereotypical female occupation (Jane the babysitter), a stereotypical female name matched to a stereotypical male occupation (Mary the doctor), a stereotypical male name matched to a stereotypical male occupation (John the doctor), or a stereotypical male name matched to a stereotypical female occupation (James the babysitter). Researchers measured how long it took participants to create sentences for each pairing and tested participants' memory of the pairings presented. Study findings indicated (a) children were more efficient at processing female name-male occupations pairings than male name-female occupation pairings, and (b) it took longer for participants to process and create sentences for male name-female occupation than malename-male occupations. The results support social role theory by revealing children's stereotypes of gender roles reflect social trends. Specifically, children more easily recognized occupations deemed stereotypical male when a male name was presented. The same was true of female name-female occupations. The study substantiates early research hypothesis that children are taught appropriate gender role behavior early in life (Bem, 1974).

Role congruity theory and leadership. One construct relevant to psychological gender role is role congruity theory. Role congruity occurs when an individual's socially 
desirable psychological role matches his or her socially expected leader role (Eagly, 2007; Eagly \& Karau, 2002). Role congruity theory has received much attention in the last 20 years, often framed in regards to female leaders. As more women have entered leadership roles, the possibility that leadership styles differ among men and women has gained increasing attention. Women leaders have undergone much scrutiny, partly due to the barriers they face in obtaining leader roles. Albeit, newspaper and magazine journalists do increasingly praise women for demonstrating leadership styles affiliated with effective leadership performance. Even with such praise for female leaders, however, the public generally prefers male leaders, causing women to face the paradox of having a leadership advantage and disadvantage when it comes to obtaining a leadership role (Eagly, 2007). The female leader paradox is caused by an era marked by a change in women roles in a society that continually stresses strong traditional expectations of desirable and appropriate traits of females.

Society, at large, generally expects and prefers women to be communal (i.e., sensitive, nurturing, caring) and men to be agentic (i.e., assertive, forceful, and headstrong) (Bem, 1974; Newport, 2001; Spence, 1991). Additionally, society expects and prefers leaders to be more agentic (i.e., to take charge); consequently, society associates leaders with desirable male traits. Men, therefore, are naturally seen as leaders, thereby placing women at a disadvantage (Eagly \& Karau, 2002; Heilman, 2001 as cited by Eagly \& Karau, 2002). Due to agentic traits being desirable for leaders, women often experience role incongruity prejudice and are perceived as lacking qualities of good and/or effective leaders- that is, as not being assertive or taking charge. Women frequently encounter a conflict between their female role and their leadership role (Eagly 
\& Carli, 2004). The incongruity between the female gender role and the leadership role leads to two forms of prejudice: (a) perceiving women less favorably than men as potential occupants of leadership roles, and (b) evaluating behavior that fulfills the prescriptions of a leader role less favorably when enacted by a woman (Eagly \& Karau, 2002). Consequences of such prejudices are less favorable attitudes toward female leaders, and women have greater difficulty becoming leaders and achieving success (Eagly \& Johnson, 1990; Eagly \& Karau, 1991; Ragins \& Sundstrom, 1989). Evidence from varying research studies substantiates such consequences. In a meta-analytical review of 61 studies, Eagly, Makhijani, \& Klonsky (1992) confirmed that prejudices against female leaders occur. First, Eagly, Makhijani, \& Klonksy found evaluations for females were less favorable than for males occupying the same leadership role. Second, in more than half of the studies, men and women both favored male leaders over female leaders. Third, women were negatively evaluated when exhibiting desirable masculine traits. Fourth, men compared to women showed a stronger tendency to devalue female leaders. Role incongruity research suggests women experience disapproval for displaying both agentic and communal behaviors (Catalyst, 2001; Eagly, 2007). Such an experience creates a challenge for women to find an appropriate and effective leadership style perceived as neither too agentic nor too communal.

To solve such conflicting pressures, it is reasonable that women may split the difference between the demands of the female role and the leader role, displaying half agentic traits and half communal traits (Eagly, 2007). Perhaps women seek a leadership style considered to be balanced and effective, yet neither unacceptably male or female. The contemporary coach/mentor model of transformational leadership might approximate 
this middle ground (Eagly, 2007). Transformational leadership consists of socially acceptable feminine aspects, especially its individual consideration factor, and is otherwise quite androgynous (Hackman, Furniss, Hills, \& Patterson, 1992).

Transformational leadership fosters followers' commitment and ability to contribute to an organization (Bass, 1985; Eagly, 2007). Previously reviewed research literature substantiates transformational leadership as an effective leadership behavior. Female leaders displaying transformational leadership potentially experience a leadership advantage. Thus, for the claim to be valid women will more frequently display transformational leadership compared to men (Eagly, 1992; 2007; Trinidad \& Normore, 2005); various researchers attest that women do display transformational leadership more frequently.

Carless (1998) reported superiors evaluated female leaders as more transformational than male leaders in a study of 345 Australian metropolitan branch managers. Eagly and Johannessen-Schmidt (2001) further investigated the difference between men and women in transformational leadership with the norm sample for the Multifactor Leadership Questionnaire (Bass, 1985). Study results proposed that women exceed men on three transformational factors (idealized influence, inspiration/motivation, and individualized consideration) and the contingent reward factor of transactional leadership. The largest of the differences was the individualized consideration factor, theorized to have the most communal aspects. The most recent meta-analytical review comparing leadership styles of men and women further upholds the observation that women more frequently display transformational leadership behavior compared to men. Eagly, Johannesen-Schmidt \& van Egen (2003) integrated the findings of 45 different 
studies to reveal female leaders were more transformational and more transactional in their contingent reward behaviors than male leaders. Male leaders were more likely than female leaders to manifest the transactional factor of management by exception (active and passive), in addition to laissez-faire leadership.

One factor relevant to examining the relationship between gender role and leader effectiveness is context. Various empirical research supports the potential effectiveness of female leaders as somewhat dependent on context. Specifically, the cross pressures of gender role and female role are prominent in male-dominated, numerically, and culturally defined masculine leadership roles, such as a military officer. In such contexts, women face the challenge of incapability between society's expectations of leaders and expectations of females. Consequentially, people suspect women are not qualified for such leadership roles and may resist female authority (Carli, 1999; Eagly \& Karau, 2002). Correlational and experimental studies have supported females contend with a disadvantage in male-dominated roles. Eagly, Karau, \& Makhijani (1995) examined the principle that effectiveness depends on context in a meta-analytical review of 96 research studies. The study findings showed males' effectiveness as leaders surpassed females' in roles defined as culturally masculine. Specifically, the meta-analytical review alluded that women are judged less effective than men in leadership roles occupied by more men or having more male followers. This suggests that the cross pressures women feel potentially do not exist when women hold leadership roles that are female dominated, numerically, or culturally defined as feminine roles, such as in human resources, social work, or education (Eagly, Karau, Makhijani, 1995; Eagly, 2007). In such cases, the female role and leadership role are congruent, whereas, the male role and leadership role 
are conflicting. Although role incongruity is often framed in a feminist perspective, the potential for men to experience cross pressures in female-dominated and culturally defined feminine leader roles does exist. Men, in female-dominated or defined roles, face the challenge of incompatibility between individuals' expectations of the male role and of the female leader role. Consequently, society deems men as unqualified for such femaledefined leadership roles and men experience a disadvantage.

One leader role in which both men and women potentially have experienced role incongruity is that of the elementary school principal. Men and women have both potentially experienced role congruity between their gender roles and leadership roles. In the last three decades, public education has experienced continual change in the gender composition of elementary school principals (Loder \& Spillane, 2005). Specifically, in the late 1970 s, early 1980 s, and then again in the early 1990 s, the majority of elementary school principals were men, but in the early $2000 \mathrm{~s}$, the majority were women $(N=52 \%)$ (U.S. National Center for Education Statistics, 2010). Today, women remain the majority of elementary school principals $(N=59 \%)$ (U.S. National Center for Education Statistics, 2010). The study's participating school district's biological gender demographics does match that of the nation $($ Female $=80 \%$, Male $=20 \%$ ). Thus, scholars can raise many questions, such as, is the elementary school principal role subject to gender role stereotypes? Do male principals display agentic traits and female principals, communal traits? With the principalship being currently female-dominated, do men experience cross pressures associated with role incongruity? Such questions generated the current research study to examine role congruity among elementary school principals. 


\section{Gender role perspective of public elementary school principals. Sex}

differences in leadership styles of school principals have received considerable research attention during the last several decades. Research concerning the potential sex differences in principal leadership reflects educational researchers' desire to understand gender equality within the administrative position. One perspective that predicts differences between male and female principal leadership is gender role expectations of men and women-that is, the extent to which male and female principals carry out their gender roles as desired by society. Thus, a gender role perspective suggests male principals would be more agentic and less communal than female principals; ultimately, the sex differences in leadership styles in the private sector remain intact among school principals. In addition, the gender role perspective holds that role incongruity prejudices potentially exist in the principalship. As research has shown, the incongruity between gender role and leadership role has the potential to lead to less favorable attitudes toward individuals experiencing role incongruity and making it harder for such individuals to achieve success (Eagly \& Johnson, 1990; Eagly \& Karau, 1991; Ragins \& Sundstrom, 1989). Currently, one can surmise that men would experience such role incongruity as an elementary school principal due to the principalship being female-dominated leadership role. Research has substantiated such a hypothesis. For example, Eagly \& Johnson (1990) found in data collected from college-age respondents that the elementary school principal was perceived as a career more congruent for women. Additionally, study findings showed female respondents reported themselves more competent in the principal role compared to male respondents. Moreover, male and female respondents both regarded women as more interested in principalship. 
The gender role perspective suggests that to solve such cross pressures, it is reasonable that male principals may split the difference between the demands of the male role and the principal role-that is, displaying half agentic traits and half communal traits (Eagly, 2007). Thus, male principals perhaps seek a leadership style considered quite androgynous. With the exception of the individual consideration factor, transformational leadership might approximate such an androgynous-effective leadership style (Hackman, Furniss, Hills, \& Patterson, 1992). Research suggests that transformational leadership leads to higher levels of teacher satisfaction, student outcomes, leader effectiveness, and teachers' extra effort (Bass, 1985; Kirby, King, \& Paradise, 1992, Leithwood \& Jantzi, 1999; Silins, 1994). However, research reports that men compared to women less frequently display transformational leadership. Men are more likely to display transactional leadership that relates weakly to effectiveness (Eagly, 2007, Eagly \& Johannesen-Schmidt, 2001; Eagly \& Johannesen-Schmidt, 2003). Thus, do male elementary school principals on average display transactional leadership, seen as less effective, and experience a disadvantage compared to female principals? Speculatively, if men experience role incongruity as elementary school principals, the answer to the inquiry is yes.

Nevertheless, the population of principals for past studies differed in sex distributions, generating mixed findings. For example, some studies have found female principals tend to adopt leadership styles that are less female stereotypic, when women were numerically rare in the principal role. Consequently, female elementary school principals potentially would experience a loss of authority if they adopted strictly distinctive feminine leadership styles (Eagly \& Johnson, 1990; Eagly, Karau, \& Johnson, 
1992). Various empirical research supports the potential effectiveness of leaders as somewhat dependent on context (Carli, 1999; Eagly, Karau, Makhijani, 1995; Eagly \& Karau, 2002; Eagly, 2007); the elementary school principalship is no different. Thus, depending on context (female-dominated or male-dominated), women or men could face the challenge of incapability between a specific society's expectation of an elementary school principal and expectations of men and women.

Nonetheless, as recommended by Eagly, Karau, \& Johnson (1992), the sex differences in elementary principal leadership style should be interpreted with caution and therefore treated as a hypothesis to be further tested. Currently, not much is known empirically about the relationship between the elementary school principal role and gender role and its effect on leader outcomes such as teacher perceptions of satisfaction, extra effort, and principal effectiveness. The current study aims to add such empirical research to the extant literature.

Summary of psychological gender role literature. The current review presented a multitude of different constructs to conceptualize the psychological gender role. The presentation of a succinct list of relevant findings is believed the most efficient method to summarize the literature reviewed.

1. Generally, psychological gender is descriptive and prescriptive in nature. Descriptively, gender role perceptions tell individuals what is considered "typical" for his or her gender (Eagly\& Carli, 2009). For example, descriptively, society expects women to be sensitive and men to be strong. Prescriptively, gender role perceptions tell individuals how they should act based on what is considered appropriate for his or 
gender. For example, society expects women to cry and men to behave in assertive behaviors.

2. Traditional psychological theorists, prior to the early 1970 s, suggested psychological gender is a single bipolar dimension.

3. Constantinople's (1973) correlation study of major existent masculinityfemininity (M-F) measurement scales showed M-F potentially as a multidimensionality.

4. Modern psychological theorists' view of gender as multidimensional in nature generated a more modern view of the construct, proposing two distinct dimensions of masculinity and femininity.

5. Bem (1974) theorized about a single individual who could be androgynous, displaying both masculine and feminine traits. Bem's theory suggests exhibited traits differ based upon specific ambience. Research literature implies androgynous individuals are more adaptable and do not experience turmoil or great distress when genderincongruent behavior is incumbent (Bem, 1975; O'Neil, Helms, Gable, David, \& Wrightsman, 1986).

6. Research has shown individuals deeply ingrained in such gender role prescriptions potentially experience psychological distress, which results in low selfesteem and negative mental health. Overall, research suggests androgynous individuals have better psychological outcomes, are more adaptable and do not experience great turmoil or distress.

7. Children are taught appropriate gender role behavior early in life (Bem, 1974). Such gender roles developed at an early age are sustained throughout adulthood (Eagly \& Karau, 2002). 
8. One construct relevant to psychological gender role is role congruity theory. Role congruity occurs when an individual's socially desirable psychological role matches his or her socially expected leader role (Eagly \& Karau, 2002).

9. Both men and women can experience crosses from incongruity between their leader role and gender role. To solve or minimize such cross pressure, literature has suggested for such individuals to use the transformational leadership model. Transformational leadership appears quite androgynous (Hackman, Furniss, Hills, \& Patterson, 1992).

10. Research literature suggests women compared to men more frequently display transformational leadership, and consequentially manifest leadership behavior evidenced as effective. Men, on the other hand, more frequently display transactional leadership-that is, leadership that relates weakly to effectiveness.

11. One leader role in which both men and women potentially have experienced role incongruity is that of the elementary school principal due to the changing gender composition of principals in the last 40 years.

\section{Statement of Research Questions}

In light of the voids revealed by this literature review, the study investigated if there exist a significant relationship between leadership and psychological gender role group on teachers' perceptions of principal effectiveness, teachers' perceived satisfaction, and teachers' perceived extra effort. Specifically, the study addressed the following four research questions:

1. Is there a significant canonical correlation between the leadership variables set (idealized influence-attribute, idealized influence-behavior, inspiration motivation, 
intellectual stimulation, individualized consideration, contingent reward, managementby-exception-active, management-by-exception-passive, and laissez-faire) and the psychological gender role variable set (masculinity and femininity)? Review figure 1.

2. Is there a significant interaction effect of principal biological gender and principal psychological gender role group on teachers' perceived principal effectiveness, teachers' perceived satisfaction, and teachers' perceived extra effort?

Independent Variable: principal biological gender, principal psychological gender Dependent Variables: teachers' perceived principal effectiveness, teachers' perceived satisfaction, teachers' perceived extra effort

3. Is there a significant main effect of principal biological gender on teachers' perceived principal effectiveness, teachers' perceived satisfaction, and teachers' perceived extra effort?

Independent Variable: principal biological gender Dependent Variables: teachers' perceived principal effectiveness, teachers' perceived satisfaction, teachers' perceived extra effort

4. Is there a significant main effect of principal psychological gender role group (androgynous, femininity, masculinity, and undifferentiated) on teachers' perceived principal effectiveness, teachers' perceived satisfaction, and teachers' perceived extra effort?

Independent Variable: principal psychological gender role group Dependent Variables: teachers' perceived principal effectiveness, teachers' perceived satisfaction, teachers' perceived extra effort 
Figure 1. Canonical correlation between leadership and psychological gender variables sets

Leadership Variable Set

Idealized Influence (attribute)

Idealized Influence (behavior)

Inspiration Motivation

Intellectual Stimulation

Individual Consideration

Contingent Reward

Management-by-exception (active)

Management-by-exception (passive)

Laissez-faire
Psychological Gender Role Set

Masculinity

Femininity 


\section{CHAPTER III}

\section{METHOD}

The purpose of this study was to examine the relationship between leadership style (transformational, transactional, and laissez) and psychological gender role group (androgynous, femininity, masculinity, and undifferentiated) of elementary school principals. Specifically, is there a significant relationship between leadership and psychological gender role group on teacher perceptions of principal effectiveness, satisfaction, and extra effort? This chapter explicates the description of the study design, instrumentation, data collection procedures, and statistical analysis used to answer the study's research questions.

\section{Research Questions}

The study's four research questions addressed the relationship of leadership style and gender role to principals and teachers. To achieve the study's purpose, the following research questions were addressed:

1. Is there a significant canonical correlation between the leadership variables set (idealized influence-attribute, idealized influence-behavior, inspiration motivation, intellectual stimulation, individualized consideration, contingent reward, managementby-exception-active, management-by-exception-passive, and laissez-faire) and the psychological gender role variable set (masculinity and femininity)? Review figure 1. 
2. Is there a significant interaction effect of principal biological gender and principal psychological gender role group on teacher perceived principal effectiveness, teacher perceived satisfaction, and teacher perceived extra effort? .

Independent Variable: principal biological gender, principal psychological gender Dependent Variables: teachers' perceived principal effectiveness, teachers' perceived satisfaction, teachers' perceived extra effort

3. Is there a significant main effect of principal biological gender on teachers' perceived principal effectiveness, teachers' perceived satisfaction, and teachers' perceived extra effort?

Independent Variable: principal biological gender

Dependent Variables: teachers' perceived principal effectiveness, teachers' perceived satisfaction, teachers' perceived extra effort

4. Is there a significant main effect of principal psychological gender role group (androgynous, femininity, masculinity, and undifferentiated) on teachers' perceived principal effectiveness, teachers' perceived satisfaction, and teachers' perceived extra effort?

Independent Variable: principal psychological gender role group

Dependent Variables: teachers' perceived principal effectiveness, teachers' perceived satisfaction, teachers' perceived extra effort

The study research questions addressed teacher perceptions regarding leadership behaviors and gender role of their principals. 


\section{Research Design}

The current study employed two quantitative research designs. First, a crosssectional survey study design was used in collecting study data. Quantitative procedures were used to survey a sample of Kentucky elementary school teachers regarding current attitudes, opinions, behaviors, and characteristics of the population from which the sample was drawn (Creswell, 2008). Second, an explanatory correlational research design was used. Designated as "relational research" (Cohen \& Manion, 1994, as cited in Creswell, 2008) or "accounting-for-variance studies" (Punch, 1998, as cited in Creswell, 2008), the explanatory design allowed for the examination of the extent to which perceptions of psychological gender role and leadership style covary - that is, where changes in one variable reflect a change in the other. Specifically, the design aids in investigating the combined relationship of perceptions of gender role and leadership style with principal effectiveness.

\section{Study Participants}

The current study elected to gather data from public elementary school teachers in Kentucky, that is the school district target is one southern metropolitan school district. The district serves approximately 48,392 elementary students in 90 schools, averaging 587 students per school. Minority students comprised $51.2 \%$ of the student population, with $61.9 \%$ receiving FRL, $15.1 \%$ identified for exceptional childhood educational (ECE) services, and 7.5\% identified with limited English proficiency. There are approximately 3000 certified schoolteachers in the district, averaging 33 teachers per school. 


\section{Sampling}

In the current study, the survey population included all public elementary school teachers residing in Kentucky - that is, the population represents "all of the units to which one desires to generalize survey results" (Dillman, 2007, p. 196). Specifically, the current study used a sample of teachers to generalize the results to all public elementary Kentucky teachers' perceptions of principal psychological gender, leadership, and effectiveness. According to Dillman (2007), a survey sample is defined as "all units of the population that are drawn for inclusion" (p. 196). To obtain the study sample, using a list of all elementary public school teachers from the school district to create a list of potential respondents is desirable. The sampling frame is the "list from which a sample is to be drawn in order to represent the survey population" (Dillman, 2007, p. 196). However, the school district has policies restricting the distribution of its teacher contacts. Thus, selecting potential respondents from a district-wide list was eliminated as a sampling option. Therefore, the study used a convenience sampling method, that is 500 district elementary school teachers were included in the sample.

The convenience sampling technique does have limitations, including results reflective of a unique sample and a limited ability to generalize the results to the population (McMillan \& Schumacher, 2006). The study attempted to minimize the disadvantage by collecting data from a wide variety of teachers from schools with different degrees of achievement, racial/ethnic groups, free-reduce lunch status, and principal tenure. Responses from teachers of this school district do not reflect responses from other school districts; therefore, caution should be use when generalizing the results 
of the study back to the larger survey population (Dillman, 2007), as noted in the limitations section.

The study's minimum suggested sample size was determined using two separate methods. First, based on the school districts' population of approximately 3,000 teachers, Dillman, Smyth, and Christian (2009) suggested a minimum sample of size of 341 to attain a $95 \%$ confidence level, a power of .80 , and an effect size of .75 . Second, to achieve adequate statistical power, Stevens (2002) suggests a minimum of fifteen cases be used for each predictor variable. Taking the larger of the two numbers, the current study aimed to collect completed and usable surveys from at least 351 teachers. The estimated sample size would be large enough to achieve statistical power and generalizability.

\section{Procedures}

The data used in the study were considered primary data. Once the researcher secured approval for the study from the university institutional review board and school district review board, the researcher began data collection proceedings. The data collection procedures employed were those recommended by Dillman, Smyth, and Christian (2009). First, selected schoolteachers were sent an emailed invitation to participate, description of research, and instructions on how to access the electronic survey. The teachers were then instructed to access the link, where he/she was provided a preamble, assured confidentially, and consent to participate. At the conclusion of the survey, the teachers were re-directed to a second form to fill in their email address. This information was used to enter teachers completing the survey into a drawing for a chance 
to win one of two incentives. Teachers were given one month to access the survey link. Additionally, a follow up email was sent to teachers to encourage participation.

\section{Instrumentation}

Two commonly used instruments were used to gather the study data. The Multifactor Leadership Questionnaire (Form 5X) was used to collect data on teacher beliefs about principal leadership style. The Bem Sex-Role Inventory Short Form was used to collect data on teacher perceptions of principal gender role and teacher selfperceptions of gender role. Additionally, teachers were asked additional demographic questions regarding their principals. The participants were asked to respond to a total of 67 survey items. The estimated time for completion of the survey is approximately $20-25$ minutes.

Multifactor leadership questionnaire form 5X. Transformational and transactional leadership behavior has been the primary focus of leadership theory over the past twenty years (Powell, Butterfield, \& Bartol, 2008). Bass (1985; 1988; 1990) and his colleagues (Bass, Avolio, \& Goodheim, 1987; Bass \& Riggio, 2006; Waldman, Bass, \& Yammarino, 1990) developed the most comprehensive theory of the conceptualization of transformational and transactional leadership with the Full Range Leadership Model. Bass's Full Range Leadership Model consists of five transformational factors, three transactional factors, and one laissez-faire leadership factor. As a way to explore the model, Bass (1985) developed the Multifactor Leadership Questionnaire (MLQ). The MLQ has become the most widely used instrument to assess transformational, transactional, and laissez-faire leadership (Hunt, 1999). Since its original development, the MLQ has undergone a number of significant revisions based on a series of 
confirmatory factor analysis resulting in the current nine-factor model (Bass \& Avolio, 2004). Based on a review from a panel of leadership experts and revisions by Bass (Bass \& Avolio, 2004) the MLQ was revised to a 63 -item long form and a 45 -item short form measuring the full range of the leadership model's components and three leader outcomes (extra effort, effectiveness, and satisfaction).

The current MLQ form, $5 \mathrm{X}$, has been used in approximately 300 research programs, doctoral dissertations, and master's theses, demonstrating the questionnaire's strong empirical basis (Bass \& Avolio, 2004). The 45-item short form, MLQ Form 5Xshort, was used in the current study. The MLQ Form $5 \mathrm{X}$-short uses a 5-point Likert-type scale ranging from 0 (not at all) to 4 (frequently, if not always), with individuals rating how frequently their leaders engage in specified leadership-related behaviors. The MLQ Form 5X-short contains four items measuring each leadership factor and nine items for each leadership outcome. Specifically, 20 items assess the five transformational leadership factors, twelve items assess the three transactional leadership factors, and four items assess the laissez-faire leadership component. Moreover, the MLQ Form 5X-short contains two forms, a follower form and a leader form. The follower form asks followers to rate the frequency of their leader behaviors. The leader form asks leaders to rate themselves on the frequency with which they engage in leader behavior. In the current study, the follower form was administered to teachers. The MLQ Form 5X-short provides 12 scores, grouped as follows: five transformational scores (idealized influence attributes, idealized influence behaviors, inspirational motivation, intellectual stimulation, and individualized consideration); three transactional scores (contingent reward, management-by-exception active, and management-by-exception passive); one laissez- 
faire score; and three leadership outcome scores (extra effort, effectiveness, and satisfaction with leadership).

Reliability. The MLQ subscales are reported to have acceptable levels of internal consistency reliability scores. Avolio and Bass (1995) and Riggio and Bass (2006) have reported Cronbach's alpha reliabilities ranging from $\alpha=.74$ to $\alpha=.94$ for each leadership factor. According to DeVellis (2002), Cronbach's alphas ranging from .70-.80 are respectable and alphas ranging from .80-.90 are best. According to Urbina (2004), when evaluating reliability evidence, $r>.70$ is acceptable, $r>.80$ is better, and $r>.90$ is best. Based on the work of DeVellis and Urbina the internal consistency reliabilities reported are moderate to desirable in nature.

Validity. Several studies have been conducted for better understanding of the psychometric properties of the MLQ: specifically, the questionnaires' construct validity. Validity is "always a matter of degree to which all accumulated evidence supports the intended interpretation of test scores for the proposed purpose" (Urbina, 2004, p. 151). Construct validity specifically is "the extent to which a measure 'behaves the way that the construct it purports to measure should behave" (DeVellis, 2002, p. 53). Over the past 10 years, the MLQ factor has received criticism. The results from varying studies have indicated ambiguity and a lack of stability in the MLQ factor structure (Antonakis, Avolio, \& Sivasubramaniam, 2003; Yukl, 1999). Furthermore, confirmatory factor analyses have suggested a combination of transformational leadership factors of idealized influence and inspirational motivation factors (Bycio et al., 1995). However, researchers have criticized such a factor structure due to heterogeneity in the samples (Antonakis, Avolio, \& Sivasubramaniam, 2003). Additionally, a number of empirical studies have 
questioned the patterns of convergent and divergent validity comprising the transformational leadership factors and the transactional factor of contingent reward. Specifically, critics of the MLQ have found high correlations between the transformational leadership factors and the transactional factor of contingent reward (Bycio et al., 1995; Podaskoff, MacKenzie, Moorman, \& Fetter, R, 1990; Yammarino \& Bass, 1990). To provide further evidence of the ambiguity often found in the MLQ construct validity, a brief review is presented.

In 2001, Tejeda, Scandura, and Pillai explored the underlying constructs of the MLQ in an examination of first-order and second-order confirmatory factor analysis (CFA). In light of incongruity among prior findings, the authors tested two hypothesis: (a) there will be intercorrelations among the items across the subscales employed in the first-order, hypothesized structure of the MLQ, resulting in poor model fit as assessed by CFA; (b) the hypothesized second-order structure of the MLQ will be supported in second-order CFA. To test the hypotheses, the authors used four independent samples. The first and second samples consisted of 782 healthcare employees; the sample was split in two for cross-validation purposes. Sample three consisted of 486 employees from a temporary service agency. The fourth sample consisted of 199 middle managers enrolled in an executive certificate program at a southeastern university. The study did not specify the reason for such differences in the samples. The study results revealed that hypothesis 1 was supported, with CFI and NNFI indices below the conventional minimum (sample 1: $\mathrm{RMR}=.11, \mathrm{NNFI}=.85, \mathrm{CFI}=.87$; sample $2: \mathrm{RMR}=.13, \mathrm{NNFI}=.81, \mathrm{CFI}=.83$; sample 3 : $\mathrm{RMR}=.08, \mathrm{NNFI}=.83, \mathrm{CFI}=.85$; and sample $4: \mathrm{RMR}=.09, \mathrm{NNFI}=.81, \mathrm{CFI}=.83$ ). Ultimately, the support for hypothesis 1 does not provide support for the first-order factor 
structure of MLQ, as prior research had reported. Additionally, the study findings revealed partial support for hypothesis 2 . The second-order factor structure was confirmed in sample 3, which also had the lowest fit indices in the first-order analysis. Ultimately, the study supported prior research (Howell \& Avolio, 1993), suggesting a second-order factor structure of the MLQ.

In a more recent study, Hinken and Schriesheim (2008) examined the psychometric properties of the transactional leadership factors and laissez-faire leadership component. Specifically, Hinken and Schriesheim (2008) addressed the following research questions: (a) Does a four-factor structure best represent the MLQ Transactional Leadership measures? (b) Is the MLQ contingent reward consist of two distinct factors as suggested by others? (c) Does the MLQ Active Management by Exception measure demonstrate sound psychometric properties? (d) Are the MLQ Passive Management by Exception and Laissez-Faire measures conceptually and empirically independent? The study findings suggested two contingent reward factors rather than one: contingent reward and contingent reward exchange. The results suggested that contingent reward is a higher-order exchange linking it to transformational leadership, while contingent reward exchange is a lower-order change and a true transactional factor. Additionally, the findings revealed a convergence between passive management by exception and laissez-faire leadership, specifically suggesting that "respondents typically do not differentiate between the two when describing their leaders" (p. 512). The authors stated that future research should use either passive management by expectation or laissez-faire leadership, but not both, to represent nonleadership behavior. Hinkin and Schriesheim's (2008) study provides further support for 
earlier studies suggesting a combination of the passive management by exception factor and the laissez-faire leadership component.

Despite the empirical debate over the construct validity of the MLQ factor structure, it is still one of the most popular measures of transformational, transactional, and laissez-faire leadership in the research literature.

Bem sex role inventory-short form. Published in 1974, the Bem Sex-Role Inventory (BSRI) is a measurement of psychological gender. The instrument comprises three 20-item scales: Masculinity (BSRI-M), Femininity (BSRI-F), and Neutral Social Desirability. The Femininity Scale includes 20 socially accepted traits for females. The Masculinity Scale comprises 20 socially acceptable traits for males. The Neutral Social Desirability Scale contains 20 items regarded as neutral regarding biological sex. For the current study, the neutral social desirability was not be used. The items comprising each scale were selected on the basis of judges' ratings of specific personality traits desirable for males, females, and those considered neutral. Decisions to include items on each scale were based on the results of $400 t$-tests (Choi, Fuqua, \& Newman, 2008). The BSRI uses a 7-point Likert-type scale ranging from 1 (never or almost never true) to 7 (always or almost always true). The participants respond to the 60 items as an indication of how well each descriptor applies to them personally; in the current study, teachers will respond to how well each descriptor applies to their principals. The participants receive two scores, a masculinity score and femininity score. A participant is further categorized into four categories based on a median two-way split of the scores obtained: masculine, feminine, androgynous, or undifferentiated. High masculine and high feminine traits categorize 
Table 2

BSRI Sex-type scoring \& classifications

Masculinity Score High Masculinity Score Low

\begin{tabular}{ccc}
\hline Femininity Score High & Androgynous & Female \\
\hline Femininity Score Low & Male & Undifferentiated \\
\hline
\end{tabular}

an individual as androgynous, while low masculine and low feminine traits categorize individuals as undifferentiated (see Table 2).

Reliability. The BSRI subscales are reported to have acceptable levels of internal consistency reliability scores (Choi \& Fuqua, 2003). Bem reported the Cronbach's alpha reliabilities and test-retest reliability for two undergraduate samples. The chosen reliabilities were used to estimate the internal consistency and time sampling error of the BSRI subscales. For the first undergraduate sample, the following internal consistency reliabilities were reported: masculinity scale $\alpha=.86$, femininity scale $\alpha=.80$, and social desirability scale $\alpha=.70$. For the second sample, the following internal consistency reliabilities were reported: masculinity scale $\alpha=.86$, femininity scale $\alpha=.82$, and social desirability scale $\alpha=$. 70. According to DeVellis (2002) and Urbina (2004), both samples have acceptable to moderate internal consistency reliabilities, ranging from .70 to .86 . Furthermore, Bem (1974) reported time sampling error with test-retest reliability coefficients on a sample of 28 females and 28 males from the first sample four weeks following the initial test administration. Bem (1974) reported the following test-retest reliability coefficients: masculinity $r_{t t}=.90$, femininity $r_{t t}=.90$, social desirability $r_{t t}=$ 
.89 , and androgyny $r_{t t}=.93$. According to DeVellis (2002) and Urbina (2004), the testretest reliability coefficients reported are desirable.

Validity. Several studies have been conducted for better understanding of the psychometric properties of the BSRI: specifically, the inventory's construct validity. DeVellis (2003) and Urbina (2004) defined a construct as an unobservable or latent trait. Bem excluded validity in her 1974 article. The ambiguity of validity has caused a number of researchers to question what the BSRI actually measures and what inferences can be appropriately drawn from test scores (Choi, Fuqua, \& Newman, 2008; Spence \& Helmreich, 1978, 1981). Furthermore, a number of empirical studies have questioned the patterns of convergent and divergent validity evidence through factorial analysis of the BSRI subscales.

In 1979, Pedhazur and Tetenbaum explored the underlying constructs of the BSRI in two experimental studies. In the first study, a sample of 1,464 graduate education students rated the desirability of BSRI traits for a man, woman, or adult in American society. In the second study, 2,572 graduate education students responded to self-ratings on the BSRI. The results indicated that, regardless of referent (man, woman, adult), masculine traits were rated highly desirable, but some the feminine traits were rated low on desirability. Furthermore, discriminant function analysis showed that discrimination among groups was due to the differential ratings of masculine and feminine traits for different referents. Additionally, factor analysis of the ratios of desirability for the referents and self-ratings indicated that the dimensions underlying desirability ratings are not the same as those that underlie self-ratings, that self-ratings for males differed from those of females, and that the original BSRI items did not load on the expected factors. 
More recent studies have shown the BSRI to retain four factors rather than the initial two that Bem (1974) reported. For example, Choi and Fuqua (2003) reviewed 23 factor analytic studies of the BSRI. Their results showed frequency in retaining two to four factors, with two additional factors retained for both men and women on the masculinity scale. In 2008, Choi, Fuqua, and Newman hypothesized that the two resulting factors reflect the social and personal dimensions of masculinity. The items found that were most strongly associated with the social dimension of masculinity included dominant, aggressive, forceful, competitive, and assertive. The items found that were most associated with personal dimensions of masculinity included independent, has leadership abilities, self-reliant, self-sufficient, own beliefs, and acts as leader. Despite empirical debate over the validity of the BSRI factor structure, it is still the most common measure of psychological gender used in research.

\section{Statistical Analysis}

To address question 1, canonical correlation analysis was proposed. According to Stevens (2002), canonical correlation analysis "is appropriate if the wish is to parsimoniously describe the number and nature of mutually independent relationships existing between the two sets" (p. 471). Specifically, canonical correlation allows for the examination of maximum linear combinations of Pearson correlation $\left(r_{\mathrm{u} 1 \mathrm{vl}}\right)$ between the leadership and psychological variable sets. Examining how the leadership factors (idealized influence-attribute, idealized influence-behavior, inspiration motivation, intellectual stimulation, individualized consideration, contingent reward, management- 
by-exception-active, management-by-exception-passive, and laissez-faire) relate to the psychological gender factors (masculinity and femininity) provided insight into the variable sets shared variance.

Multivariate analysis of variance (MANOVA) techniques were proposed to address research questions 2,3, and 4. According to Stevens (2002), MANOVA has the potential to lead to more powerful test by reducing within cell variance and allows the examination of joint effects of independent variables on dependent variables. Wilks' lambda multivariate $F$ statistic was used to know the overall significance of the model. Statistically significant multivariate $F s$ were followed by univariate analysis of variance (ANOVA) for each dependent variable. Furthermore, statistically significant differences found in ANOVAs were followed by Tukey post hoc test to determine where difference in means occurs. Additionally, partial eta square $\left(\eta^{2}\right)$ was used to report the percentage of variance in each dependent variable accounted for by the independent variables. Specifically, MANOVA analysis tested the following three null hypotheses:

1. $\mathrm{H}_{0}$ : There is not a significant main effect of principal biological gender on teachers' perceived principal effectiveness, teachers' perceived satisfaction, and teachers' perceived extra effort.

2. $\mathrm{H}_{0}$ : There is not a significant main effect of principal psychological gender role group (androgynous, femininity, masculinity, and undifferentiated) on teachers' perceived principal effectiveness, teachers' perceived satisfaction, teachers' perceived extra effort

3. $\mathrm{H}_{0}$ : There is not a significant interaction effect of principal biological gender and principal psychological gender role on teachers' perceived principal effectiveness, teachers' perceived satisfaction, teachers' perceived extra effort. 
To complete the analysis, descriptive statistics (e.g. measures of central tendency, measures of variability, and percentages) were computed to identify basic summary information about the independent and dependent variables. Furthermore, Pearson product-moment correlations were examined for the independent and dependent variables. In addition to descriptive statistics and correlations, Cronbach's alphas were computed to measure the internal consistency reliability of each set of items on the BSRI and MLQ; specifically internal consistency reliability coefficients greater than or equal to .70 were deemed acceptable (Nunnally,1978). The Statistical Package for the Social Sciences (SPSS) version 18 was used to conduct all aforementioned statistical procedures. Table 3 illustrates the alignment of the research questions, variables, and statistical analysis. 
Table 3

Summary of Research Questions, Variables, and Statistical Analysis

\begin{tabular}{|c|c|c|c|}
\hline $\begin{array}{l}\text { Research } \\
\text { Question }\end{array}$ & Independent Variable(s) & Dependent Variable(s) & $\begin{array}{l}\text { Statistical } \\
\text { Analysis }\end{array}$ \\
\hline 1 & $\begin{array}{l}\text { Psychological gender } \\
\text { variable set }\end{array}$ & $\begin{array}{l}\text { Leadership variable } \\
\text { set }\end{array}$ & Canonical correlation \\
\hline 2 & $\begin{array}{l}\text { Principal biological gender, } \\
\text { Principal psychological } \\
\text { gender role group } \\
\text { (androgynous, feminine, } \\
\text { masculine, } \\
\text { undifferentiated) }\end{array}$ & $\begin{array}{l}\text { Teachers' perceived } \\
\text { principal effectiveness, } \\
\text { teachers' perceived } \\
\text { satisfaction, teachers' } \\
\text { perceived extra effort }\end{array}$ & $\begin{array}{l}\text { MANOVA, ANOVA, } \\
\text { follow-up Tukey } \\
\text { pairwise comparison }\end{array}$ \\
\hline 3 & Principal biological gender & $\begin{array}{l}\text { Teachers' perceived } \\
\text { principal effectiveness, } \\
\text { teachers' perceived } \\
\text { satisfaction, teachers' } \\
\text { perceived extra effort }\end{array}$ & $\begin{array}{l}\text { MANOVA, ANOVA, } \\
\text { follow-up Tukey } \\
\text { pairwise comparison }\end{array}$ \\
\hline 4 & $\begin{array}{l}\text { Principal psychological } \\
\text { gender role group } \\
\text { (androgynous, feminine, } \\
\text { masculine, } \\
\text { undifferentiated) }\end{array}$ & $\begin{array}{l}\text { Teachers' perceived } \\
\text { principal effectiveness, } \\
\text { teachers' perceived } \\
\text { satisfaction, teachers' } \\
\text { perceived extra effort }\end{array}$ & $\begin{array}{l}\text { MANOVA, ANOVA, } \\
\text { follow-up Tukey } \\
\text { pairwise comparison }\end{array}$ \\
\hline
\end{tabular}




\section{CHAPTER IV}

\section{RESULTS}

The purpose of this study was to examine the relationship between leadership behavior and psychological gender role of elementary school principals. Specifically, the study's four research questions addressed if a relationship exist between teachers perceptions of principal leadership behavior, perception of psychological gender role and perception of three leader outcomes-- principal effectiveness, teacher satisfaction, and teacher extra effort. This chapter explicates the statistical results, as well as preliminary analysis, including descriptive statistics, reliability analysis, and intercorrelations of the variables.

\section{Sample Size}

A total of 279 surveys were collected from one school district, for an overall response rate of $55 \%$ (out of the 500 that were distributed). Of the 279 surveys, 275 were deemed usable for the study; the four excluded responses contained incomplete data. The sample included 14 male principals and 38 female principals representing 52 unique schools (28 teachers did not provide school or principal identifying information). Based on the school districts' population of approximately 3,000 teachers, a minimum sample size of 341 (to attain a $95 \%$ confidence level), a power of .80 , and an effect size of .75 were desired (Dillman, Smyth, \& Christian, 2009). Stevens (2002) suggested that a 
Table 4

Comparison of Reliability Coefficients

\begin{tabular}{|c|c|c|c|}
\hline \multirow[b]{2}{*}{ Variable } & \multirow[b]{2}{*}{$\begin{array}{c}\text { Number of } \\
\text { Items }\end{array}$} & \multicolumn{2}{|c|}{ Coefficient of Internal Consistency } \\
\hline & & Current Study & Literature \\
\hline \multicolumn{4}{|l|}{ Psychological Gender } \\
\hline Feminine & 10 & .97 & $.80-.82$ \\
\hline Masculine & 10 & .90 & .86 \\
\hline \multicolumn{4}{|l|}{ Transformational Leadership } \\
\hline Idealized Influence (attribute) & 4 & .83 & $.74-.94$ \\
\hline Idealized Influence (behavior) & 4 & .80 & $.74-.94$ \\
\hline Inspiration Motivation & 4 & .91 & $.74-.94$ \\
\hline Intellectual Stimulation & 4 & .90 & $.74-.94$ \\
\hline Individual Consideration & 4 & .80 & $.74-.94$ \\
\hline \multicolumn{4}{|l|}{ Transactional Leadership } \\
\hline Contingent Reward & 4 & .84 & $.74-.94$ \\
\hline Management-by-Exception (active) & 4 & .70 & $.74-.94$ \\
\hline Management-by-Exception(passive) & 4 & .75 & $.74-.94$ \\
\hline Laissez-Faire Leadership & 4 & .81 & $.74-.94$ \\
\hline \multicolumn{4}{|l|}{ Leadership Outcomes } \\
\hline Effectiveness & 4 & .90 & $.74-.94$ \\
\hline Extra Effort & 3 & .85 & $.74-.94$ \\
\hline Satisfaction & 2 & .90 & $.74-.94$ \\
\hline
\end{tabular}

minimum of 15 cases be used for each predictor variable to achieve adequate statistical power equating to 30 , which the current study surpasses. However, the smaller-thanrecommended sample size potentially contributed to the nonsignificant statistical findings (discussed later in the chapter); that is, larger sample sizes are linked to statistical significance and power (Field, 2005; Stevens, 2002). 


\section{Reliability Analysis}

To examine the reliability of the sample, Cronbach's alphas were computed to measure the internal consistency reliability of each set of items on the BSRI and MLQ; specifically, internal consistency reliability coefficients greater than or equal to .70 were deemed acceptable. Table 4 shows the resulting coefficient alpha estimates, compared against those reported by developers for each scale. The internal consistency reliability coefficients for the BSRI scores were comparable to those reported in extant literature (Bem, 1974; Choi \& Fuqua, 2003). According to DeVellis (2002), Henson (2001), and Urbina (2004), internal consistency reliabilities greater than .90 are best. In addition, the resulting coefficient alpha estimates for the MLQ were similar to those reported in the literature (Avolio \& Bass, 1995; Riggio \& Bass, 2006). According to DeVellis (2002), Cronbach's alphas ranging from $.70-.80$ are respectable. Based on the work of DeVellis (2002), Henson (2001), and Urbina (2004), the internal consistency reliabilities reported are deemed acceptable to desirable in nature.

\section{Descriptive Statistics}

Eighty-there percent of teachers reported that their principals were female ( $n=$ 229 ) and $11.3 \%$ reported having male principals ( $n=31$ ), with 28 participants not specifying school identifying information. Teachers' responses on the BSRI indicated that principals had higher mean masculine scores $(M=5.39, S D=1.09)$ compared to mean feminine scores $(M=5.07, S D=1.09)$. On average, teachers perceived their principals as displaying higher levels of transformational leader behaviors $(M=3.93, S D$ $=0.97)$, as compared to transactional $(M=2.97, S D=0.43)$ and laissez-faire behavior $(M=1.89, S D=0.92)$. Teachers reported that principals displayed the highest level of 
Table 5

Means and Standard Deviations for Perceived Principal Psychological Gender Role, Perceived Principal Leadership Behavior, and Leadership Outcome Variables

\begin{tabular}{|c|c|c|c|}
\hline Variable & $N$ & $M$ & $S D$ \\
\hline \multicolumn{4}{|l|}{ Psychological Gender } \\
\hline Masculine Raw Score & 275 & 5.39 & 1.09 \\
\hline Feminine Raw Score & 275 & 5.07 & 1.44 \\
\hline Transformational Leadership & 267 & 3.93 & 0.97 \\
\hline Idealized Influence Attribute & 268 & 3.97 & 0.94 \\
\hline Idealized Influence Behavior & 266 & 4.00 & 0.84 \\
\hline Inspiration Motivation & 266 & 4.26 & 0.85 \\
\hline Intellectual Stimulation & 269 & 3.60 & 1.04 \\
\hline Individual Consideration & 267 & 3.55 & 1.01 \\
\hline Transactional Leadership & 264 & 2.97 & 0.43 \\
\hline Contingent Reward & 268 & 3.94 & 0.94 \\
\hline Management-by-Exception Active & 265 & 2.68 & 0.88 \\
\hline Management-by-Exception Passive & 268 & 2.29 & 0.96 \\
\hline Laissez-Faire Leadership & 268 & 1.89 & 0.92 \\
\hline \multicolumn{4}{|l|}{ Leadership Outcome } \\
\hline Extra Effort & 266 & 3.74 & 1.15 \\
\hline Effectiveness & 260 & 3.98 & 1.03 \\
\hline Satisfaction & 268 & 4.02 & 1.10 \\
\hline
\end{tabular}

inspiration motivation $(M=4.26, S D=0.85)$ compared to all other transformational factors. Additionally, teachers perceived that principals expressed higher levels of the transactional contingent reward factor $(M=3.94, S D=0.94)$ compared to the management by exception active and management by exception passive factors. Table 5 
Table 6

Perceived Principal Psychological Gender Role Group Breakdown

\begin{tabular}{lcc}
\hline BSRI Category & $N$ & $\%$ \\
\hline Androgynous & 77 & 28.0 \\
Feminine & 56 & 20.4 \\
Masculine & 58 & 21.1 \\
Undifferentiated & 84 & 30.5 \\
Total & 275 & 100.0 \\
\hline
\end{tabular}

shows the summary of means and standard deviations for teachers' perceptions of principals' psychological gender role, leadership behavior, and leadership outcomes. Additional analyses were run to explore differences between perceived principals' psychological gender role, principal biological gender, perceived principal leadership behavior, and leadership outcomes. To have a full understanding of the differences investigated, the breakdown of psychological gender role group is explicated next.

Principal psychological gender role group. Participants' responses to questions on their principals' psychological gender role contained two raw scores: a masculine score and feminine score. Responses were then further broken down into four categories based on a median two-way split of the masculine $(M d n=5.6)$ and feminine $(M d n=5.4)$ scores obtained. Specifically, responses with masculine raw scores greater than 5.6 and feminine raw scores greater than 5.4 were categorized as androgynous. Responses with masculine raw scores greater than 5.6 and feminine raw scores less than 5.4 were 
Table 7

Perceived Psychological Gender Role Group by Principal Biological Gender Breakdown

\begin{tabular}{lrcrc}
\hline & \multicolumn{3}{c}{ Principal Biological Sex } \\
\cline { 2 - 5 } & \multicolumn{2}{c}{ Male } & \multicolumn{2}{c}{ Female } \\
\hline BSRI Category & $N$ & $\%$ & $N$ & $\%$ \\
\hline Androgynous & 14 & 45.0 & 60 & 26.2 \\
Feminine & 4 & 12.9 & 47 & 20.5 \\
Masculine & 5 & 16.1 & 50 & 21.8 \\
Undifferentiated & 8 & 26.0 & 72 & 31.4 \\
Total & 31 & 100.0 & 229 & 100 \\
\hline
\end{tabular}

categorized as masculine. Responses with masculine raw scores less than 5.6 and feminine raw scores greater than 5.4 were categorized as feminine. Responses with masculine raw scores less than 5.6 and feminine raw scores less than 5.4 were categorized as undifferentiated. Compared to the medians obtained with the BSRI normative sample, the current study's masculine median is slightly lower and minimally lower for the feminine scale scores. The BSRI normative data produced a masculine scale score median of 4.80 and 5.50 for the feminine scale scores (Bem, 1981). However, median scale scores in the normative sample were obtained from Standford University students rather than teachers, thus the difference in medians was not surprising. Furthermore, according to Bem (1981) it is appropriate to use medians from one's own study sample. Table 6 shows the delineation of teachers' perceptions of principals' psychological gender role. Teachers mostly perceived principals, regardless of biological gender, as either undifferentiated $(30.5 \%)$ or androgynous $(28 \%)$. Furthermore, accounting for biological gender, biological males were perceived as androgynous (45\%), and biological females were perceived mostly as undifferentiated (31.4\%). Table 7 
Table 8

Perceived Principal Leadership Behavior by Perceived Psychological Gender Role Group

\begin{tabular}{lcccccccc}
\hline & \multicolumn{8}{c}{ BSRI Category } \\
\cline { 2 - 9 } & \multicolumn{1}{c}{ Androgynous } & Masculine & Feminine & \multicolumn{2}{c}{ Undifferentiated } \\
\cline { 2 - 9 } Leadership Factor Scores & $M$ & $S D$ & $M$ & $S D$ & $M$ & $S D$ & $M$ & $S D$ \\
\hline Transformational & 4.53 & 0.42 & 3.83 & 0.7 & 4.22 & 0.86 & 3.27 & 1.13 \\
Idealized Influence - A & 4.68 & 0.48 & 3.89 & 0.79 & 4.28 & 0.57 & 3.17 & 0.95 \\
Idealized Influence -B & 4.57 & 0.43 & 4.11 & 0.68 & 4.13 & 0.60 & 3.33 & 0.92 \\
Inspiration Motivation & 4.81 & 0.31 & 4.24 & 0.79 & 4.54 & 0.57 & 3.59 & 0.91 \\
Intellectual Stimulation & 4.44 & 0.60 & 3.43 & 0.89 & 3.8 & 0.74 & 2.84 & 1.02 \\
Individual Consideration & 4.18 & 0.67 & 3.47 & 0.94 & 3.85 & 0.61 & 2.85 & 1.08 \\
Transactional & 2.96 & 0.45 & 2.98 & 0.49 & 2.92 & 0.4 & 2.99 & 0.38 \\
Contingent Reward Score & 4.59 & 0.55 & 3.92 & 0.84 & 4.22 & 0.58 & 3.19 & 0.96 \\
Management-by-Exception & 2.62 & 0.98 & 2.70 & 0.91 & 2.42 & 0.79 & 2.87 & 0.77 \\
Active & & & & & & & & \\
Management-by-Exception & 1.68 & 0.63 & 2.38 & 0.92 & 2.09 & 0.83 & 2.90 & 0.94 \\
Passive & 1.32 & 0.45 & 1.86 & 0.85 & 1.69 & 0.65 & 2.57 & 1.02 \\
Laissez-Faire & & & & & & &
\end{tabular}

delineates teachers' perceptions of principals' psychological gender role by reported principal biological gender.

Perceived principal leadership by variable. Table 8 provides information regarding teachers' perceptions of principal leadership behaviors in conjunction with perceptions of principal psychological gender. Results indicate there are noticeable differences among psychological gender role groups on transformational leadership and its subscale factors, as well as the contingent reward factor of transactional leadership. Specifically, teachers perceiving their principals as androgynous $(M=4.53, S D=0.42)$ 
Table 9

Perceived Principal Leadership Behavior by Principal Biological Gender

\begin{tabular}{lcccc}
\hline & \multicolumn{3}{c}{ Principal Biological Gender } \\
\cline { 2 - 5 } Leadership Factor Scores & \multicolumn{2}{c}{ Male } & \multicolumn{2}{c}{ Female } \\
\cline { 2 - 5 } & $M$ & $S D$ & $M$ & $S D$ \\
\hline Transformational & 4.27 & 1.37 & 3.90 & 0.91 \\
Idealized Influence Attribute & 4.07 & 0.92 & 3.96 & 0.96 \\
Idealized Influence Behavior & 4.05 & 0.77 & 4.02 & 0.85 \\
Inspiration Motivation & 4.33 & 0.83 & 4.27 & 0.86 \\
Intellectual Stimulation & 3.69 & 1.12 & 3.60 & 1.04 \\
Individual Consideration & 3.74 & 1.10 & 3.54 & 1.01 \\
Transactional & 2.98 & 0.54 & 2.97 & 0.42 \\
Contingent Reward & 4.18 & 0.86 & 3.93 & 0.96 \\
Management by Exception Active & 2.59 & 1.06 & 2.69 & 0.86 \\
Management by Exception Passive & 2.19 & 0.93 & 2.31 & 0.98 \\
Laissez-Faire & 1.89 & 0.93 & 1.90 & 0.93 \\
\hline
\end{tabular}

and feminine $(M=4.22, S D=0.86)$ reported the highest mean levels of transformational leader behaviors compared to principals perceived as masculine $(M=3.83, S D=0.70)$ or undifferentiated $(M=3.27, S D=1.13)$. Additionally, teachers perceiving their principals as androgynous and feminine reported higher mean levels of the rewarding behavior associated with transactional leadership. In contrast, principals were rated similarly on the transactional leadership factors (excluding contingent reward) across all psychological gender role groups. Furthermore, teachers perceiving their principals as undifferentiated rated such principals as expressing high levels of laissez-faire leadership behavior. 
Table 9 provides information regarding teachers' perceptions of principal leadership behavior in conjunction with principals' biological gender. Male and female principals were perceived to display high levels of transformational behaviors and faired similarly regarding their display of transactional leadership. In addition, both male $(M=$ $4.18, S D=0.86)$ and female $(M=3.93, S D=0.96)$ principals were perceived to display higher levels of contingent reward behavior. There was not much difference in perception of male and female principals on the transactional subscales (excluding contingent reward) and laissez-faire leadership. Study results show that male principals $(M=4.27$, $S D=1.37$ ) score higher on transformational leadership factors compared to female principals $(M=3.9, S D=0.91)$. However, it is important to note that any generalizability to the male principal population is made with caution considering the study's small male sample. When considering leadership behavior in conjunction with psychological gender and biological gender, teachers perceiving principals as androgynous or feminine, regardless of biological sex, perceived principals as expressing the highest levels of transformational leadership behavior (see Table 10).

Leadership outcomes by variable. Table 11 shows descriptive results for the consideration of the study's three leadership outcomes--perceived principal effectiveness, teachers' willingness to extra effort, and teacher satisfaction in conjunction with psychological gender role and biological gender. Teachers with perceived androgynous male, androgynous female, feminine male, and feminine female principals reported higher levels of perceived principal effectiveness, teacher satisfaction, and teacher extra effort compared to all other psychological gender role group-biological gender combinations. 


\section{Correlation Analysis}

Examination of intercorrelations among study variables indicated statistically significant correlations between the feminine scale, the transformational leadership, transformational subscales, and the contingent reward transactional leadership factor; specifically correlations ranged from $r=.63$ to $r=.77$. Moreover, $r^{2}$ calculations indicate shared variance ranging from $39 \%$ to $59 \%$. Results of the correlations analysis showed the femininity score had higher correlations with the transformational leadership subscale scores than did masculinity scores. A similar relationship pattern was observed between femininity and masculinity scores with leader outcome variables. That is, femininity scores $(r=.69$ to $r=.79)$ compared to masculinity scores $(r=.42$ to $r=.53$ ) had higher correlations with leader outcome variables. Moreover, $r^{2}$ calculations indicate shared variance between femininity and leader comes ranged from $47 \%$ to $62 \%$. Both contingent reward scores $(r=.80$ to $r=.86)$ and transformational total scores $(r=.70$ to $r=.88)$ had high correlations with leader outcome variables. These correlational patterns indicated that transformational leadership, contingent reward, femininity, and leader outcome variables were strongly and positively related with one another. This means principals perceived as feminine tended to be viewed as expressing transformational behaviors and partially transactional behaviors with regard to contingent reward. In addition, principals who were perceived as feminine were also positively associated with high ratings of principal effectiveness, teacher satisfaction, and teacher willingness to exert extra effort. These findings are consistent with what has been reported in past research. Specifically, Leithwood \& Jantzi (2000), Hackman, Furniss, Hill, \&Paterson (1992) and their colleagues have substantiated that effective leadership requires both transformational and 
transactional elements. Additionally, Eagly and Johnson (2001) and their colleagues (Eagly \& Johannesen- Schmidt, 2001) have substantiated a positive relationship between femininity, transformational leadership, and leader outcomes. 
Table 10

Perceived Leadership Behavior and Leadership Outcomes by Perceived Principal Psychological Gender Role Group by Principal

\section{Biological Gender}

\begin{tabular}{|c|c|c|c|c|c|c|c|c|}
\hline \multirow[b]{5}{*}{ Leadership Factor } & \multicolumn{8}{|c|}{ BSRI Category } \\
\hline & \multicolumn{4}{|c|}{ Androgynous } & \multicolumn{4}{|c|}{ Masculine } \\
\hline & \multicolumn{4}{|c|}{ Principal Biological Sex } & \multicolumn{4}{|c|}{ Principal Biological Sex } \\
\hline & \multicolumn{2}{|c|}{ Male } & \multicolumn{2}{|c|}{ Female } & \multicolumn{2}{|c|}{ Male } & \multicolumn{2}{|c|}{ Female } \\
\hline & $M$ & $S D$ & $M$ & $S D$ & $M$ & $S D$ & $M$ & $S D$ \\
\hline Transformational Leadership Score & 4.54 & 0.41 & 4.53 & 0.42 & 3.40 & 0.81 & 3.89 & 0.69 \\
\hline Idealized Influence Attribute Score & 4.64 & 0.62 & 4.68 & 0.45 & 3.55 & 0.74 & 3.95 & 0.81 \\
\hline Idealized Influence Behavior Score & 4.50 & 0.35 & 4.58 & 0.45 & 3.75 & 0.47 & 4.17 & 0.69 \\
\hline Inspiration Motivation Score & 4.88 & 0.16 & 4.79 & 0.34 & 3.60 & 1.21 & 4.34 & 0.72 \\
\hline Intellectual Stimulation Score & 4.46 & 0.59 & 4.42 & 0.61 & 3.10 & 1.01 & 3.47 & 0.90 \\
\hline Individual Consideration Score & 4.23 & 0.76 & 4.16 & 0.66 & 3.00 & 1.24 & 3.54 & 0.92 \\
\hline Transactional Leadership Score & 2.92 & 0.56 & 2.98 & 0.43 & 3.30 & 0.74 & 2.95 & 0.47 \\
\hline Contingent Reward Score & 4.63 & 0.44 & 4.58 & 0.57 & 3.80 & 0.84 & 3.96 & 0.85 \\
\hline Management by Exception Active Score & 2.41 & 1.05 & 2.68 & 0.97 & 3.10 & 1.40 & 2.64 & 0.87 \\
\hline Management by Exception Passive Score & 1.73 & 0.65 & 1.68 & 0.62 & 3.00 & 1.00 & 2.33 & 0.93 \\
\hline Laissez-Faire Leadership Score & 1.30 & 0.45 & 1.33 & 0.46 & 2.70 & 1.04 & 1.78 & 0.81 \\
\hline
\end{tabular}


Table 10 Continued

\begin{tabular}{|c|c|c|c|c|c|c|c|c|}
\hline \multirow[b]{5}{*}{ Leadership Factor } & \multicolumn{8}{|c|}{ BSRI Category } \\
\hline & \multicolumn{5}{|c|}{ Feminine } & \multicolumn{3}{|c|}{ Undifferentiated } \\
\hline & \multicolumn{5}{|c|}{ Principal Biological Sex } & \multirow{2}{*}{\multicolumn{3}{|c|}{$\frac{\text { Principal Biological Sex }}{\text { Female }}$}} \\
\hline & \multicolumn{2}{|c|}{ Male } & \multicolumn{2}{|c|}{ Female } & \multirow{2}{*}{$\frac{\text { Male }}{M}$} & & \\
\hline & $M$ & $S D$ & $M$ & $S D$ & & $S D$ & $M$ & $S D$ \\
\hline Transformational Leadership Score & 5.50 & 2.55 & 4.14 & 0.50 & 3.73 & 1.66 & 3.22 & 1.09 \\
\hline Idealized Influence Attribute Score & 4.50 & 0.20 & 4.29 & 0.59 & 3.19 & 0.88 & 3.15 & 0.97 \\
\hline Idealized Influence Behavior Score & 4.25 & 0.74 & 4.16 & 0.57 & 3.34 & 0.94 & 3.34 & 0.94 \\
\hline Inspiration Motivation Score & 4.67 & 0.38 & 4.56 & 0.59 & 3.69 & 0.65 & 3.58 & 0.95 \\
\hline Intellectual Stimulation Score & 4.06 & 0.75 & 3.80 & 0.75 & 2.50 & 0.88 & 2.87 & 1.05 \\
\hline Individual Consideration Score & 4.19 & 0.94 & 3.82 & 0.59 & 3.04 & 1.19 & 2.82 & 1.10 \\
\hline Transactional Leadership Score & 2.98 & 0.42 & 2.92 & 0.41 & 2.90 & 0.44 & 3.02 & 0.37 \\
\hline Contingent Reward Score & 4.50 & 0.54 & 4.22 & 0.60 & 3.47 & 1.08 & 3.15 & 0.96 \\
\hline MBE Active Score & 2.75 & 0.68 & 2.39 & 0.82 & 2.50 & 1.09 & 2.94 & 0.73 \\
\hline MBE Passive Score & 1.69 & 0.38 & 2.12 & 0.87 & 2.72 & 0.95 & 2.95 & 0.95 \\
\hline Laissez-Faire Leadership Score & 1.50 & 0.35 & 1.71 & 0.68 & 2.71 & 0.83 & 2.61 & 1.03 \\
\hline
\end{tabular}


Table 11

Leadership Outcomes Means and Standard Deviations by Perceived Principal

Psychological Gender Role Group by Principal Biological Gender

\begin{tabular}{|c|c|c|c|c|c|c|}
\hline \multirow[b]{2}{*}{ Outcome Variable } & \multicolumn{3}{|c|}{ Males } & \multicolumn{3}{|c|}{ Females } \\
\hline & $N$ & $M$ & $S D$ & $N$ & $M$ & $S D$ \\
\hline \multicolumn{7}{|c|}{ Principal Effectiveness } \\
\hline Androgynous & 14 & 4.82 & 0.28 & 59 & 4.68 & 0.53 \\
\hline Feminine & 4 & 4.75 & 0.35 & 46 & 4.24 & 0.59 \\
\hline Masculine & 5 & 3.70 & 0.89 & 49 & 4.04 & 0.88 \\
\hline Undifferentiated & 7 & 3.07 & 1.12 & 67 & 3.09 & 1.10 \\
\hline \multicolumn{7}{|l|}{ Teacher Satisfaction } \\
\hline Androgynous & 14 & 4.89 & 0.29 & 60 & 4.81 & 0.42 \\
\hline Feminine & 4 & 4.75 & 0.50 & 50 & 3.99 & 0.96 \\
\hline Masculine & 5 & 3.40 & 1.24 & 50 & 3.99 & 0.96 \\
\hline Undifferentiated & 8 & 3.13 & 1.19 & 70 & 3.09 & 1.18 \\
\hline \multicolumn{7}{|l|}{ Extra Effort } \\
\hline Androgynous & 14 & 4.71 & 0.32 & 60 & 4.47 & 0.64 \\
\hline Feminine & 4 & 4.17 & 0.43 & 47 & 4.02 & 0.85 \\
\hline Masculine & 5 & 3.73 & 0.83 & 50 & 3.62 & 1.18 \\
\hline Undifferentiated & 7 & 2.90 & 1.36 & 70 & 2.93 & 1.19 \\
\hline
\end{tabular}

\section{Canonical Correlation Analysis}

To address question 1, canonical correlation analysis was used to examine the relationship between the leadership factors (idealized influence-attribute, idealized influence-behavior, inspiration motivation, intellectual stimulation, individualized consideration, contingent reward, management-by-exception-active, management-byexception-passive, and laissez-faire) the psychological gender factors (masculinity and femininity). Canonical correlation is a multivariate statistical model that allows for the examination of maximum linear combinations of Pearson correlations $\left(r_{\mathrm{u} l v l}\right)$ between the 
leadership and psychological variable sets. For analysis purposes, the leadership variables were designated as the independent variable set and the psychological gender role variables were designated as the dependent variable set. Scholars refer to the independent and dependent variables as canonical covariates that are correlated to produce canonical functions. The canonical correlations were restricted to producing only two possible canonical functions (function 1 and function 2); the number of canonical functions is equal to the number of variables in the smallest variable set (Thompson, 1987). According to Thompson (1987), canonical analysis produces synthetic scores for each participant, similar to the synthetic factor scores used in factor analysis and the predicted dependent variable scores in regression. Such scores are the focus of canonical analysis. The statistical significance of the canonical correlations for the two canonical functions as well as multivariate significance was tested. Wilks' lambda detected that both canonical correlations were statistically significant; function $1, \mathrm{~F}_{(18,498)}=29.79, p$ $<.05$ and function $2, \mathrm{~F}_{(8,250)}=5.48, p<.001$. Additionally, shown in Table 13, various multivariate test statistics (Wilks' lambda, Pillai's trace, Hotelling's trace, and Roy's gcr), indicated that the canonical functions, taken collectively, are statistically significant at the .001 alpha level. As a measure of shared variance, redundancy coefficients were computed for variable in function 1 and function 2 . Analogous to $R^{2}$, the redundancy index provides a summary of the amount of variance in one set of variables that can be explained by another set. The redundancy coefficient for the dependent covariate in function 1 indicates $47 \%$ of the variance in the original psychological gender role variables is accounted for by the leadership covariate. The redundancy coefficient for the independent covariate shows $68 \%$ of the variance in the original leadership variables is 
Table 12

\section{Intercorrelations}

\begin{tabular}{|c|c|c|c|c|c|c|c|c|}
\hline & 1 & 2 & 3 & 4 & 5 & 6 & 7 & 8 \\
\hline 1. Masculine Score & - & & & & & & & \\
\hline 2. Feminine Score & $.32^{* *}$ & - & & & & & & \\
\hline 3. Principal Biological Sex & -.12 & -.05 & - & & & & & \\
\hline 4. Idealized Influence Attribute Score & $.53^{* *}$ & $.77^{* *}$ & -.03 & - & & & & \\
\hline 5. Idealized Influence Behavior Score & $.54^{* *}$ & $.63^{* *}$ & -.01 & $.81^{* *}$ & - & & & \\
\hline 6. Inspiration Motivation Score & $.49^{* *}$ & $.68^{* *}$ & -.02 & $.84^{* *}$ & $.80^{* *}$ & - & & \\
\hline 7. Intellectual Stimulation Score & $.46^{* *}$ & $.74^{* *}$ & -.02 & $.85^{* *}$ & $.76^{* *}$ & $.77^{* *}$ & - & \\
\hline 8. Individual Consideration Score & $.39^{* *}$ & $.74^{* *}$ & -.06 & $.83^{* *}$ & $.72^{* *}$ & $.74^{* *}$ & $.85^{* *}$ & - \\
\hline 9. Contingent Reward Score & $.50^{* *}$ & $.72^{* *}$ & -.08 & $.84^{* *}$ & $.79^{* *}$ & $.79^{* *}$ & $.85^{* *}$ & $.81^{* *}$ \\
\hline 10. Management by Exception Active Score & -.03 & $-.25^{* *}$ & .03 & $-.21^{* *}$ & -.08 & $-.19^{* *}$ & $-.17^{* *}$ & $-.21^{* *}$ \\
\hline 11. Management by Exception Passive Score & $-.46^{* *}$ & $-.56^{* *}$ & .04 & $-.66^{* *}$ & $-.52^{* *}$ & $-.61^{* *}$ & $-.64^{* *}$ & $-.59^{* *}$ \\
\hline 12. Transformational Score & $.42^{* *}$ & $.66^{* *}$ & $-.12^{*}$ & $.81^{* *}$ & $.79^{* *}$ & $.81^{* *}$ & $.81^{* *}$ & $.84^{* *}$ \\
\hline 13. Transactional Score & -.01 & -.06 & -.00 & -.02 & $.12^{*}$ & -.02 & .06 & .00 \\
\hline 14. Laissez-Faire Score & $-.52^{* *}$ & $-.60^{* *}$ & .00 & $-.74^{* *}$ & $-.60^{* *}$ & $-.68^{* *}$ & $-.68^{* *}$ & $-.62^{* *}$ \\
\hline 15. Extra Effort Score & $.42^{* *}$ & $.69^{* *}$ & -.09 & $.80^{* *}$ & $.69^{* *}$ & $.70^{* *}$ & $.84^{* *}$ & $.76^{* *}$ \\
\hline 16. Effectiveness Score & $.53^{* *}$ & $.74^{* *}$ & -.08 & $.87^{* *}$ & $.78^{* *}$ & $.81^{* *}$ & $.84^{* *}$ & $.80^{* *}$ \\
\hline 17. Satisfaction Score & $.46^{* *}$ & $.79^{* *}$ & -.05 & $.88^{* *}$ & $.76^{* *}$ & $.81^{* *}$ & $.86^{* *}$ & $.83^{* *}$ \\
\hline
\end{tabular}

*Significant at $p<.05 ;{ }^{* *}$ significant at $p<.01$ 
Table 12

Continued

\begin{tabular}{|c|c|c|c|c|c|c|c|c|c|}
\hline & 9 & 10 & 11 & 12 & 13 & 14 & 15 & 16 & 17 \\
\hline 9. Contingent Reward Score & - & & & & & & & & \\
\hline 10. Management by Exception Active Score & $-.18^{* *}$ & - & & & & & & & \\
\hline $\begin{array}{l}\text { 11. Management by Exception Passive } \\
\text { Score }\end{array}$ & $-.61^{* *}$ & $.29^{* *}$ & - & & & & & & \\
\hline 12. Transformational Score & $.75^{* *}$ & $-.14^{*}$ & $-.57^{* *}$ & - & & & & & \\
\hline 13. Transactional Score & $.15^{*}$ & $.76^{* *}$ & $.49^{* *}$ & .02 & - & & & & \\
\hline 14. Laissez-Faire Score & $-.67^{* *}$ & $.30^{* *}$ & $.76^{* *}$ & $-.66^{* *}$ & $.28^{* *}$ & - & & & \\
\hline 15. Extra Effort Score & $.80^{* *}$ & $-.20^{* *}$ & $-.59^{* *}$ & $.77^{* *}$ & -.00 & $-.63^{* *}$ & - & & \\
\hline 16. Effectiveness Score & $.85^{* *}$ & $-.26^{* *}$ & $-.67^{* *}$ & $.85^{* *}$ & -.06 & $-.74^{* *}$ & $.81^{* *}$ & - & \\
\hline 17. Satisfaction Score & $.86^{* *}$ & $-.27^{* *}$ & $-.68^{* *}$ & $.79^{* *}$ & -.06 & $-.75^{* *}$ & $.83^{* *}$ & $.89^{* *}$ & - \\
\hline
\end{tabular}

*Significant at $p<.05 ; * *$ significant at $p<.01$ 
Table 13

Multivariate Test of Significance

\begin{tabular}{lccc}
\hline \multicolumn{1}{c}{ Statistic } & Value & $\mathrm{F}$ & P value \\
\hline Pillais trace & 0.87 & 21.68 & $.000^{*}$ \\
Hotellings trace & 2.84 & 39.18 & $.000^{*}$ \\
Wilks' lambda & 0.23 & 29.79 & $.000^{*}$ \\
\hline
\end{tabular}

* Significant $\mathrm{p}<.001$

explained by the psychological gender covariate. The redundancy analysis for function 2 detected less shared variance-psychological gender covariate, $R_{\mathrm{d}}=.05$ and leadership covariate, $R d=.04$. The near zero redundancy coefficients in function 2 reveal that the psychological gender role and leadership covariates are weak predictors of the respective original variables.

For substantive results, canonical weights, canonical loadings, and canonical communality coefficients were computed. According to Stevens (2002), there should be as least $20: 1$ case to variable ratio to obtain reliable results, which the current study meets. However, Barcikowski and Stevens (1975) recommended 40-60 times as many variables for two functions, which the current study did not meet. Therefore, based on Barcikowski and Stevens (1975) recommendations, interpretations of function 2 should be reviewed with caution.

A more traditional approach to interpreting canonical functions, the magnitude of canonical weights for each variable was computed with higher weights indicating more importance. Based on the size of weights, the order of relative contribution of the independent variables to the leadership covariate is idealized influenced, contingent reward, intellectual stimulation, laissez-faire, management by exception passive, 
idealized influence behavior, individual consideration an inspiration-motivation and management by exception active. The relative importance of the dependent variables on the psychological gender role covariate is femininity followed by masculinity. A different pattern of relative contributors of the dependent and independent variables was revealed for function 2. The order of relative contribution of the leadership variables is idealized influence attribute, contingent reward, intellectual stimulation, laissez-faire, management by exception passive, idealized influence behavior, inspiration motivation, and management by exception active, for the leadership covariate. For the psychological gender role variables, the order was masculinity followed by femininity for the psychological gender role covariate. According to Stevens (2002), using canonical weights to interpret canonical analysis is unstable, often due to high multicollineary among variables. To offset any instability, canonical loadings were computed, see Table 14.

Canonical loadings (also referenced as canonical structure correlations) represent the correlation between an original variable set and its associating canonical covariate. The canonical loading $\left(r_{\mathrm{s}}\right)$ detects the relative contribution of each variable to each canonical function, mirroring the interpretation of a factor loading in factor analysis techniques. As recommended by Stevens (2002), the criterion for determining the significance of canonical loadings was the absolute value of .40 . A squared canonical loading $\left(r_{\mathrm{s}}^{2}\right)$ indicates the percentage of variance in an original variable accounted for by the variables' canonical covariate. The canonical loadings in function 1 exceed the threshold, except for the leadership variable management by exception-active. Furthermore, in function 1 , the variables with the highest factor loadings had the highest 
Table 14

Canonical Structure of the Two Canonical Functions

\begin{tabular}{|c|c|c|c|c|c|c|c|}
\hline \multirow[b]{2}{*}{ Variable } & \multicolumn{3}{|c|}{ Function 1} & \multicolumn{3}{|c|}{ Function 2} & \multirow[b]{2}{*}{$h^{2}$} \\
\hline & $\begin{array}{c}\text { Weight } \\
\mathrm{s}\end{array}$ & $r_{s}$ & $r_{s}^{2}$ & $\begin{array}{c}\text { Weight } \\
\mathrm{s} \\
\end{array}$ & $r_{s}$ & $r_{s}^{2}$ & \\
\hline \multicolumn{8}{|l|}{ Psychological Gender Role } \\
\hline Feminine & 0.80 & .93 & .86 & -0.69 & 3.37 & .13 & .99 \\
\hline Masculine & 0.39 & .65 & .42 & 0.98 & .75 & .56 & .98 \\
\hline$R_{\mathrm{d}}$ & & .47 & & & .05 & & \\
\hline \multicolumn{8}{|l|}{$\begin{array}{l}\text { Transformational Leadership } \\
\text { Behavior }\end{array}$} \\
\hline Idealized Influence A & 0.42 & .97 & .94 & -0.02 & .00 & .00 & .94 \\
\hline Idealized Influence B & 0.07 & .85 & .72 & 0.89 & .23 & .05 & .77 \\
\hline Inspiration-Motivation & 0.03 & .88 & .77 & -0.20 & .02 & .00 & .77 \\
\hline Intellectual Stimulation & 0.13 & .92 & .85 & -0.90 & -.20 & .04 & .89 \\
\hline Individual Consideration & 0.07 & .88 & .77 & -0.72 & -.29 & .08 & .85 \\
\hline \multicolumn{8}{|c|}{ Transactional Leadership Behavior } \\
\hline Contingent Reward & 0.17 & .91 & .83 & 0.23 & -.01 & .00 & .83 \\
\hline MBEA & -0.03 & -.26 & .07 & 0.44 & .37 & .14 & .21 \\
\hline MBEP & -0.09 & -.76 & .58 & -0.38 & -.19 & .03 & .61 \\
\hline Laissez-Faire Leadership & -0.10 & -.82 & .67 & -0.64 & -.26 & .07 & .74 \\
\hline$R_{\mathrm{d}}$ & & .68 & & & .04 & & \\
\hline$R_{\mathrm{c}}$ & & .85 & & & .39 & & \\
\hline$R_{\mathrm{c}}^{2}$ & & .72 & & & .15 & & \\
\hline
\end{tabular}

Note. $\mathrm{A}=$ attribute; $\mathrm{B}=$ behavior; $\mathrm{MBEA}=$ management by exception (active); $\mathrm{MBEP}=$ management by exception (passive); $R_{\mathrm{c}}=$ canonical correlation coefficient; $R_{\mathrm{c}}{ }^{2}=$ squared canonical correlation coefficient; $r_{\mathrm{s}}=$ loadings; $R_{\mathrm{d}}=$ redundancy coefficient set; $h^{2}=$ canonical communality coefficient.

canonical weights. The leadership variable idealized influence attribute and the psychological gender role femininity were the most important in determining the canonical correlations and displayed the most variance with their associating covariates. Specifically, the femininity and psychological gender role covariate shared variance is 
$86 \%$. The shared variance among idealized influence attribute and the leadership behavior covariate is $94 \%$. Moreover, a number of the leadership variables have low weights but high loadings, indicating that one or more variables contain the same information - that is, since canonical correlation is a mathematical maximization technique, a function only allows one variable to capture the essence of what the variables measure (Thompson, 2000). Function 2 followed a similar pattern as function 1-the variables with the highest factor loadings had higher canonical weights.

In addition to canonical weights and loadings, canonical commonality coefficients were calculated. Commonality coefficients are the sum of all squared canonical loadings across functions (Thompson, 1987). Commonality coefficients account for the amount of variance in an original variable which is reproducible from the canonical covariates. As indicated in Table 14 , synthetic femininity scores $\left(h^{2}=.99\right)$ from function 1 and function 2 reproduced $99 \%$ of the variance in the original femininity variable. Likewise, the synthetic idealized influence attribute $\left(h^{2}=.94\right)$ scores from function 1 and function 2 reproduced $94 \%$ of the variance in the original idealized influence attribute variable. Communality coefficients resulted in femininity $\left(h^{2}=.99\right)$, masculinity $\left(h^{2}=.98\right)$, and idealized influence attribute $\left(h^{2}=.94\right)$, accounting for more of the variance in their respective original variables compared to others, while management by exception active $\left(h^{2}=.21\right)$ and management by exception passive $\left(h^{2}=.61\right)$ accounted for the least. Overall, the $h^{2}$ values for both the masculinity and femininity scales were high, revealing that both are important in defining the two canonical functions. Of the leadership variables, idealized influence attribute, and intellectual stimulation were the most important in defining the two canonical functions. 
Examination of $R_{\mathcal{c}}{ }^{2}$ of function 1 indicated the leadership covariate accounted for $72 \%$ of the variance in the psychological gender role covariate; this was distinctly lower in function $2\left(R_{\mathrm{c}}{ }^{2}=.15\right)$. Therefore, function 1 represents the maximum correlation that can be obtained through the best linear combination of both variable sets, indicating that only one relationship exist. Furthermore, the analysis revealed psychological gender role group can be fairly well predicted with the collective effect of the leadership variables. Analysis of $r$, and $r_{\mathrm{s}}{ }^{2}$ and $h^{2}$ for both variable sets indicates femininity, masculinity, idealized influence attribute, idealized influence behavior, inspiration-motivation, intellection stimulation, individual consideration, contingent reward, and laissez-faire provide the best maximum linear combinations of Pearson correlation $\left(r_{\mathrm{u} 1 \mathrm{v} 1}\right)$ between the leadership behavior and psychological gender role variable sets.

\section{MANOVA Analysis}

A factorial multivariate analysis of variance (MANOVA) technique was used to address research questions 2, 3, and 4. According to Stevens (2002), MANOVA has the potential to result in a more powerful test by reducing within-cell variance, and it allows for the examination of joint effects of multiple independent variables (biological gender and psychological gender role group) on dependent variables (perceived principal effectiveness, teachers' perceived satisfaction, and teachers' perceived extra effort).

MANOVA assumptions. Prior to calculating or interpreting factorial MANOVA results, three multivariate assumptions must be met: independence of observations, multivariate normality, and equality of covariance matrices (Stevens, 2002; Field, 2005; Tabachnick \& Fidell, 2001). First, independence of observations implies that "the score for any particular subject is independent of the scores of all other subjects" (Shavelson, 
1996, p. 378). In the current study, independence was addressed prior to data collection-that is, the survey design facilitated teachers to complete the survey independently and only once. The independence of observation, however, was not met becausea single principal was rated by multiple teachers.

Second, normality indicates that "sampling distributions of means of the various DVs in each cell and linear combinations of them are normally distributed" (Tabachnick \& Fidell, 2001, p. 329). There is no direct test for multivariate normality; thus, univariate normality tests were performed on each of the three dependent variables. Specifically, data for each dependent variable were presented in a histogram compared to the normal distribution curve. Additionally, the Shapiro-Wilk statistic was used to test normality. The Shapiro-Wilk statistic for the three dependent variables (principal effectiveness $W=$ $.87, p<.05$; teacher extra effort $W=.88, p<.05$; teacher satisfaction $W=.83, p<.05$ ) indicated rejection of the null hypothesis: the population is normality distributed, implying that the normality assumption was not met. Exploration of the histograms confirmed the Shapiro-Wilk statistics, indicating that all three dependent variables are negatively skewed (skewness for principal effectiveness $=-0.86$, skewness for teacher extra effort $=-1.00$, skewness for teacher satisfaction $=-1.07$ ). Despite the violation of multivariate normality, Stevens (2002) and Tabachnick and Fidell (2001) stated that the effect of non-normal data on the $F$ statistic in MANOVA is minimal.

Third, the assumption of equality of covariance matrices was tested using Box's test of equality of covariance matrices. The results of Box's test implied that the third assumption was violated, indicating variability between groups $\left(F_{(42,1448.90)}=3.67, \mathrm{p}\right.$ $<.05)$. Tabachnick and Fidell (2001) reported that MANOVA is robust against the 
violation of this assumption. However, the significance found in Box's text is potentially due to the non-normal data, as it is sensitive to non-normal data (Stevens, 2002). Despite violation of the normality and equality of variances assumptions, based on recommendations from Stevens (2002), Tabachnick and Fidell (2001), and Field (2005), MANOVA was used to examine the main and interaction effects of psychological gender role and biological gender on three leadership outcomes.

MANOVA results. A $2 \times 4$ factorial MANOVA (biological gender at two levels [male and female] and psychological gender role group at four levels [androgynous, masculine, feminine, and undifferentiated]) analysis addressed research questions 2, 3, and 4:

2. Is there a significant interaction effect of principal biological gender and principal psychological gender role group on teacher perceived principal effectiveness, teacher perceived satisfaction, and teacher perceived extra effort?

3. Is there a significant main effect of principal biological gender on teachers' perceived principal effectiveness, teachers' perceived satisfaction, and teachers' perceived extra effort?

4. Is there a significant main effect of principal psychological gender role group (androgynous, feminine, masculine, and undifferentiated) on teachers' perceived principal effectiveness, teachers' perceived satisfaction, and teachers' perceived extra effort?

Biological gender and psychological gender role group served as the independent variables, while perceived principal effectiveness, teachers' satisfaction, and teachers' perceived extra effort served as the dependent variables. According to Field (2005), main 
effects can be misleading without interpretation of interaction effects; thus, research question 2 is discussed first.

Research question 2 addressed the null hypothesis: there is not a significant interaction effect of principal biological gender and principal psychological gender role on teachers' perceived principal effectiveness, teachers' satisfaction, and teachers' extra effort. According to MANOVA results (Table 15), the null hypothesis is retained. There was no significant multivariate interaction effect between principal biological gender and perceived principal psychological gender role group on teacher perceived principal effectiveness, teacher satisfaction, and teacher extra effort (Wilks' $\Lambda=.97, F_{(9,584)}=.91$, $p>.05)$. The lack of a significant interaction effect indicates that the effect of perceived psychological gender role group on the dependent variables is similar for biological males and females. The eta square statistic $\left(\eta^{2}=.01\right)$ is considered a very small effect size (Cohen, 1988); specifically, only $1 \%$ of the variance in the dependent variables is accounted for by the interaction effect of psychological gender role group by biological gender interaction.

Following the nonsignificant psychological gender role group by biological gender interaction effect, the main effect of biological gender on the three leader outcomes was explored. Addressing the hypothesis, there was not a significant main effect of principal biological gender on teachers' perceived principal effectiveness, teachers' satisfaction, and teachers' extra effort. MANOVA results indicated a nonsignificant multivariate main effect of biological gender (Wilks' $\Lambda=.99, F_{(3,240)}=$ $.44, p>.05)$. Thus, the effect of biological gender on the three dependent variables is similar for biological males and females, retaining the null hypothesis. Additionally, the 
eta square statistic $\left(\eta^{2}=.005\right)$ is considered a very small effect size (Cohen, 1988); specifically, $0.5 \%$ of the variance in the dependent variables is accounted for by biological gender.

Following the nonsignificant biological gender by psychological gender role group effect and nonsignificant biological gender main effect, the main effect of psychological gender role group on the three dependent variables was examined. MANOVA results revealed a statistically significant multivariate main effect of psychological gender role group on leadership outcomes (Wilks' $\Lambda=.73, F_{(9,584)}=8.60$, $p<.01$ ), thus failing to retain the null hypothesis. Furthermore, follow-up analyses on the individual dependent variables revealed significant univariate main effects of perceived psychological gender role group on teacher perceived principal effectiveness $\left(F_{(3,249)}=24.28, p<.01\right)$, teacher extra effort $\left(F_{(23,249)}=16.99, p<.01\right)$, and teacher satisfaction $\left(F_{(3,247)}=23.84, p<.01\right)$. Partial eta square statistics for the univariate main effect-for principal effectiveness $\eta^{2}=.23$, for teacher extra effort $\eta^{2}=.17$, and for teacher satisfaction $\eta^{2}=.22$-were large in effect size (Cohen, 1988). Specifically, $17 \%$ to $23 \%$ of the variance in the dependent variables was accounted for by the four levels of the psychological gender role group. To locate the differences in psychological gender role group among the dependent variables, a univariate analysis of variance for each dependent variable was examined.

ANOVA post hoc analysis. Results of the univariate analysis indicate that teacher satisfaction, teacher extra effort, and perceived principal effectiveness differed based on teachers' perceptions of their principals' psychological gender role group. Given that the psychological gender role group variable consisted of four levels (androgynous, 
masculine, feminine, and undifferentiated), a Tukey post hoc analysis was conducted to identify the between-group differences on each dependent variable (see Tables 16 and 17).

Psychological gender and leader outcomes. Tukey post hoc analysis revealed teachers who perceived their principals as androgynous or feminine reported higher levels of principal effectiveness, teacher satisfaction, and teacher willingness to exert extra effort. Results for the Tukey post hoc test by leader outcome variable are explicated next.

Principal effectiveness. Results revealed a statistically significant difference between the androgynous-masculine means, the androgynous-feminine means, the androgynous-undifferentiated means, the masculine-undifferentiated means, and the feminine-undifferentiated means. The perception of principals as androgynous led to higher levels of reported principal effectiveness compared to the perception of principals as masculine or undifferentiated at the .05 alpha level. In addition, results from the post hoc analysis detected that the perception of androgynous principals resulted in significantly higher levels of principal effectiveness $(M=4.71, S D=0.09)$ than feminine principals $(M=3.26, S D=0.11)$ at the .05 alpha level. Teachers who perceived their principals as feminine reported significantly higher levels of principal effectiveness $(M=$ $3.26, S D=0.11$ ) compared to teachers who perceived their principals as undifferentiated $(M=3.01, S D=0.96)$

Teacher satisfaction. Results from the post hoc analysis revealed a statistically significant difference between the androgynous and masculine, feminine, and undifferentiated means. Furthermore, a statistically significant difference was found 
Table 15

Factorial MANOVA Summary

\begin{tabular}{lcccccc}
\hline & $\begin{array}{c}\text { Wilks' } \\
\text { Lambda }\end{array}$ & F & $\begin{array}{c}\text { Hypothesis } \\
\text { df }\end{array}$ & Error df & Sig. & $\begin{array}{c}\text { Partial Eta } \\
\text { Squared }\end{array}$ \\
\hline Biological Gender & .99 & .44 & 3 & 240 & .724 & .005 \\
$\begin{array}{l}\text { Psychological Gender } \\
\begin{array}{l}\text { Biological Gender x } \\
\text { Psychological Gender }\end{array}\end{array}$ & .73 & 8.60 & 9 & 584 & $.000^{*}$ & .096 \\
\hline
\end{tabular}

"significant at $\mathrm{p}<.05$.

between perceived feminine principals, perceived undifferentiated principals, and perceived masculine principals on teachers' satisfaction. Specifically, teachers who perceived their principals as androgynous $(M=4.83, S D=0.10)$ or feminine $(M=4.38$, $S D=0.12$ ) reported higher levels of satisfaction compared to teachers who perceived their principals as masculine or undifferentiated. In addition, analysis detected a statistically significant difference between the masculine and undifferentiated psychological gender role groups. Specifically, teachers who perceived their principals as masculine $(M=3.92, S D=0.12)$ reported higher levels of satisfaction than teachers who perceived their principals as undifferentiated $(M=3.12, S D=0.09)$ at the .05 alpha level. A similar pattern was found in the post hoc test for the psychological gender role group moderating effect of teacher extra effort. 
Table 16

Comparisons of All Possible Variable Combinations

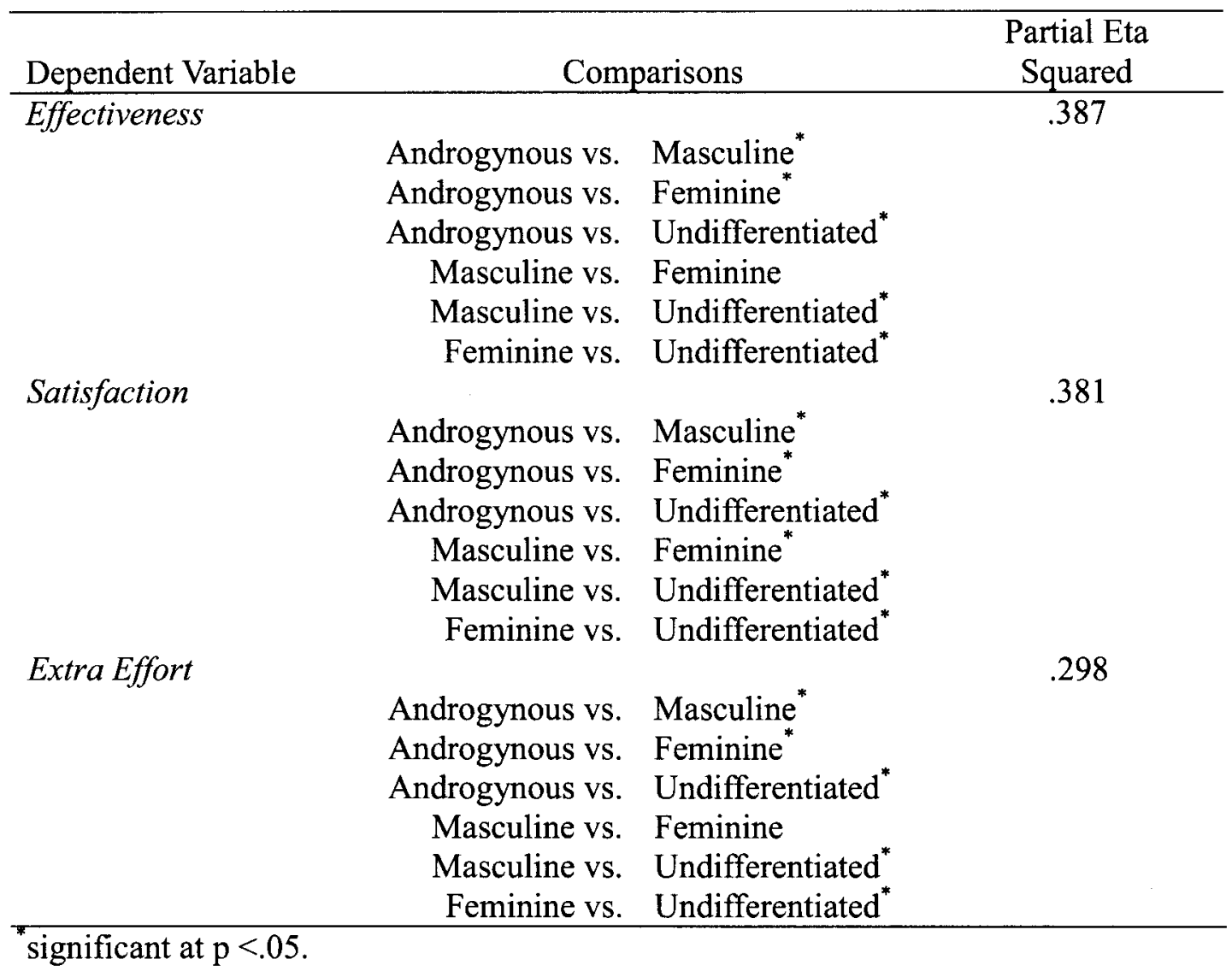

Teacher Extra Effort. Results from the post hoc analysis revealed a statistically significant difference between the androgynous, masculine, feminine, and undifferentiated means. Furthermore, a statistically significant difference was found between perceived feminine principals and perceived undifferentiated principals on teachers' willingness to exert extra effort. Teachers who perceived their principals as androgynous $(M=4.52, S D=0.11)$ or feminine $(M=3.98, S D=0.13)$ reported higher levels of extra effort compared to teachers who perceived their principals as masculine or undifferentiated. In addition, analysis detected a statistically significant difference 
Table 17

Means and Standard Deviations for Leadership Outcomes

\begin{tabular}{lcccccc}
\multirow{2}{*}{$\begin{array}{l}\text { Psychological } \\
\text { Gender Role Group }\end{array}$} & \multicolumn{2}{c}{ Effectiveness } & \multicolumn{2}{c}{ Satisfaction } & \multicolumn{2}{c}{ Extra Effort } \\
\cline { 2 - 7 } & Mean & $S D$ & $S D$ & $S D$ & Mean & $S D$ \\
\hline Androgynous & 4.71 & 0.09 & 0.11 & 0.11 & 4.83 & 0.10 \\
\hline Feminine & 4.26 & 0.11 & 0.13 & 0.13 & 4.38 & 0.12 \\
\hline Masculine & 3.97 & 0.11 & 0.13 & 0.13 & 3.92 & 0.12 \\
\hline Undifferentiated & 3.01 & 0.09 & 0.11 & 0.11 & 3.12 & 0.09 \\
\hline
\end{tabular}

between the masculine and undifferentiated psychological gender role groups.

Specifically, teachers who perceived their principals as masculine $(M=3.692, S D=0.13)$

reported higher levels of satisfaction than teachers who perceived their principals as

undifferentiated $(M=2.92, S D=0.11)$ at the .05 alpha level.

\section{Summary of Results}

Canonical correlation analysis and MANOVA technique was used to examine the relationship between the leadership factors and the psychological gender factors.

Canonical correlation analysis indicated that there was a close correspondence between femininity and transformational leadership. Results from a 2-way MANOVA indicated statistically significant differences in leader outcomes by teacher perceived level of principal psychological gender. Specifically, teachers who perceived their principals as androgynous and feminine reported higher levels of perceived principal effectiveness, satisfaction, and extra effort. 


\section{CHAPTER V}

\section{DISCUSSION}

The purpose of this study was to examine the relationship between leadership style (transformational, transactional, and laissez faire) and psychological gender role group (androgynous, femininity, masculinity, and undifferentiated) of elementary school principals. Specifically, the study sought to understand the relationship between teachers' perceptions of leadership behavior and psychological gender on perceptions of principal effectiveness, teacher satisfaction, and teacher extra effort. Four research questions were addressed to achieve the study's purpose and are explicated separately in the following pages.

\section{Psychological Gender Role and Leadership}

The psychological gender role and leadership relationship was examined first by research question 1: is there a significant canonical correlation between the leadership variables set (idealized influence-attribute, idealized influence-behavior, inspirationmotivation, intellectual stimulation, individualized consideration, contingent reward, management-by-exception-active, management-by-exception-passive, and laissez-faire) and the psychological gender role variable set (masculinity and femininity)? Based on prior literature, the current study hypothesized that a relationship would exist between the full range of leadership factors and psychological gender factors in education. Study 
results indicated that a relationship exists between the leadership behavior variables and the psychological gender role variables. The femininity and transformational leadership scale scores emerged as the most important variables in defining the leadership behaviorpsychological gender role group relationship. The findings suggest that psychological gender role can be fairly well predicted with the collective effect of the leadership variables, specifically accounting for $72 \%$ of the variance. The study findings were not surprising given past research. For example, Hackman, Furniss, Hill, and Paterson (1992) and Eagly and Johnson (2001) found significant positive-moderate correlations between psychological gender factors and transformational and transactional contingent reward leadership factors.

According to Bass $(1974,1983)$, psychological gender role differences are critical to the ways in which one experiences and make sense of the world (Bem, 1974, 1983); thus, there is an important relationship between gender and leadership behavior (Eagly \& Johannesen- Schmidt, 2001). Specifically, because leadership is such an important aspect of school achievement and reform, investigation of dimensions of leadership, including the role of psychological gender, was important.

\section{Biological Gender, Psychological Gender Role, and Leader Outcomes}

Research question 2 addressed the existence, if any, of a significant interaction effect of principal biological gender and principal psychological gender role group on teacher perceived principal effectiveness, teacher perceived satisfaction, and teacher perceived extra effort. The interaction effect of leadership behavior and psychological gender role group on leader outcomes was found not to be significant. The lack of significance indicates that the effect of psychological gender on the three leader outcomes 
was not related to biological gender. The fact that no differences emerged in the interaction effect was surprising. Based on prior research and the different experiences of men and women, significant differences in the interaction were expected to emerge. The existence of different social expectations of attributes and behavior of men and women (i.e., males are agentic and women are communal) has been consistently documented (Eagly \& Karau, 1991; Deaux \& Lewis, 1983; Eagly, Wood, \& Diekman, 2000). As a result of gender roles-shared expectations that apply to individuals based solely on one's biological sex (Eagly, 1987)-leaders elicit expectancies based on people's categorization of them as male or female (Eagly \& Johannesen-Schmidt, 2001). It is possible that both biological and psychological gender differences contribute to men and women displaying somewhat different leadership outcomes while sharing the same leadership role, in this case that of elementary school principal.

This study may serve to demonstrate that men and women are more alike than previously speculated. Perhaps if society realizes that more similarities than differences exist between men and women educators than previously believed, the strong traditional expectations of desirable and appropriate traits (stereotypically feminine) of principals would be eliminated and the potential role incongruity prejudices will subside. However, because of the study's substantially small male sample, generalizations must be made with caution.

\section{Biological Gender and Leader Outcomes}

The relationship between biological gender and leader outcomes was addressed through research question $3:$ is there a significant main effect of principal biological gender on teachers' perceived principal effectiveness, teachers' perceived satisfaction, 
and teachers' perceived extra effort? Study findings showed principal biological gender in isolation did not have a significant effect on leader outcomes. Specifically, teachers expressed relatively equal and non-significant levels of satisfaction, extra effort, and principal effectiveness regardless of their principal's biological gender. These nonsignificant results, on one hand, were not surprising. Leadership scholars and social scientists continue to posit that reliable differences or a clear pattern of differences between men's and women's leadership, based on biological sex, do not exist (Bartol \& Martin, 1986; Eagly \& Johnson, 1990; Hollander, 1985; Kanter, 1977; Nivea \& Guetk, 1981). Moreover, Eagly and Johnson's (1990) work substantiated stereotypical sex differences are found less in natural organization settings than in laboratory settings. Since this study occurred in a natural school setting, sex differences are not likely to be pronounced.

On the other hand, prior research has posited several reasons to expect differences in men and women leadership. One reason is ingrained sex differences because of biological influences (Eagly \& Johnson, 1990). From an early age, American boys and girls are expected to exhibit socially desirable traits associated with their gender roles (Eagly, Woods, \& Steffen, 1982; Harrison \& Lynch, 2005; Wilburn \& Kee, 2010). For example, boys learn to wear blue and girls learn to wear pink. Likewise, boys are rewarded for being strong and girls are rewarded for being nurturing (Bem, 1974). Such gender roles, developed at an early age, are sustained and reinforced throughout adulthood through social role theory (Eagly \& Karau, 2002). Specifically, social role theory posits that the desirable attributes of males and females (i.e., males oriented to be agentic and females oriented to be communal) can be explained by the different social 
roles ascribed to men and women. This process of social expectations carries over into occupation roles including leadership roles (Hackman, Furniss, Hills, \& Paterson, 1992; Harrison \& Lynch, 2005; Wilburn \& Kee, 2010). This study may serve to demonstrate that there exists a more complex underpinning that highlights the differences among leaders rather than biology.

\section{Psychological Gender Role and Leader Outcomes}

Research question 4 examined the existence, if any, of a significant main effect of principal psychological gender role group (androgynous, femininity, masculinity, and undifferentiated) on teachers' perceived principal effectiveness, teachers' perceived satisfaction, and teachers' perceived extra effort. Results indicated teachers' perceptions of their principals' psychological gender role group affects teachers' perceptions of leader outcomes. Teachers identifying principals more strongly as androgynous or feminine reported higher levels of principal effectiveness, teacher satisfaction, and extra effort compared to those who perceived their principal as masculine or undifferentiated. The current study findings support prior research from Eagly (2007) and her colleagues (Deaux \& Lewis, 1983; Eagly \& Karau, 1991; Eagly, Wood, \& Diekman, 2000), which suggests leaders need a combination of feminine and masculine traits.

According to Eagly and Karau (1991) differences in leader outcomes may be due to differences in psychological gender role traits (Johnson, Busch, \& Slate, 2008; Smulyan, 2000). For example, Eagly (2007) posited that leaders who are perceived to have androgynous characteristics are more effective. Androgynous individuals are more adaptive and do not experience turmoil or great distress when gender-incongruent behavior is incumbent (Bem, 1975; O’Neil, Helms, Gable, David, \& Wrightsman, 1986). 
Research has substantiated that, when a sex-typed individual-masculine men or feminine women-is called upon to exhibit traits associated with the opposite sex, significant psychological distress can ensue (Good \& Mintz, 1990). Androgynous individuals have better psychological outcomes compared to sex-typed individuals (Sanchez \& Crocker, 2005), perhaps resulting in more effective leadership.

Additionally, the relationship between psychological gender and leader outcomes was further supported through the current study's correlational analyses. Correlations revealed that transformational leadership was associated with both androgyny and femininity, which was not surprising considering the fact that past literature has substantiated such a link (Eagly \& Johnson, 1990; Eagly, Karau, \& Johnson, 1992). Ultimately, the current results and extant research suggest that transformational leadership in education requires a balance between masculine and feminine traits, and this is in line with contemporary leadership theory (Hackmen, Furniss, Hills, \& Paterson, 1992). Overall, the study results suggested that the combination of androgyny and transformational leadership behavior (regardless of biological gender) results in higher ratings of teacher satisfaction, teacher assessment of their willingness to exert extra effort, and perception of principal effectiveness.

Considering that the communality between the androgynous group and the feminine group is femininity, this suggests that elementary school leaders clearly need to exhibit highly feminine traits with the combination of transformational leadership to result in higher ratings of perception of principal effectiveness, teacher satisfaction, and teacher assessment of their willingness to exert extra effort. 


\section{Study Implications}

Given the ambiguity that continues to surround effective principal leadership, this study was salient and timely. The study provided several findings regarding the role of psychological gender, leadership behavior, and leader outcomes in the principalship from the teacher's perceptive.

The main contribution of this study is that it sheds light on how as the perceptions of principal psychological gender change, the perceptions of leader outcomes change. Specifically, study findings suggest perceptions of principal effectiveness, teacher satisfaction, and teacher extra efforts are not the same across levels of principal psychological gender. When the perception of feminine levels are high, teachers feel more satisfied with their job, view their principal as more effective, and express greater willingness to exert extra effort. This suggests principals need to be encouraged to display femininity for optimal leader outcomes.

Another contribution of the study is the link found between transformational leadership and leader outcomes. Past research has posited transformational leadership and the transactional contingent reward factor lead to high levels of teacher satisfaction, principal effectiveness, and teacher extra effort (Bass, 1985; Hoover, 1987; Kirby, King, \& Paradise, 1992), which was replicated in the current study. One possibility for the finding is that transformational principals' actions in developing shared goals and establishing high expectations (Leithwood, Jantzi, Silins, \& Dart, 1993). This implies that teachers prefer principals who exhibit transformational leadership behavior, which supports prior research of Kirby, King, and Paradise (1992), among others (Bass, 1985; Hoover, 1987; Binkowski, Cordeiro, \& Iwanicki, 1995; Silin, 1994). 
One other contribution of the study is that it replicated Bass $(1985,1999)$ and his colleagues' (Waldman, Bass, \& Einstein, 1986; Avolio, Bass, \& Jung, 1995) findings of the "correlational hierarchy" of the Full Range Leadership Model (FRLM). Specifically, transformational factors were found to be more highly correlated with leadership outcomes than contingent reward, contingent reward was more highly correlated with leader outcomes than management-by-exception, and laissez-faire leadership was negatively correlated with leader outcomes. The similar correlations between the leadership factors found in this study provide evidence that the hierarchical nature of the FRLM found in prior studies was not spurious.

Furthermore, the high correlation between transformational factors and the transactional contingent reward factor found in the current study provide support for prior validity studies by Antonakis, Avolio, and Sivasubramaniann (2003), Podaskoff, MacKenzie, Moorman, and Fetter (1990), and Tejada, Scandura, and Pillai (2001). Specifically, prior research has substantiated the contingent reward factor of transactional leadership represents a leadership behavior similar to transformational leadership. The current study provides evidence that, from a teacher's perspective, this is true in elementary education.

Of course, in spite of the effectiveness of transformational leadership, research has shown that not all principals display transformational leadership. One speculation is that differences between male and female principal leadership is partly related to gender role expectations of men and women---that is, the extent to which male and female principals carry out their gender roles as desired by society. One final contribution of the current study is it supported Eagly et. al (1992) and her colleagues' findings on role 
congruity in principal leadership. According to Eagly et al. (1992), the extent to which male and female school principals carry out their leader role in a manner consistent with gender expectations causes differences in their respective leadership styles. Women in male-dominated or defined roles (e.g., military officer) face the challenge of incompatibility between expectations of the women role and the male leader role. Consequently, society deems women unqualified for such male-defined leadership roles and women may experience a disadvantage. One can surmise that women do not experience role incongruity in the leader role of elementary school principal because, currently, it is a female-dominated role (Eagly \& Johnson, 1990; Eagly, Karau, \& Johnson, 1992). For example, Eagly and Johnson (1990) found in data collected from college-age respondents that the elementary school principal was perceived as a career more congruent for women. Additionally, the previous findings have shown that female respondents reported themselves to be more competent in the principal role compared to male respondents (Eagly \& Johnson, 1990). Moreover, male and female respondents in their study both regarded women as more interested in elementary school principalship.

Eagly (2007) and her colleagues (Hackman, Furniss, Hills, \& Patterson, 1992) suggest in order for men to be perceived as effective as women in an elementary education setting, men must find a balance between their male role and leader role, which means displaying androgyny — both high agentic traits and high communal traits (Eagly, 2007). Thus, male principals must display a leadership style that is considered to be quite androgynous-transformational leadership (Hackman, Furniss, Hills, \& Patterson, 1992). The current study findings supported these conclusions: women and men perceived as feminine or androgynous had higher ratings of leader outcomes compared to those 
perceived as masculine or undifferentiated. However, the current study's male principal sample ( $n=14)$ was substantially small and any generalizations must be made with caution.

\section{Study Conclusion}

Research concerning the potential gender differences in principal leadership reflects educational researchers' desire to understand gender equality within administrative positions. Since effective school leadership has received considerable research attention during the last several decades, research concerning the potential predictors of leader outcomes is relevant. Thus, this particular study was salient and timely with propositions for education researchers and scholars, as well as school district personnel.

The present study adds further empirically based research to several important areas of study in educational leadership, including the study of principals, teachers, principal behavior, principal leadership, and psychological gender of principals, to name a few. Understanding the relationship between psychological gender and leadership provides school districts with information to maximize the positive aspects of the school environment. In addition, the study's findings have implications for principal hiring. According to Bass and Riggo (2006), research that addresses personality differences in relation to leadership can help in leader identification, selection, and development. Thus, understanding psychological gender and leadership differences may contribute to matching candidates to schools. Psychological gender and leadership can be used to identify candidates for selection as a school principal or transfer to another school within the same district. Specifically, if a district knows which psychological gender and 
leadership behaviors are identified as effective in certain types of schools (e.g. low or high performing) a principal candidate can take the BSRI and MLQ to determine his or her applicability as a leader of a specified school. The same process can be used to transfer principals to different schools within the same district.

Study findings suggest there exists a need for a leadership approach comprised of femininity in the elementary school principalship. Principals need to be encouraged to display femininity for optimal leader outcomes such as teacher satisfaction, teacher willingness to exert extra effort, and effectiveness. Such leader outcomes have been proven to influence student outcomes, school climates, and instructional organization (Bass, 1985; Binkowski, Cordeiro, \& Iwanicki, 1995; Leithwood, Jantzi, Silins, \& Dart, 1993; Silin, 1994). To prepare high quality and effective leaders we need to start looking at how to encourage more feminine leadership behaviors during principal professional development. For example, the MLQ is designed to provide leaders with a comprehensive profile of his/her leadership performance. Used as a professional development tool, the MLQ can provide leaders with specific behaviors or skills they need to develop to be more effective at organizational task. Once a principal takes the MLQ he or she is advised to create an individualized development/growth plan (Bass and Avolio, 2004). For example, principals can create a leadership development plan to improve and build on the skills necessary to effectively express desirable leader behaviors. In the current study a principal in the participating district would write a plan to improve his/her transformational leadership behavior, such as taking into consideration teacher self-interest. A principal can then retest a few months later to assess his/her improvement and determine which areas need further attention. According to Bass and 
Avolio (2004), use of the MLQ to develop improvement plans aids in effective leadership behaviors replacing ineffective ones in a relatively short amount of time; especially when periodic assessments are interwoven prior to retaking the MLQ.

\section{Study Limitations}

Several limitations existed with the study. First, the study focused on a single school district within Kentucky. The teachers in this study may have provided different responses as compared to teachers in other districts or teachers in general. Caution should be used when generalizing the current study findings to principals in other districts and schools within the Kentucky education system. Second, the majority of teachers assessed female principals $(n=38)$ and any generalizations regarding male principals $(n=14)$ must be made with caution. Third, research has substantiated the reliability and validity of the Multifactor Leadership Questionnaire (MLQ) in many professions. However, the instrument does not specifically address the responsibilities of an elementary school principal. There exists minimal research on the applicability of the MLQ factor structure with elementary school principals or teachers. Thus, caution should be made when generalizing the study findings regarding leadership behavior to principals. Lastly, teachers came from a number of schools in the districts. There was some degree of clustering of the data since teachers at a given school were rating the same principal. Following up the current analysis with multilevel modeling procedures potentially might give additional insights into the data. 


\section{Recommendations}

The current study provides enlightening information that can be used to better understand the nature of principal leadership; however, it is only the first step in understanding the role that psychological gender plays in elementary school leadership.

Researchers and scholars would be well-served to further examine the individual scales of the Bem Sex Role Inventory (BSRI) and MLQ Form 5x. Specifically, a closer look at single items that comprise the feminine and masculine scales of the BSRI may shed light on specific traits that are important to leader outcomes. The current study highlighted only the mean averages of the masculine and feminine scores. Perhaps high scores on some items of the masculine scale are present so the mean is high but low scores on a few items on the feminine scale lower the feminine score mean. This would result in the importance of few traits being suppressed by the high means of others. In addition, examining the MLQ items similarly will be helpful. Currently, this study focused on the overall transformational, transactional, and laissez-faire leadership mean scores. Investigating individual items that comprise each leadership scale may highlight specific behaviors that are important to leader outcomes. Conceivably, high scores on some transformational items are present, but low scores on a few items on the transactional scale are lowering the transactional scale mean; thus, the importance of a few transactional items is being suppressed.

Additionally, future studies should address the multidimensionality of the FRLM with a sample of elementary school principals. Although numerous educational studies have used the FRLM, it has yet to be substantiated that the model addresses the leadership responsibilities of elementary school principals. Analyzing the factor structure 
of the FRLM would determine its applicability to elementary education. The current study focused only on the reliability of the model; a validity study would contribute further psychometric understanding of the FRL in education. Studying the structural theory of the FRLM would shed light on whether the model adequately describes leadership for elementary school principals or needs to be respecified to represent it.

Furthermore, it would be interesting to examine the relationship between androgynous principals who display transformational behavior and student achievement, since questions still remain in the education field regarding the association between principal leadership and student achievement (Bossert \& Dwyer, 1993; Hallinger \& Murphy; 1986; Pitner, 1988; Stobaugh, 2003). The current study results suggest that teachers perceive androgynous-transformational principals to have higher ratings of leader outcomes; thus, the next logical step is to relate this to student achievement. This is proposed because existing literature suggests that effective school leadership has been associated with student achievement (Bryk et al., 2010; Duke, 2007; Hallinger \& Heck, 1996; Knoeppel \& Rinehart, 2008). Furthermore, educational researchers have identified principals as an essential factor in school achievement (Bryk et al., 2010; Herman et al., 2008; Sammons, 2007; Teddlie \& Reynolds, 2000; Teddlie \& Stringfield, 1993). For example, Sammons (2007) identified school leadership as second to classroom teaching as an influence on student learning. In a meta-analytical review, Waters et al. (2003) found substantial relationships between school leadership and student achievement, citing previous revealing effect sizes as large as 0.50 . Vanderhaar, Munoz, and Rodosky (2006) determined that principals play a pivotal role in transforming and shaping student achievement. Further research employing student achievement measures could illustrate 
the role that the psychological gender-leadership relationship plays in school success. In addition, such research could help to shape the leader role of school principals in the current era of high-stakes accountability as well as potentially eliminate some of the ambiguity in elementary school leadership.

Moreover, an examination of the relationship between school-level factors is a needed area of research. The current study did not account for dependence among teachers in schools. Traditionally, teachers are naturally clustered within schools, resulting in the likelihood of relatedness-independence among schools. Since traditional statistical methods were used to analyze the current data, it was assumed that the observations were independent of each other. In particular, no adjustments were made to take into account naturally occurring dependence in schools. Given the hierarchical structure of the study data, teachers nested within schools, use of hierarchical linear modeling could account for intraclass correlation (ICC). The ICC is used to determine homogeneity within schools (HLM; Raudenbush \& Bryk, 2002). Such an investigation is suggested because the extant literature has indicated that there are mediating variables that affect the relationship between school leadership and perceptions of leader outcomes (Silins 1994; Leithwood \& Jantzi 1999; Stobaugh, 2003). For example, Leithwood, Jantzi, Silins, and Dart (1993) found that school-level factors such as school culture, goals, and climate were the main predictors of teacher perceived outcomes. Binkowski, Cordeiro, and Iwanicki (1995), Barth (1990), and Leithwood and Janzti (1990) have indicated that school culture (e.g., collaboration) affects teachers' perceptions of effectiveness. Furthermore, Smith and Piele (1997) found that the school climate is positively and significantly related to teachers' perceptions of principal leadership, 
specifically most strongly related to perceptions of teacher satisfaction (Taylor \& Tashakkori, 1994). In addition, past research has shown that differences in transformational leadership exist between high- and low-performing schools, as well as between high and low socioeconomic schools (Philin, 1997; Stobaugh, 2003). Thus, researchers would benefit from knowing the different affects that school-level factors (e.g., culture, performance, socioeconomic status, policies, organization, and classroom conditions) have on the relationship between leadership and leader outcomes. This study, as well as the others proposed, serves as a useful starting point for future efforts. If effective elementary school leadership continues to be ambiguous, a variety of leadership studies are needed to enhance scholars', practitioners', and policymakers' understanding of the principal role.

\section{Study Summary}

School principals, despite their evolving roles, still figure prominently in school reform efforts. Educational researchers have continually identified principals as an essential force in school effectiveness and school improvement (Bryk, Sebring, Allensworth, Luppescu, \& Easton, 2010; Herman et al., 2008; Teddlie \& Reynolds, 2000). According to Leithwood, Seashore-Louis, Anderson, and Wahlstrom (2004), effective or successful educational leadership is necessary for school reform. Therefore, national and statewide reform initiatives to improve school leadership have been adopted. In spite of these continual reform initiatives, empirical research has shown principal's expression of transformational leadership positively influences teacher satisfaction, teacher extra effort, and principal effectiveness (Leithwood, Jantzi, Silins, \& Dart, 1993; Binkowski, Cordeiro, \& Iwanicki, 1995). Thus, as states continually rethink leadership, 
transformational leadership emerges as a conceptual framework that is useful for motivating teachers and promoting student success. However, while there has been much discussion on transformational school leadership, empirical evidence is thin (Leithwood \& Jantzi, 2006).

Many research avenues of principal leadership exist; however, the lack of empirical data on the relationship between psychological gender role, leadership behavior, and leader outcomes represents a gap in empirical literature this study addressed. The current study represents a unique investigation of the effect of the relationship between leadership behavior (transformational, transactional, and laissezfaire) and psychological gender (masculine, feminine, undifferentiated, androgynous) on principals' effectiveness, teacher satisfaction, and teacher extra effort in Kentucky.

Findings from the current study indicated a relationship does exist between psychological gender and leader behaviors. The link between femininity and masculinity to transformational leadership was supported and perceptions of psychological gender role affecting leader outcomes were sustained. Specifically, teachers who perceive female principals as feminine or androgynous express higher ratings of principal effectiveness, teacher satisfaction, and extra effort. Furthermore, a contemporary leadership approach to the elementary school principalship was supported. That is, there is a need for Kentucky male and female principals to express both masculine (i.e., independence, assertiveness, and forcefulness) and feminine characteristics (i.e., compassion, nurturing, and sensitivity). This study serves to demonstrate teachers' perceptions of their principal's gender roles and leadership style are clearly associated with how teachers perceive their 
principal as a leader, how much more effort they put into their work, and their job satisfaction. 


\section{REFERENCES}

Albulushi, A., \& Hussain, S. (2008). Transformational leadership takes Majan to the top of the class. Human Resource Management International Digest, 16(2), 31-33.

Altieri, B. B. (2008). Comparison of staff nurse perceptions of nurse executive and nurse manager leadership in magnet and non-magnet hospitals. Dissertation Abstract International (UMI No. AAT 3324448). Retrieved September 12, 2010 from Dissertation and Theses database.

Antonakis, J., Avolio, B. J., \& Sivasubramaniam, N. (2003). Context and leadership: An examination of the nine-factor full-range leadership theory using the Multifactor Leadership Questionnaire. Leadership Quarterly, 14, 261-295.

Avolio, B. J., \& Bass, B. M. (1987). Charisma and beyond. In Hunt, J.G, Baliga, B.,

Dachler, H., Schriesheim, C.A. (Eds.), Emerging leadership vistas (pp. 29-49).

Boston, MA: Lexington Books.

Avolio, B. J., \& Bass, B. M. (1995). Team leadership, team development and effectiveness: Final report to the Eisenhower Fund. Binghamton, NY: State University of New York at Binghamton, Center for Leadership Studies.

Avolio, B. J., \& Bass, B. M. (Eds.). (2002). Developing potential across a full range of leadership: Cases on transactional and transformational leadership. Mahwah, $\mathrm{NJ}$ : Lawrence Erlbaum Associates, Publishers. 
Avolio, B. J., Bass, B. M., \& Jung, D. I. (1995). Construct validation and norms for the Multifactor Leadership Questionnaire (MLQ-Form 5X). (CLS Report 95-4). Binghamton, NY: State University of New York, Center of Leadership Studies. Avolio, B. J., Bass, B. M., \& Jung, D. I. (1999). Reexamining the components of transformational and transactive leadership using the Multifactor Leadership Questionnaire. Journal of Occupational and Organizational Psychology, 72, 441462.

Avolio, B. J., Waldman, D. A., \& Einstein, W. O. (1988). Transformational leadership in a management simulation: Impacting the bottom line. Group and Organizational Studies, 13, 59-80.

Avolio, B. J., \& Yammarino, F. J. (Eds.). (2002). Transformational and charismatic leadership: The road ahead. Boston, MA: JAI.

Bakan, D. (1966). The duality of human existence: An essay on psychology and religion. Chicago, IL: RAND.

Barcikowski, R., \& Stevens, J. P. (1975). A Monte Carlo study of the stability of canonical correlations, canonical weights, and canonical variate-variable correlations. Multivariate Behavioral Research, 10, 353-364.

Barth, R. S. (1990). Improving schools for within: Teachers, parents, and principals can make the difference. San Francisco, CA: Jossey-Bass.

Bass, B. M. (1985). Leadership and performance beyond expectations. New York: Free Press. 
Bass, B. M. (1988). Evolving perspectives on charismatic leadership. In J. Conger and R. N. Kanugo (Eds.), Charismatic leadership: The elusive factor in organizational effectiveness (pp. 40-77). San Francisco, CA: Jossey-Bass.

Bass, B. M. (1990). Bass \& Stogdill's handbook of leadership. New York: The Free Press. Bass, B. M. (1997). Does the transactional-transformational leadership paradigm transcend organizational and national boundaries? American Psychologist, 52, 130-139.

Bass, B. M. (1998). The ethics of transformational leadership. In J. Ciulla (Ed.), Ethics: The heart of leadership (pp. 169-192). Westport, CT: Praeger.

Bass, B. M., \& Avolio, B. J. (1993). Transformational leadership: A response to critiques. In M. M. Chemers \& R. Ayman (Eds.), Leadership theory and research: Perspectives and directions (pp. 49-88). San Diego, CA: Academic Press.

Bass, B. M., \& Avolio, B. J. (2004). Technical report for the $M L Q\left(3^{\text {rd }}\right.$ ed.). Redwood, CA: Mind Garden.

Bass, B. M., Avolio, B. J., \& Goodheim, L. (1987). Biography and the assessment of transformational leadership at the world class level. Journal of Management, 13, $7-19$.

Bass, B. M, Avolio, B., Jung, D., \& Berson, Y. (2003). Predicting unit performance by assessing transformational and transactional leadership. Journal of Applied Psychology, 88, 207-278.

Bass, B. M., \& Riggio, R. E. (2006). Transformational Leadership (2 ${ }^{\text {nd }}$ ed.). Mahwah, NJ: Lawrence Erlbaum. 
Bem, S. L. (1974). The measurement of psychological androgyny. Journal of Consulting and Clinical Psychological, 42, 196-205.

Bem, S. L. (1975). Sex-role adaptability: One consequence of psychological androgyny. Journal of Personality and Social Psychology, 31, 634-643.

Bem, S. L. (1976). Sex typing and the avoidance of cross-sex behavior. Journal of Personality and Social Psychology, 33, 48-54.

Bem, S. L. (1981). Gender schema theory: A cognitive account of sex-typing. Psychological Review, 88(4), 354-364.

Bennis, W. G., \& Naus, B. (1985). Leaders: The strategies for taking charge. New York: Harper \& Row.

Biddle, B. J. (1979). Role theory: Expectations, identities, and behaviors. New York: Academic Press.

Binkowski, K., Cordeiro, P., \& Iwanicki, E. (1995, April). A qualitative study of higher and lower performing elementary schools. A paper presented at the meeting of the American Educational Research Association, San Francisco, CA.

Blake, R. R., \& Mouton, J. S. (1964). The managerial grid. Houston, TX: Gulf Publishing Company.

Bossert, S., Dwyer, D., Rowan, B., \& Lee, G. (1982). The instructional management role of the principal. Educational Administration Quarterly, 13, 34-63.

Bowers, D. G., \& Seashore, S. E. (1966). Predicting organizational effectiveness with a four-factor theory of leadership. Administrative Science Quarterly, 11, 238-263. 
Bryk, A. S., Sebring, P. B., Allensworth, E., Luppescu, S., \& Easton, J. Q. (2010). Organizing schools for improvement: Lessons from Chicago. Chicago, IL: University of Chicago Press.

Burns, J. M. (1978). Leadership. New York: Harper \& Row.

Bycio, P., Hackett, R. D., \& Allen, J. S. (1995). Further assessments of Bass's (1985) conceptualization of transactional and transformational leadership. Journal of Applied Psychology, 80, 468-478.

Carless, S. A. (1998). Gender differences in transformational leadership: An examination of superior, leader, and subordinate perspectives. Sex Roles, 39, 881-902.

Carli, J. (1999). Gender, interpersonal power, and social influence. Journal of Social Issues, 55, 81-99.

Carnegie Corporation. (1986). A nation prepared: Teachers for the 21st century. The report of the task force on teaching as a profession. Hyattsville, MD: Carnegie Forum on Education and the Economy.

Cartwright, D., \& Zander, A. (1960). Group dynamics research and theory. Evanston, IL: Row, Peterson.

Catalyst. (2001). Women in corporate leadership: Comparisons among the US, the UK, and Canada. Retrieved October 4, 2010 from http://www.catalyst.org/files/fact/comparions.pdf.

Choi, N., \& Fuqua, D. R. (2003). The structure of the Bem Sex Role Inventory: A summary report of 23 validation studies. Educational and Psychological Measurement, 63, 872-887. 
Choi, N., Fuqua, D. R., Newman, J. (2008). The Bem Sex-Role Inventory: Continuing theoretical problems. Educational and Psychological Measurement, 68(5), 881900.

Cohen, J. (1988). Statistical power analysis for the behavioral sciences (2nd ed.). Hillsdale, NJ: Lawrence Erlbaum Associates.

Collins, J. C., \& Porras, J. I. (1994). Public and private schools. New York: Basic Books. Constantinople, A. (1973). Masculinity-femininity: An exception to a famous dictum? Psychological Bulletin, 80, 389-407.

Cosentino, F., \& Heilbrun, A. B. (1964). Anxiety correlates of sex-role identity in college students. Psychological Reports, 14, 729-730.

Creswell, J. W. (2008). Educational research: Planning, conducting, and evaluating quantative and qualitative research. (3rd ed.). Boston, MA: Pearson.

Cross, C. T., \& Rice, R. C. (2000). The role of the principal as instructional leader in a standards-driven system. NASSP Bulletin, 84(20), 61-65.

Deaux, K., \& Kite, M. E. (1987). Thinking about gender. In B. B. Hess, \& M. M. Ferree (Eds.), Analyzing gender: A handbook of social science researcher (pp. 92-117). Newbury Park, CA: Sage Publications, Inc.

DeVellis, R. F. (2003). Scale development: Theory and applications. (2nd ed.) Thousand Oaks, CA: Sage Publications, Inc.

Dillman, D. A. (2007). Mail and internet surveys: The tailored design method. (2nd ed.). Hoboken, NJ: John Wiley \& Sons, Inc.

Dillman, D. A., Smyth, J. D., \& Christian, L. M. (2009). Mail and internet surveys: The tailored design method. (3rd ed.). Hoboken, NJ: John Wiley \& Sons, Inc. 
Eagly, A. H. (2007). Female leadership advantage and disadvantage: Resolving the contradictions. Psychology of Women Quarterly, 31, 1-12.

Eagly, A. H., \& Carli, L. (2004). Women and men as leaders. In J. Antonakis, A. T. Cianciolo, \& R. J. Sternberg (Eds.), The nature of leadership (pp. 279-301). Thousand Oaks, CA: Sage Publications, Inc.

Eagly, A. H, \& Carli, L. (2009). Navigating the labyrinth. School Administrator, 66, 10 16.

Eagly, A. H., \& Karau, S. (1991). Gender and the emergence of leaders: A meta-analysis. Journal of Personality and Social Psychology, 60(5), 685-710.

Eagly, A. H., \& Karau, S. (2002). Role congruity theory of prejudice toward female leaders. Psychological Review, 109, 573-598.

Eagly, A. H., \& Johannesen-Schmidt, M. C. (2001). The leadership styles of men and women. Journal of Social Issues, 57, 781-797.

Eagly, A. H., Johannesen-Schmidt, M. C., \& van Egen, M. L. (2003). Transformational, transactional, and laissez-faire leadership styles: A meta-analysis comparing women and men. Psychological Bulletin, 129, 569-591.

Eagly, A. H., \& Johnson, B. T. (1990). Gender and leadership style: A meta-analysis. Psychological Bulletin, 108, 233-256.

Eagly, A. H., Karau, S. J., \& Johnson, B. T. (1992). Gender and leadership style among school principals: A meta-analysis. Educational Administration Quarterly, 28, 76-102.

Eagly, A. H., Kaurau, S. J., \& Makhijani, M. G. (1995). Gender and the effectiveness of leaders: A meta-analysis. Psychological Bulletin, 117(1), 125-145. 
Eagly, A. H., Makhijani, M. G., \& Klonsky, B. G. (1992). Gender and the evaluation of leaders: A meta-analysis. Psychological Bulletin, 117, 125-145.

Eagly, A. H., Woods, W., \& Steffen, V. J. (1982). Gender and social roles: A Distributional theory of gender stereotypes. Paper presented at the Annual Convention of American Psychological Association, Washington, DC.

English, H., \& English, A. (1958). A comprehensive dictionary of psychological and psychoanalytical terms: A guide to usage. New York: Longmans.

Evans, M. G. (1970). The effects of supervisory behavior on the path-goal relationship. Organizational Behavior and Human Performance, 5, 277-298.

Evans, M. G. (1996). R. J. House's “A path-goal theory of leader effectiveness.” Leadership Quarterly, 7(3), 305-309.

Field, A. (2005). Discovering statistics: Using SPSS for Windows. (2nd ed.). Thousand Oaks, CA: Sage Publications, Inc.

Fielder, F. E. (1967). A theory of leadership effectiveness. New York: McGraw-Hill. Fielder, F. E., \& House, R. J. (1988). Leadership: A report of progress. In C. Cooper (Ed.), International review of industrial and organizational psychology (pp.7392). Greenwich, CT: JAI Press.

Fleishman, E. A., Mumford, M. D., Zaccaro, S. J., Levin, K. Y., Korotkin, A. L., \& Hein, M. B. (1991). Taxonomic efforts in the description of leader behavior: A synthesis and functional interpretation. Leadership Quarterly, 2(4), 245-287.

Georgopoulos, B. S., Mahoney, G. M., \& Jones, N. W. (1957). A path goal approach to productivity. Journal of Applied Psychology, 41, 345-353. 
Good, G. E., \& Mintz, L. B. (1990). Gender role conflict and depression in college men: Evidence for compound risk. Journal of Counseling and Development, 69, 17-21.

Graeff, C. L. (1983). The situational leadership theory: A critical view. Academy of Management Review, 8, 285-291.

Graeff, C. L. (1997). Evolution of situational leadership theory: A critical review. Leadership Quarterly, 8(2), 153-170.

Graen, G. B. (1976). Role-making processes within complex organizations. In M. D. Dunnette (Ed.), Handbook of industrial and organizational psychological (pp. 1202-1245). Chicago. IL: Rand McNally.

Graen, G. B., \& Cashman, J. (1975). A role-making model of leadership in formal organizations: A developmental approach. In J. G. Hunt ,\& L. L. Larson (Eds.), Leadership frontiers (pp. 143-166). Kent, OH: Kent State University Press.

Hackman, M. Z., Furniss, A. H., Hills, M. J., \& Patterson, T. J. (1992). Perceptions of gender-role characteristics and transformational and transactional leadership behaviors. Perceptual and Motor Skills, 75, 311-319.

Hallinger, P., \& Heck, R. H. (1996). Reassessing the principal's role in school effectiveness: a review of empirical research, 1980-1995. Education Administration Quarterly, 32(1), 5-44.

Harrison, L., \& Lynch, A. (2005). Social role theory and the perceived gender role orientation of athletes. Gender roles, 52(3), 227-236.

Hartford, T. C., Willis, C. H., \& Deabler, H. L. (1967). Personality correlates of masculinity-femininity. Psychological Reports, 21, 881-884. 
Hater, J. J., \& Bass, B. M. (1988). Superiors' evaluations and subordinates' perceptions of transformational and transactional leadership. Journal of Applied Psychology, 73(4), 695-702.

Heller, T., \& Van Til, J. (1982). Leadership and followership: Some summary propositions. Journal of Applied Behavioral Science, 18, 405-414.

Hemphill, J. K., \& Coons, A. E. (1957). Development of the Leader Behavior Description Questionnaire. In R. M. Stodgill, \& A. E. Coons (Eds.), Leader behavior: Its description and measurement (pp. 6-38) Columbus. OH: Ohio State University, Bureau of Business Research.

Herdman, K. J. (2007). The effects of psychological and biological gender on role conflict and mental health of gay and lesbian individuals. Dissertation Abstract International, 68(12) (UMI No. AAT 3293523). Retrieved July 20, 2009 from Dissertations and Theses database.

Herman, R., Dawson, P., Dee, T., Greene, J., Maynard, R., \& Redding, S. (2008). Turning around chronically low performing schools. Washington, DC: United States Department of Education.

Hersey, P., \& Blanchard, K. H. (1969). Management of organizational behavior. Englewood Cliffs, NJ: Prentice-Hall.

Hinkin, T., \& Schriesheim, C. (2008). A theoretical and empirical examination of the transactional and non-leadership dimensions of the Multifactor Leadership Questionnaire (MLQ). Leadership Quarterly, 19, 501-513.

Hinkle, D., Wiersma, W., \& Jurs, S. (1988). Applied statistics for the behavioral sciences (5th ed.). Boston, MA: Houghton Mifflin. 
Hollander, E. P. (1978). Leadership dynamics: A practical guide to effective relationships. New York: Free Press.

Hollander, E. P. (1992). Leadership, followership, self and others. Leadership Quarterly, $3,43-54$.

Hoover, N. R. (1987). Transformational and transactional leadership: A test of the model. Dissertation Abstract International, 48 (UMI No. AAT 3020). Retrieved June 1, 2010 from Dissertations and Theses database.

House, R. J. (1971). A path-goal theory of leader effectiveness. Administrative Science Quarterly, 16, 321-328.

House, R. J. (1976). A 1976 theory of charismatic leadership. Paper presented at the Southern Illinios University Fourth Biennial Leadership Symposium, Carbondale, IL.

House, R. J. (1996). Path-goal theory of leadership: Lessons, legacy, and a reformulated theory. Leadership Quarterly, 7(3), 323-352.

House, R. J., \& Dessler, G. (1974). The path-goal theory of leadership: Some post hoc and a priori tests. In J. G. Hunt, \& L. L. Larson (Eds.), Contingency Approaches to Leadership (pp. 29-55). Carbondale, IL: Southern Illinois University Press.

House, R. J., \& Mitchell, R. R. (1974). Path-goal theory of leadership. Journal of Contemporary Business, 3, 81-97.

Howell, J. M., \& Avolio, B. J. (1993). The ethics of charismatic leadership: Submission or liberation? Academy of Management Executive, 6(2), 43-54.

Hoy, A. W., \& Hoy, W. K. (2003). Instructional leadership: A learning-centered guide. Boston, MA: Allyn and Bacon. 
Hunt, J. G. (1999). Transformational/charismatic leadership's transformation of the field: An historical essay. The Leadership Quarterly, 10, 129-144.

Jago, A. G. (1982). Leadership: Perspectives in theory and research. Management Science, 28(3), 315-336.

Jermier, J. M. (1996). The path-goal theory of leadership: A subtextual analysis. Leadership Quarterly, 7(3), 311-316.

Johnson, S., Busch, S., \& Slate, J. (2008, December 1). Leadership behaviors of school administrators: Do men and women differ? Retrieved from the Connexions Web site: http://cnx.org/content/m18693/1.1/

Kanter, R. M. (1977). Men and women of the corporation. New York: Basic.

Katz, D., \& Kahn, R. L. (1951). Human organization and worker motivation. In L.R. Tripp (Ed.), Industrial productivity (pp. 146-171). Madison, WI: Industrial Relations Research Association.

Katz, D., Maccoby, N., \& Morse, N.C. (1950). Productivity, supervision and morale in an office situation. Ann Arbor, MI: University of Michigan Institute for Social Research.

Katz, R. L. (1955). Skills of an effective administrator. Harvard Business Review, 33(1), $33-42$.

Kirby, P. C., Paradise, L.V., \& King, M. I. (1992). Extraordinary leaders in education: Understanding transformational leadership. Journal of Educational Research, 85, 303-311.

King, M. (1989). Extraordinary leadership in education: Transformational and transactional leadership as predictors of effectiveness, satisfaction, and 
organization climate in $K-12$ and higher education (Unpublished doctoral dissertation). University of New Orleans, LA.

Leithwood, K., \& Jantzi, D. (2005). A review of transformational school leadership research 1996-2005. Leadership \& Policy in Schools, 4(3), 177-199.

Leithwood, K., \& Jantzi, D. (2006). Transformational school leadership for large-scale reform: Effects on students, teachers, and their classroom practices. School Effectiveness \& School Improvement, 17(2), 201-227.

Leithwood, K., Jantzi, D., Silins, H., \& Dart, B. (1993). Transformational leadership and teachers' commitment to change. In J. Murphy \& K. Louis (Eds.), Reshaping the principalship: Insight from transformational reform efforts (pp. 77-98). Newbury Park, CA: Corwin Press.

Leithwood, K., Jantzi, D., \& Steinbach, R. (1999). Changing leadership for changing times. Philadelphia: Open University Press.

Leithwood, K., \& Levin, B. (2005). Assessing school leader and leadership programme effects on pupil learning (Research Report RR662). London: Department of Education and Skills.

Leithwood, K., Seashore-Louis, K., Anderson, S. \& Wahlstrom, K. (2004). How leadership influences student learning: A review of research for the learning from leadership project. New York: Wallace Foundation.

Loder, T. L., \& Spillane, J. P. (2005). Is a principal still a teacher? US women administrators' accounts of role conflict and role discontinuity. School Leadership and Management, 25(3), 263-279. 
Lowe, K. B., Kroeck, K. G., \& Sivasubramanian, N. (1996). Effectiveness correlates with transformational and transactional leadership: A meta-analytic review of the MLQ literature. Leadership Quarterly, 7, 385-425.

Maccoby, E. E. (1966). Sex differences in intellectual functioning. In E. E. Maccoby (Ed.), The development of sex differences. Stanford, CA: Stanford University Press.

May-Chiun Lo, T. Ramayah, E., \& Ling, V. (2009). “New leadership,”' leader-member exchange and commitment to change: The case of higher education in Malaysia. World Academy of Science, Engineering and Technology, 53, 574-580.

Mumford, M. D., Zaccaro, S. J., Harding, F. D., Jacobs, T. O., \& Fleishman, E. A. (2000). Leadership skills for a changing world: Solving complex social problems. Leadership Quarterly, 11(1), 11-35.

National Commission on Excellence in Education. (1983). A nation at risk: The imperative for educational reform. An open letter to the American people. A report to the Nation and the Secretary of Education. Washington, DC: Superintendent of Documents, Government Printing Office. (ERIC Document Reproduction Service No. ED 226 006)

Newport, F. (2001, February 21). Americans see women as emotional and affectionate, men as more aggressive: Gender specific stereotypes persist in recent Gallup poll. Retrieved from http://brain.gallup.com.

Northouse, P. G. (2007). Leadership: Theory and practice ( $4^{\text {th }}$ ed.). Thousand Oaks, CA: Sage.

Nunnally, J. C. (1978). Psychometric theory. New York: McGraw-Hill. 
O'Connor, K., Mann, D. W., \& Bardwick, J. M. (1978). Androgyny and self-esteem in the upper-middle class: A replication of Spence. Journal of Consulting and Clinical Psychology, 46, 1168-1169.

O’Neil, J. M., Helms, B. J., Gable, R. K., David, L., Wrightsman, L.S. (1986). Genderrole conflict scale: College men's fear of femininity. Sex Roles, 14, 335-350.

Pedhazur, E. J., \& Tetenbaum, T. J. (1979). Bem sex role inventory: A theoretical and methodological critique. Journal of Personality and Social Psychology, 37, 996106.

Philbin, L. P. (1997). Transformational leadership and the secondary school principal (Unpublished doctoral dissertation). Purdue University, Lafayette, IN.

Pitner, N. (1988). Leadership substitutes: Their factorial validity in education organizations. Educational and Psychological Measurement, 48, 307-315.

Podaskoff, P. M., MacKenzie, S. B., Moorman, R. H., \& Fetter, R. (1990). Transformational leader behaviors and their effects on followers trust in leader, satisfaction, and organizational citizenship behaviors. The Leadership Quarterly, $1,107-142$.

Popper, M. (2002). Narcissism and attachment patterns of personalized and socialized charismatic leaders. Journal of Social and Personal Relationships, 19, 797-809.

Powell, G., Butterfield, A., \& Bartol, K. (2008). Leader evaluations: A new female advantage? Gender in Management: An International Journal, 23(3), 156-174.

Ragins, B. R., \& Sundstrom, E. (1989). Gender and power in organizations: A longitudinal perspective. Psychological Bulletin, 105, 51-88. 
Sammons, P. (2007). School effectiveness and equity: Making connections: A review of school effectiveness and improvement research - its implications for practitioners and policy makers. Berkshire, UK: Education Trust.

Sanchez, D. T., \& Crocker, J. (2005). How investment in gender ideals affects well-being: The role of external contingencies of self-worth. Psychology of Women Quarterly, 29, 63-77.

Sarbin, T. R., \& Allen, V. L. (1968). Role theory. In G. Lindzey \& E. Aronson (Eds.), Handbook of social psychology (pp. 488 - 567). Reading, MA: Addison-Wesley.

Schriesheim, C. A., \& Kerr, S. (1977). Theories and measures of leadership: A critical appraisal. In J.G. Hunt \& L. L. Larson (Eds.), Leadership: The cutting edge (pp.945). Carbondale: Southern Illinois University Press.

Schriesheim, J. R., \& Schriesheim, C. A. (1980). A test of the path-goal theory of leadership and some suggested directions for future research. Personnel Psychology, 33, 349-370.

Seltzer, J., \& Bass, B. M. (1990). Transformational leadership: Beyond initiation and consideration. Journal of Management, 16, 693-703.

Sergiovanni, T. J. (2009). The principalship. Boston, MA: Allyn \& Bacon.

Shavelson, R. J. (1996). Statistical reasoning for the behavioral sciences. Boston: Allyn \& Bacon.

Silins, H. C. (1994). The relationship between transformational and transactional leadership and school improvement outcomes. School Effectiveness and School Improvement, 5, 272-298. 
Smith, S. C., \& Piele, P. K. (1997). School leadership: Handbook for excellence ( $3^{\text {rd }}$ ed.). Eugene, OR: University of Oregon.

Smulyan, L. (2000). Balancing acts: Women principals at work. Albany, NY: State University of New York Press.

Spence, J. T. (1991). Do the BSRI and PAQ measure the same or different concepts? Psychological of Women Quarterly, 15, 141-165.

Spence, J. T., Helmrich, R., \& Strapp, J. (1975). Ratings of self and peers on sex role attributes and their relation to self-esteem and conceptions of masculinity and femininity. Journal of Personality and Social Psychology, 32, 29-39.

Spence, J., Helmreich, R. (1978). Masculinity and femininity: Their psychological dimensions, correlates, and antecedents. Austin, TX: University of Texas Press.

Spence, J., Helmreich, R. (1981). Androgyny versus gender schema: A comment on Bem's gender schema theory. Psychological Review, 88, 365-368.

Spence, J., Helmreich, R., \& Stapp, J. (1975). Ratings of self and peers on sex role attributes and their relation to self-esteem and conceptions of masculinity and femininity. Journal of Personality and Social Psychology, 32, 29-39.

Stevens, J. P. (2002). Applied multivariate statistics for the social sciences. (4th ed.) Mahwah, NJ: Lawrence Erlbaum Associates.

Stogdill, R. M. (1949). Personal factors associated with leadership: A survey of the literature. The Journal of Psychology: Interdisciplinary and Applied, 25, 35 - 71.

Stobaugh, R. (2003). School reform, transformational leadership, and student achievement. (Unpublished doctoral dissertation). University of Louisville, Louisville, KY. 
Tabachnick, B. G., \& Fidell, L. S. (2001). Using multivariate statistics. (4th ed.). Needham Heights, MA: Allyn \& Bacon.

Taylor, Y., Tashakkori, A. (1994). Predicting teacher sense of efficacy and job satisfaction using school climate and participatory decision making. Paper presented at the annual meeting of the Southeast Education Research Association, San Antonio, TX. (ERIC Document Reproduction Service No. ED3698702).

Teddlie, C. \& Reynolds, D. (2000) The international handbook of school effectiveness research. London \& New York: Falmer Press.

Tejeda, M. J., Scandura, T. A., \& Pillai, R. (2001). The MLQ revisited - Psychometric properties and recommendations. Leadership Quarterly, 12, 31-52.

Teddlie, C. \& Stringfield, S. (1993). Schools make a difference. Lessons learned from a 10-year study of school effects. New York, NY: Teachers College Press.

Thompson, B. (2000). Canonical correlation analysis. Encyclopedia of Statistics in Behavioral Science. Hoboken, NJ: Wiley \& Sons, Inc.

Thompson, B. (1987, April 16). Fundamentals of canonical correlation analysis: Basic and three common fallacies in interpretation. Paper presented at the Annual Meeting of the Society for Multivariate Experimental Psychological, Southwestern Division, New Orleans, LA.

Trinidad, C., \& Normore, A. H. (2005). Leadership and gender: A dangerous liaison? Leadership \& Organization Development, 26(7), 574-590.

Urbina, S. (2004). Essentials of psychological testing. Hoboken, NJ: John Wiley \& Sons, Inc. 
U.S. National Center for Education Statistics. (2010). The condition of education: characteristics of school principals. Retrieved from http://nces.ed.gov/programs/coe/2010/section4/indicator29.asp.

Vanderhaar, J., Munoz, M., \& Rodosky, R. (2006). Leadership as accountability for learning: The effects of school poverty, teacher experience, previous achievement, and principal preparation programs on student achievement. Journal of Personnel Evaluation in Education, 19, 17-33.

Van Egen, M. L., van der Leeden, R., \& Willemsen, T. M. (2001). Gender, context and leaders styles: A field study. Journal of Occupational and Organizational Psychology, 74, 581-598.

Waldman, D. A., Bass, B. M, and Einstein, W. O. (1986). Effort, performance and transformational leadership in industrial and military settings (Working Paper No. 86-109). Binghamton, NY: State University of New York, School of Management.

Waldman, D. A., Bass, B. M, and Yammarino, F. J. (1990). Adding to contingent reward behavior: The augmenting effect of charismatic leadership. Group \& Organization Studies, 15, 381-394.

Waters, T., Marzano, R. \& McNulty, B. (2003). Balanced leadership: What 30 years of research tells us about the effect of leadership on student achievement. Aurora, CO: Mid-Continent Regional Educational Library.

Whitley, B. E. Jr. (2001). Gender role variables and attitudes toward homosexuality. Sex Roles, 45, 691-721. 
Wilbourn, M., \& Kee, D. (2010). Henry the nurse is a doctor too: Implicitly examining children's gender stereotypes for male and female occupational roles. Gender roles, 62(9/10), 670-683.

Woods, W. P., Christensen, N., Hebl, M. R., \& Rothgerber, H. (1997). Conformity to sex-typed norms, affect, and the self-concept. Journal of Personality and Social Psychology, 73(3), 523-535.

Yammarino, F. J., \& Bass, B. M. (1990). Long-term forecasting of transformational leadership and its effects among naval officers: Some preliminary findings. In $\mathrm{K}$. E. Clark \& M. B. Clark (Eds.), Measure of leadership (pp.151-169). West Orange, NJ: Leadership Library of America.

Yammarino, F. J., Spangler, W. D., \& Bass, B. M. (1993). Transformational leadership and performance: A longitudinal investigation. Leadership Quarterly, 41, 81-102. Yukl, G. (1999). An evaluation of conceptual weaknesses in transformational and charismatic leadership theories. The Leadership Quarterly, 10, 285-305. 


\section{APPENDIX A}

\section{Dear District Teacher:}

\section{Teacher Perception Survey on Leadership}

You are invited to participate in a research study. The study is being conducted by Namok Choi, full professor and Brittany Carpenter, a doctoral student at the University of Louisville. The study is sponsored by the University of Louisville, Department of Educational Leadership, Foundation, and Human Resource Education.

The study has the objective to measure your perceptions of elementary school principal leadership. The intent is to learn more about school principal leadership and leader outcomes (examples are effectiveness, satisfaction, extra effort) from JCPS teachers. Confidentially will be protected to the extent permitted by law; that is, your name or specific responses in no way will be linked or shared with your school or principal. It should take twenty five minutes to complete this survey. Please go to JCPS online and click Teachers Perceptions of Principal Leadership (http://tiny.cc/teachersjcps1). Participation in the survey makes you eligible to win one of two $\$ 100$ visa gift cards! Instructions on entry into the random drawing follow completion of the survey.

Procedures:

The online survey ask you to answer question pertaining to you perceptions your principal's leadership style, psychological gender, and effectiveness. You will also be asked about your personal perception of psychological gender, satisfaction with your principal's leadership, and principal's ability to promote your willingness to exert extra effort in your teaching. You will be free to decline to answer any particular questions you are not comfortable answering.

Benefits:

The benefits of this study include findings that, depending on what they are, could affect the principal leadership style and might lead to the development of professional initiatives and programs to improve school principal leadership. Understanding gender differences may contribute to matching principal candidates to schools. Additionally, the survey findings can be used as feedback to improve overall school conditions to increase teacher satisfaction.

I know teachers are constantly asked to complete surveys to share their views. As a fellow educator, please consider the benefits this study might have to shape the principalship and schools in the district. If you have any questions or concerns prior to 
receiving the survey link, please feel free to contact namok@louisville.edu or call (502) $852-4014$.

Sincerely,

Dr. Namok Choi

Brittany Carpenter 


\begin{abstract}
APPENDIX B
The Effects of Leadership Style, Psychological Gender, and Biological Gender of Elementary School Principals on Teachers Perceptions
\end{abstract}

March 28, 2011

Dear JCPS Teacher:

You are being invited to participate in a research study where you will be asked to respond to survey questions about your job and your school principal. There are no known risks for your participation in this research study. The information collected may not benefit you directly. The information learned in this study may be helpful to others. The survey will take approximately 15 minutes to complete.

Individuals from the Department of Educational Leadership, Foundation, and Human Resource Education, the Institutional Review Board (IRB), the Human Subjects Protection Program Office (HSPPO), and other regulatory agencies may inspect these records. In all other respects, however, the data will be held in confidence to the extent permitted by law. Should the data be published, your identity will not be disclosed.

Taking part in this study is voluntary. By completing this survey you agree to take part. You do not have to answer any questions that make you feel uncomfortable. You may choose not to take part at all. If you do decide to participate you may stop taking part at any time, for any reason. If you decide not participate in this study or if you stop participating at any time, you will not lose any benefits for which you may qualify.

If you have any questions, concerns, or complaints about the research study, please contact: Dr. Namok Choi at namok@louisville.edu or (502) 852-4014.

If you have any questions about your rights as a research subject, you may call the Human Subjects Protection Program Office at (502) 852-5188. You can discuss any questions about your rights as a research subject, in private, with a member of the Institutional Review Board (IRB). You may also call this number if you have other questions about the research, and you cannot reach the study doctor, or want to talk to someone else. The IRB is an independent committee made up of people from the University community, staff of the institutions, as well as people from the community not connected with these institutions. The IRB has reviewed this research study. 
If you have concerns or complaints about the research or research staff and you do not wish to give your name, you may call 1-877-852-1167. This is a 24 hour hot line answered by people who do not work at the University of Louisville.

Sincerely,

Dr. Namok Choi

Brittany D. Carpenter 


\begin{abstract}
APPENDIX C
Bem Sex Role Inventory Short-Form Sample Items

A number of personality characteristics are listed below. We would like you to use those characteristics to describe your principal, that is, we would like you to indicate, on a scale from 1 (never or almost never true) to 7 (always or almost always true), how true each of these characteristics is to your principal. Please do not leave any characteristics unmarked.
\end{abstract}

\begin{tabular}{|c|c|c|c|c|c|c|}
\hline \multirow[b]{2}{*}{ 1. Defend my own beliefs.. } & \multicolumn{4}{|c|}{$\begin{array}{l}\text { Never or } \\
\text { Almost never } \\
\text { True }\end{array}$} & \multirow{2}{*}{\multicolumn{2}{|c|}{$\begin{array}{l}\text { Always or } \\
\text { almost always } \\
\text { true } \\
677\end{array}$}} \\
\hline & $\ldots \quad 12$ & 3 & 4 & 5 & & \\
\hline 2. Affectionate.............. & 12 & 3 & 4 & 5 & 6 & 7 \\
\hline 3. Conscientious............. & 12 & 3 & 4 & 5 & 6 & 7 \\
\hline 4. Independent..... & 12 & 3 & 4 & 5 & 6 & 7 \\
\hline 5. Sympathetic............... & 12 & 3 & 4 & 5 & 6 & 7 \\
\hline
\end{tabular}




\section{APPENDIX D}

Multifactor Leadership Questionnaire Rater Form-Sample Items

A number of descriptive statements are listed below. We would like you to use those statements to describe your principal, that is, we would like you to indicate, on a scale from 0 (not at all) to 4 (frequently, if not always), how frequently each statement fits your principal. Please do not leave any statements unmarked.

1. Provides me with assistance in

\begin{tabular}{|c|c|c|c|}
\hline $\begin{array}{l}\text { Not } \\
\text { at } \\
\text { all }\end{array}$ & $\begin{array}{c}\text { Once } \\
\text { in a } \\
\text { while }\end{array}$ & Sometimes & $\begin{array}{c}\text { Fairly } \\
\text { often }\end{array}$ \\
\hline
\end{tabular}

exchange for my

efforts.......................

2. Re-examines critical assumptions

to question whether they are

appropriate..................

3. Fails to interfere until problems

become serious.

$0 \quad 1$

2

4

4. Focuses attention on irregularities, mistakes, exceptions, and deviations

from standards.

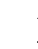

2

34

5. Avoids getting involved when

important issues arise..............

0

2

4 


\section{APPENDIX E}

School/Principal Information Items

1. Which JCPS elementary school do you teach for?

2. Please indicate your principal's biological gender: ___ Female ___ Male

Thank you for completing this survey. Please enter your email address to be place in the drawing to receive one of two $\$ 100$ visa gift cards! 


\section{APPENDIX F}

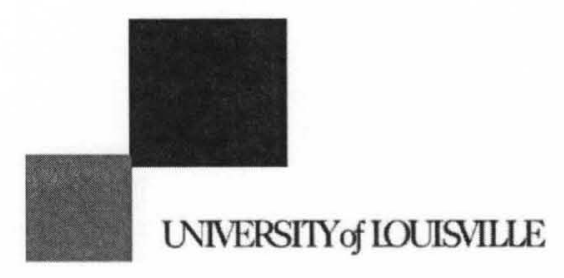

INSTITUTIONAL REVIEW BOARDS

University of Louisville MedCenter One, Suite 200

501 E. Broadway Louisville, Kentucky 40202-1798

Office: $502-852-5188$

Fax: 502-852-2164

To: Choi, Namok From: The University of Louisville Institutional Review Board (IRB) Date: Tuesday, February 22, 2011

Subject: Approval Letter

Tracking \#: 11.0058

Title: THE EFFECTS OF LEADERSHIP STYLE, PSYCHOLOGICAL GENDER, AND BIOLOGICAL GENDER OF ELEMENTARY SCHOOL PRINCIPALS ON TEACHERS' PERCEPTIONS

Approval 2/18/2011 12:00:00 AM

Date: Expiration 2/17/2012 12:00:00 AM

The Consent for the above referenced study has been received and contains the changes requested in our letter of $02 / 08 / 2011$. This study was reviewed on $02 / 17 / 2011$ by the chair/vice chair of the Institutional Review Board (IRB) and approved through the Expedited Review Procedure, according to 45 CFR 46.110(b), since this study falls under Expedited Category (7) Research on individual or group characteristics or behavior (including, but not limited to, research on perception, cognition, motivation, identity, language, communication, cultural beliefs or practices, and social behavior) or research employing survey, interview, 
oral history, focus group, program evaluation, human factors evaluation, or quality assurance methodologies.

This study was also approved through 45 CFR 46.117(c), which means that an IRB may waive the requirement for the investigator to obtain a signed informed consent form for some or all subjects if it finds either: ${ }^{\circ}$ That the only record linking the subject and the research would be the consent document and the principal risk would be potential harm resulting from a breach of confidentiality. Each subject will be asked whether the subject wants documentation linking the subject with the research, and the subject's wishes will govern; or ${ }^{\circ}$ That the research presents no more than minimal risk of harm to subjects and involves no procedures for which written consent is normally required outside of the research context.

The following items have been approved: The following items have been approved:

- Research Protocol, not dated

- $\quad$ Preamble Consent, dated 03/01/2011

- $\quad$ Survey Questions, Appendix A-C, not dated

- $\quad$ Email to Teachers, not dated

This study now has final IRB approval from 02/18/2011 through 02/17/2012. You should complete and return the Progress Report/Continuation Request Form EIGHT weeks prior to this date in order to ensure that no lapse in approval occurs. The committee will be advised of this action at their next full board meeting.

Site Approval If this study will take place at an affiliated research institution, such as Jewish Hospital/St Marys Hospital, Norton Healthcare, or University of Louisville Hospital, permission to use the site of the affiliated institution may be necessary before the research may begin. If this study will take place outside of the University of Louisville Campuses, permission from the organization should be obtained before the research may begin. Failure to obtain this permission may result in a delay in the start of your research.

Privacy \& Encryption Statement The University of Louisville's Privacy and Encryption Policy requires such information as identifiable medical and health records: credit card, bank account and other personal financial information; social security numbers; proprietary research data; dates of birth (when combined with name, address and/or phone numbers) to be encrypted. For additional information:

http://security.louisville.edu/PolStds/ISO/PS018.htm.

1099 Information (If Applicable) As a reminder, in compliance with University policies and Internal Revenue Service code, all payments (including checks, gift cards, and gift certificates) to research subjects must be reported to the University Controller's Office. Petty Cash payments must also be monitored by the issuing department and reported to the Controller's Office. Before issuing compensation, each research subject must complete a $\mathrm{W}-9$ form. For additional information, please contact the Controller's Office at $852-8237$ or contro 1l@louisville.edu. 
The following is a NEW link to an Instruction Sheet for BRAAN2 "How to Locate Stamped/Approved Documents in BRAAN2" if your item was submitted on or after 5/17/10:

http://louisville.edu/research/braan2/help/ApprovedDocs.pdf/view

Please begin using your newly approved (stamped) consent(s) at this time. The previous versions are no longer valid. If you need assistance in accessing any of the study documents, please feel free to contact our office at (502) 852 - 5188. You may also email our service account at hsppofc@1ouisville.edu for assistance. Best wishes for a successful study. If you have any questions please contact the HSPPO at (502) 852-5188 or hsppofc@louisville.edu.

Thank you.

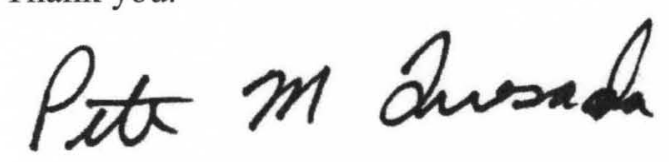

Board Designee: Quesada, Peter

Once you begin your human subject research the following regulations apply:

1. Unanticipated problems or serious adverse events encountered in this research study must be reported to the IRB within five (5) work days.

2. Any modifications to the study protocol or informed consent form must be reviewed and approved by the IRB prior to implementation.

3. You may not use a modified informed consent form until it has been approved and validated by the IRB.

4. Please note that the IRB operates in accordance with laws and regulations of the United States and guidance provided by the Office of Human Research Protection (OHRP), the Food and Drug Administration (FDA), the Office of Civil Rights (OCR) and other Federal and State Agencies when applicable.

5. You should complete and SUBMIT the Continuation Request Form eight weeks prior to this date in order to ensure that no lapse in approval occurs.

Letter Sent By: Peek, Tamara, 2/22/2011 10:06 AM

Full Accreditation since June 2005 by the Association for the Accreditation of Human Research Protection

Programs, Inc.

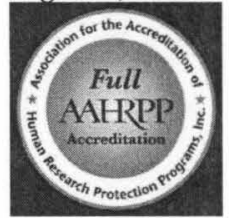




\title{
CURRICULUM VITAE
}

\section{Brittany Diane Carpenter}

\author{
American Institutes for Research \\ 1990 K Street, NW \\ Washington DC, 20006 \\ bcarpenter@air.org
}

\section{EDUCATION}

Ph.D. Education Leadership and Organizational Development

Concentration: Evaluation

University of Louisville, Louisville

Fall 2011 (Anticipated)

\section{M.S. Communication}

Spalding University, Louisville

December 2006

\section{B.A. Communication \& Political Science}

Bellarmine University, Louisville

May 2005

\section{PROFESSIONAL WORK EXPERIENCE}

\section{Research Analyst, NAEP-ESSI, Federal Statistics Program, American Institutes for Research, Washington, D.C. , Present \\ Works across projects supporting various program activities supporting NAEP assessment design and development, planning research, analyzing data, technical reviews and writing reports. \\ Essential responsibilities include lead and manage reviews of NAEP publications or small scale studies, monitoring various aspects of overall quality of NAEP data and procedure reports, and prepare and present presentations to internal and external clients at briefings and technical panel meetings.}

Graduate Research Assistant, Nystrand Center of Excellence in Education, College of Education and Human Development, University of Louisville, January 2009 - June 2011 Conducted research and assisted professional staff on specific projects associated with center initiatives (Louisville Writing Project, The Holmes Partnership, Minority Teacher Recruitment Project, and OVEC/UofL Partnership for School Improvement, and Signature Partnership initiative). Assisted with the development, implementation, and study of collaborative efforts to improve public school education and teaching. 
Independent Research Methods and Statistics Consultant August 2008- Present Independent contractor. Consult on descriptive and inferential data analysis, as well as quantitative research design for professionals and students (doctoral dissertation \& thesis) at local area universities.

Evaluation and Research Intern, Department of Accountability, Resesarch and Planning, Jefferson County Public Schools, Louisville, KY, June 2009- June 2010

Worked with JCPS Evaluation and Research Specialists in conducting, implementing, and evaluating various district programs and initiatives. Specific tasks included: conducting literature reviews; development of classroom observation instruments; conducting classroom observations; development of surveys; conducting descriptive and inferential analysis of program implementation and student achievement data; and assisting in writing internal and external program evaluation reports, and white papers.

Research Analyst Senior, Undergraduate Affairs/Office of University Provost, University of Louisville, Louisville, KY, August 2006 - January 2009

Developed the research design, assessment and evaluation of Undergraduate Affairs' student development services. Prepared the Annual Report on Tutoring and Retention Programs by collecting, organizing, and analyzing all data. Conducted surveys, focus groups, and additional procedures to determine the effectiveness of Undergraduate Affairs' programs and services, and trained others on data analysis and evaluative procedures. Supervised 15 Graduate Assistants yearly on various research projects. Served as liaison to Institutional Research and Planning and Office of Retention Management and Research.

\section{TEACHING EXPERIENCE}

Instructor, Educational Psychology, Measurement, and Evaluation Program, Educational and Counseling Psychology Department, College of Education and Human Development, University of Louisville, Fall 2010

- Evaluation and Measurement in Education

Adjunct Faculty, School of Communication, Spalding University, Louisville, KY, Summer 2010

- Interviewing Techniques

Invited Lecturer, Department of Leadership, Foundations, and Human Resource Education, College of Education and Human Development, University of Louisville, Louisville, KY, 2010-2011

- Advanced Organization Theory

- Doctoral Seminar in Educational Leadership

\section{PUBLICATIONS}

Adelson, J. L., \& Carpenter, B. D. (2011). Grouping for achievement gains: For whom does achievement grouping increase kindergarten reading growth? 
Carpenter, B. D., and Sherretz, C. (2011) Professional Development Schools and University Partnership as a Catalyst for Teacher Leadership. Manuscript in review

Hochbein, C., \& Carpenter, B. D. (2011). Longitudinal analysis of the impact of principal change on elementary school achievement. Manuscript in revision.

Adelson, J. L., \& Carpenter, B. D. (2010). The use of inferential statistics: How advanced is gifted education research? SIGnificance. SIGnificance (the AERA Research on Giftedness, Creativity, and Talent SIG newsletter), 5-6.

\section{CONFERENCE PAPERS \& PRESENTATIONS}

(2011) Carpenter, B.D. (with Adelson, J.) "Grouping for achievement gains: For whom does achievement grouping increase kindergarten reading growth?". American Education Research Association. New Orleans, LA.

(2010) Carpenter, B. D. (with Hochbein, C.) "Longitudinal analysis of the impact of principal change on elementary school achievement". University Council for Educational Administration Convention. New Orleans, LA.

(2010) Carpenter, B. D. (with Sauer, T., \& Choi, N.) "A reliablity generalization study of the personal attributes questionnaire."American Educational Research Association. Denver, CO.

(2009) Carpenter, B. D. (with Vanderhaar, J.). "Responsiveness to culture and context in evaluation". National Evaluation Institute CREATE Conference. Louisville, KY.

(2008) Carpenter, B. D. (with Leist, C., Carmichael, G., Hohmann, J., and Seng, K.). "A formula for a successful learning resource center". College Reading and Learning Association Annual Conference. Cleveland, $\mathrm{OH}$.

\section{GRANTS \& FELLOWSHIPS}

2010 - 2011 Research and Faculty Development Grant, University of Louisville, \$1,490

The purpose of this funding is to (a) build a culture of research and professional improvement within the College of Education and Human Development (CEHD), (b) increase faculty engagement in research and faculty development activities, and (c) support CEHD students.

2009 - 2011 Doctoral Fellow, Southern Region Education Board State Doctoral Scholars (SREB), Kentucky

Awarded three year doctoral fellowship for study at the University of Louisville.

2009-2011 Holmes Doctoral Scholar, American Association of Colleges For Teacher Education Awarded three year doctoral fellowship for study at College of Education and Human Development at the University of Louisville. 


\section{PROFESSIONAL SERVICE}

\section{National}

2009 Proposal Reviewer, $14^{\text {th }}$ Annual Holmes Partnership Conference: Closing the Achievement Gap

\section{University}

2011 Assessment Reviewer, General Education and Curriculum University of Louisville

2010 Student Representative, Dean Search Committee, College of Education and Human Development, University of Louisville

2010 Student Representative, General Education and Curriculum Committee, University of Louisville

2009 Proposal Reviewer, Regional Graduate Spring Research Conference, University of Louisville

2007- 2009 Member, University of Louisville Cardinal Covenant Advisory Committee

2007 -2009 Faculty Trainer, University of Louisville SAGE Academic Referral System

\section{Community}

2009 Golden Key International Society

2008 Rotaract Club of Greater Louisville

2008 Louisville Gas \& Electric Project Warm

2004 Hearts in Motion Guatemala Mission Service

\section{PROFESSIONAL AFFLICATIONS}

American Educational Research Association (AERA)

Division D: Measurement and Research Methodology

School/University Collaborative Research SIG

National Evaluation Institute (NEI)

\section{AWARDS AND HONORS}

2010 Who's Who among Students in American Universities and Colleges

2006 College Leadership Award, School of Communication, Spalding University

2006 Governor Distinguished Kentucky Colonels Award

2005 Distinguished Citizens Award (Key to the City), Louisville, KY 